\title{
Current status and future perspectives of lithium metal batteries
}

\author{
Alberto Varzi ${ }^{\text {a,b, }}$, Katharina Thanner ${ }^{\mathrm{a}, \mathrm{b}, \mathrm{c}}$, Roberto Scipioni ${ }^{\mathrm{d}}$, Daniele Di Lecce ${ }^{\mathrm{e}}$, \\ Jusef Hassoun $^{\mathrm{f}}$, Susanne Dörfler ${ }^{\mathrm{g}}$, Holger Altheus ${ }^{g}$, Stefan Kaskel ${ }^{\mathrm{h}}$, Christian Prehal ${ }^{\mathrm{i}, \mathrm{j}}$, \\ Stefan A. Freunberger ${ }^{\mathrm{i}, \mathrm{k}}$
}

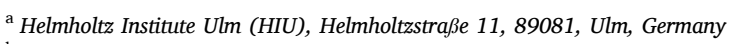

${ }^{\mathrm{b}}$ Karlsruhe Institute of Technology (KIT), P.O.Box 3640, 76021, Karlsruhe, Germany

${ }^{\mathrm{c}}$ BMW Group, Petuelring 130, 80788, München, Germany

d Department of Sustainable Energy Technology, SINTEF Industry, 7034, Trondheim, Norway

${ }^{\mathrm{e}}$ Electrochemical Innovation Lab, Department of Chemical Engineering, University College London, Torrington Place, London, WC1E 7JE, United Kingdom

${ }^{\mathrm{f}}$ Department of Chemical and Pharmaceutical Sciences, University of Ferrara, Via Fossato di Mortara 17, 44121, Ferrara, Italy

${ }^{\mathrm{g}}$ Fraunhofer Institute for Material and Beam Technology (IWS), Winterbergstraße 28, 01277, Dresden, Germany

${ }^{\mathrm{h}}$ Technische Universität Dresden (TUD), Bergstrasse 66, 01069, Dresden, Germany

${ }^{\mathrm{i}}$ Institute for Chemistry and Technology of Materials, Graz University of Technology, Stremayrgasse 9, 8010, Graz, Austria

${ }^{\mathrm{j}}$ Department of Information Technology and Electrical Engineering, ETH Zürich, Gloriastrasse 35, 8092, Zürich, Switzerland

${ }^{\mathrm{k}}$ IST Austria (Institute of Science and Technology Austria), Am Campus 1, 3400, Klosterneuburg, Austria

\section{H I G H L I G H T S}

- The historical development of lithium metal batteries is briefly introduced.

- General strategies for protection of $\mathrm{Li}$ metal anodes are reviewed.

- Specific challenges of ASSBs, Li-S and Li-air batteries are extensively discussed.

- Current development status is reviewed and compared to the EU SET Plan targets.

\section{A R T I C L E I N F O}

\section{Keywords:}

Battery

Lithium metal

Lithium-sulfur

Lithium-air

All-solid-state

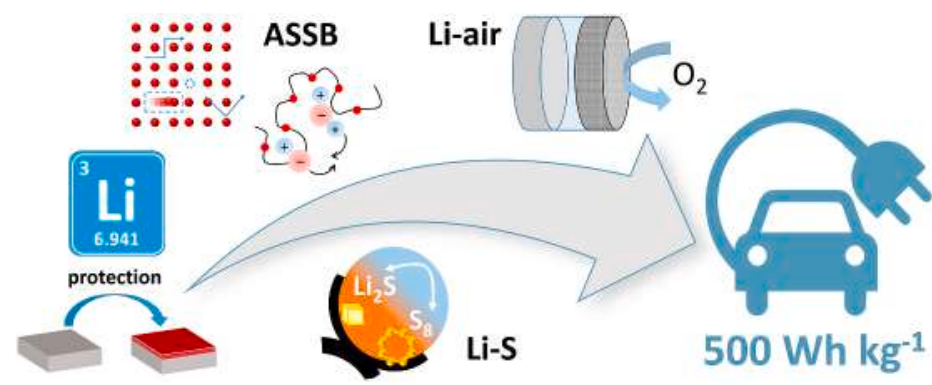

* Corresponding author. Helmholtz Institute Ulm (HIU), Helmholtzstraße 11, 89081, Ulm, Germany.
E-mail address: alberto.varzi@kit.edu (A. Varzi). 
1. - The "holy grail" Li anode: brief history, early failures and future targets of rechargeable Li-metal batteries

Since the mid- $20^{\text {th }}$ century, metallic Li has been of high interest for high energy density batteries. In particular, its high theoretical gravimetric capacity of $3861 \mathrm{mAh} \mathrm{g}^{-1}$, and the most negative standard reduction potential $(-3.040 \mathrm{~V}$ vs. standard hydrogen electrode, SHE) render $\mathrm{Li}$ an attractive anode material [1,2]. The historical development of Lithium Metal Batteries (LMBs) has already been extensively covered by several recent reviews [3-5] and goes beyond the aim of this paper. Nevertheless, it is worth highlighting a few key events that determined the development of this field.

Following the pioneering work done in the late 60 s and early 70 s by Rüdorff, Rouxel, and co-workers on the intercalation of alkali metals in transition metal di-chalcogenides [4], it was Whittingham in 1976 (who was then working at Exxon) to patent the first rechargeable $\mathrm{Li} / \mathrm{TiS}_{2}$ rechargeable chemistry [6]. In the following years, several cathode materials have been proposed in combination with Li metal, including transition metal oxides $\left(\mathrm{V}_{2} \mathrm{O}_{5}, \mathrm{~V}_{6} \mathrm{O}_{13}\right)$ and metal selenides $\left(\mathrm{NbSe}_{3}\right)$ [7]. In the late 80s, the Canadian Moli Energy succeeded with commercializing the first rechargeable LMBs based on a molybdenum sulfide $\left(\mathrm{MoS}_{2}\right)$ cathode $[8,9]$. Unfortunately, millions of sold cells had to soon be recalled due to frequent fire accidents [10]. In fact, while potentially providing high gravimetric energy, the low standard reduction potential of Li lies well outside the stability window of most liquid organic electrolytes [11]. The electrolyte is therefore reduced by the Li metal, leading to the formation of a Solid Electrolyte Interphase (SEI) [12-14]. Due to newly forming the full volume of hostless lithium during charge (i.e., Li plating) the SEI can rupture and fresh lithium is continuously exposed. The fresh lithium consumes electrolyte, deteriorates coulombic efficiency, and increases cell impedance due to the increase in SEI thickness [15]. The ruptured SEI also provides an inhomogeneous surface during lithium plating, eventually resulting in dead lithium and dendrite formation. Sand equation states that the time for lithium dendrite formation is inverse proportional to the current density. Hence, a homogeneous distribution of the current is crucial to balance space-charge and to avoid local electric field build-up. Depending on the applied current density, dendrites either form as mossy dendrites (high current density) or needle-like dendrites (low current density) [2]. The latter are more likely to penetrate the separator and contact the cathode, leading to short-circuit and thermal runaway, i.e., uncontrollable exothermal reactions between the cells components, raising the cell temperature and forming highly flammable and toxic gases. The temperature increase in turn increases the reaction rate, speeding up the gas formation. Eventually the internal cell pressure leads to explosion and ignition $[16,17]$. This brought the safety issues of recharging LMBs to the public attention, driving the development of the much safer carbon anode, which finally resulted on what is nowadays known as the Li-ion battery (LIB) $[7,18,19]$. Despite the incredible commercial success of LIBs having initially set aside the development of rechargeable batteries with Li metal anodes, the topic has recently experiencing a renewed interest motivated by Li-ion technology approaching its limit. Meanwhile, the academic interest in LMBs has never waned and the understanding of beyond Li-ion systems, such as, for example, Lithium-Sulfur (Li-S) and $\mathrm{Li}-\mathrm{O}_{2}$ batteries, has substantially advanced in the past decade $[20,21]$. While for $\mathrm{Li}-\mathrm{O}_{2}$ systems many fundamental questions remain unanswered, the practical development of Li-S cells has already reached a relatively high TRL. In fact, OXIS Energy (UK) has been developing $\mathrm{Li}-\mathrm{S}$ prototypes with a capacity ranging from 10 to $35 \mathrm{Ah}$, currently reaching a specific energy up to $400 \mathrm{Wh} \mathrm{kg}^{-1}$, which has been stated to increase shortly to $500 \mathrm{Wh} \mathrm{kg}^{-1}$ [22]. OXIS Energy and Codemge recently signed a lease agreement to build the world's first Li-S manufacturing plant [23]. In addition, plans to build Li-S batteries gigafactories in Norway are underway [24].

Currently, substantial efforts are made to finally benefit from the advantages of $\mathrm{Li}$ metal anodes in commercial rechargeable cells, especially for electric vehicles (EV) applications. As depicted in Fig. 1 , several R\&D programs have been launched worldwide to accelerate this transition. Some of the most ambitious examples are the "Battery 500" (USA), "Made in China 2025" (China), and "RISING II" (Japan) [25,26]. Also in Europe, batteries are included among the key clean energy technologies of the Integrated Strategic Energy Technology Plan (SET-Plan) Action 7 [27,28]. To become competitive in the battery sector, very ambitious targets have been set for performance (energy, power and lifetime), cost, and manufacturing volume [27]. In terms of battery chemistries, the transition to LMBs (i.e., Generation 4: all-solid-state with lithium metal; and Generation 5: $\mathrm{Li}-\mathrm{S}$ and $\mathrm{Li}-\mathrm{O}_{2}$ ) [28] is planned starting from 2025 [27]. Overall, independently from the timeframe, it is clear that all programmes aim to reach the same target of $500 \mathrm{Wh} \mathrm{kg}^{-1}$. Certainly, large efforts are required to overcome the still existing challenges associated with the use of Li metal. This review comprehensively covers all these aspects.

\section{The challenge of stabilizing Li metal anodes: general strategies}

As recently discussed by Cui et al. [10], among all challenges identified in the past decades, two main issues need to be addressed to enable Li metal anodes: (i) the formation/disappearance of the full volume, and (ii) the high chemical reactivity.

Regarding volumetric changes, the morphology of the anode is key. Pristine Li metal foil is soft, ductile and both a good electronic and ionic conductor. Such features justify its traditional use in form of thin foil, without needing a current collector. However, a thickness change of tens of $\mu \mathrm{m}$ results from applying cathodes with practical capacities $>3 \mathrm{mAh}$ $\mathrm{cm}^{-2}$. To mitigate the $\mathrm{Li}$ interface movement during cycling, Li powder has recently been considered as alternative. Li powder particles $(\sim 20$ $\mu \mathrm{m}$ in diameter) compacted into a round disc (15 MPa, Ø $15 \mathrm{~mm}$ ) contain roughly 4.5 times the surface area of a lithium metal foil disc of the same diameter [29]. According to the Sand equation, the increased surface area reduces the current density on the lithium surface, slowing down dendrite growth [30]. Additionally, the porous structure can accommodate part of the volume changes upon charge/discharge in the pore volume of the electrode [31]. However, lithium powder electrodes have significant disadvantages compared to foils as they are not freestanding and need a substrate, usually $\mathrm{Cu}$-foil. The porosity of the powder electrode allows contact between the $\mathrm{Cu}$ and liquid electrolyte, resulting in galvanostatic corrosion (spontaneous lithium dissolution at the $\mathrm{Cu} / \mathrm{Li}$ interface) [32]. A similar effect has been seen at the Li/electrolyte interface, resulting in pits and voids. Both dissolution effects form "dead" lithium and deteriorate the lithium electrode, causing premature cell death [32]. A solid electrolyte instead may reduce the lithium dissolution at the $\mathrm{Cu} / \mathrm{Li}$ interface, but causes issues at the lithium/electrolyte interface, discussed in detail later in section 3.1.2 [33].

The very low standard reduction potential of lithium is the root of its high reactivity. Even when stored under inert conditions, i.e., under argon, lithium readily reacts with trace residual atmospheric gases, resulting in a surface passivating layer [34]. This so-called "native SEI" consists mostly of $\mathrm{Li}_{2} \mathrm{O}, \mathrm{LiOH}$ and $\mathrm{Li}_{2} \mathrm{CO}_{3}$. While it enables handling of lithium metal in dry room conditions, its composition and morphology, can be influenced by production and storage conditions and is difficult to control. Meyerson et al. analysed the surface composition of a native SEI and determined a mostly inorganic surface $\left(\mathrm{Li}_{2} \mathrm{O}\right.$ and $\left.\mathrm{Li}_{2} \mathrm{CO}_{3}\right)$ with organic rich veins [35]. The inorganic sections were shown to be less reactive than the organic rich veins. Schmitz et al. additionally found $\mathrm{Li}_{3} \mathrm{~N}$ and $\mathrm{Li}_{2} \mathrm{C}_{2}$ when analysing the native SEI, yet their work does not mention distinct morphological differences [36]. Once the lithium electrode is exposed to the electrolyte, a "secondary SEI" forms on top of the electrode. The presence of the native SEI, and its influence on the secondary one, is often neglected in literature. This complicates a thorough understanding of the Li surface and the development of suitable surface protection strategies. 
To tackle the challenges associated with lithium metal, two main approaches have been considered, as shown in Fig. 2 The first is to stabilize the lithium metal in the liquid electrolyte via a suitable SEI [37]. The SEI requires similar properties to that applied in state-of-the-art LIBs regarding high ionic conductivity, being electronically insulating and chemically stability [38,39]. Due to the much larger volumetric changes of lithium metal compared to the graphite anode, substantially higher mechanical stability is needed. Possible SEI formation routes include: (i) electrochemical SEI formation ("in-situ" SEI) via a properly chosen electrolyte (solvent/salt/additive combination) and (ii) an artificial SEI ("ex-situ") produced prior to cell assembly. The second approach is applying a solid instead of liquid electrolyte [2]. The high mechanical strength of solid electrolytes, either polymeric or inorganic, should suppress dendrite growth, therefore prolonging cycle life. Additionally, solid electrolytes improve the overall cell safety. Unlike liquid organic electrolytes, they are not flammable. Yet, solid electrolytes tend to have additional issues, discussed later in section 3 . Of course, a number of hybrid electrolytes resulting from the combination of these two main classes (liquid and solids) could also be employed in LMBs. As reviewed by Keller et al., possible hybridization approaches include gel polymer (liquid/polymers), quasi-solid (liquid/inorganic) and solid (polymer/inorganic) hybrid electrolytes [40]. Nevertheless, for sake of brevity, in this section we will focus on general strategies to enable Li metal electrodes, solely in liquid cells.

\subsection{In-situ SEI with additives/electrolyte}

Understanding the SEI formation process has led to thorough research towards electrolyte optimization, to derive decomposition products desirable for the SEI. Galvanostatic corrosion (spontaneous lithium dissolution at the Li/electrolyte interface) is the main driving force in the SEI formation process [32]. Without a passivating additive the lithium dissolution at the $\mathrm{Li} /$ electrolyte interface will result in pits and voids, causing the formation of "dead" lithium and deterioration of the lithium electrode [32]. Therefore, electrolyte additives have gained great interest. The formation of a SEI via electrolyte additives will initially consume some lithium of the electrode. However, this consumption is limited and will cease once the lithium electrode surface is sufficiently covered with the desired SEI. Electrolyte additives are usually divided into two main groups, reduction type and reaction type additives (Fig. 3a-i) [41]. Reduction type additives, have a relatively high redox potential and are reduced prior to the electrolyte depletion. Their decomposition products form an insoluble film, protecting the electrode/electrolyte interface. Reduction type additives are divided into two subgroups. The first subgroup consists of reactive compounds containing an unsaturated carbon bond. These reactive monomers form an electrochemically stable and organic rich polymer layer, upon electrochemical reduction at $\sim 0.9 \mathrm{~V}$ vs $\mathrm{Li} / \mathrm{Li}^{+}$. This group of additives contains, amongst others, vinylene carbonate (VC) [42,43], fluoroethylene carbonate (FEC) [44], vinylene ethylene carbonate [45,46], methyl cinnamate [47], vinyl-containing silane-based compounds [48], and furan derivates [49]. The polymerization of vinylene carbonate (VC) occurs at the carbon-carbon double bond $(\mathrm{C}=\mathrm{C})$. The second subgroup are reductive agents aiding the SEI formation. The reductive agents are reduced before the electrolyte and their decomposition products adsorb to the electrode surface. They additionally react with other species involved in the initial reduction process, reducing the overall amount of radicals present. Most common are sulfur-containing additives such as sulflane [50], ethylene sulfite [44], sulfur dioxide $\left(\mathrm{SO}_{2}\right)$ [51] or 1,3-propane sultone [52]. Their reduction leads to the formation of $\mathrm{Li}_{2} \mathrm{SO}_{3}$ and $\left(\mathrm{RSO}_{3} \mathrm{Li}\right)_{2}$. The presence of $\left(\mathrm{RSO}_{3} \mathrm{Li}\right)_{2}$ additionally enhances the ionic conductivity of the SEI. The reaction type additives belonging to the second group tend to be so-called "scavenger" additives. They react with intermediate compounds or radicals, aiding the formation of a more stable SEI. Although most scavenger additives have been tested in LIBs, their mode of operation should be identical in combination with LMBs. (Trimethylsilyl)isothiocyanate (TMSNCS) has a high electron donating ability and scavenges $\mathrm{PF}_{5}$ and $\mathrm{HF}$ in $\mathrm{LiPF}_{6}$ based electrolytes [53]. Phosphite containing compounds such as tris(2,2,2-trifluoethyl) phosphite (TTFP) and trimethyl phosphite are excellent $\mathrm{PF}_{5}$ scavengers, due to being highly nucleophilic, hence acting as Lewis bases [54,55]. P(III) acts as electron donor and forms a stable complex with $\mathrm{PF}_{5}$. Effective HF scavengers contain simple electron-donating sites and form a complex with HF [56]. Lithium hexamethyldisilylimide scavenges HF and produces $\mathrm{NH}_{3}$, LiF and trimethylsilyl fluoride [57]. Scavenger additives overall improve the stability of $\mathrm{LiPF}_{6}$ containing electrolytes and prolong cycle life. Lithium salts have also been used as additives (Fig. 3a-i.). Salts with an active multivalent cation (e.g., $\mathrm{Mg}^{2+}, \mathrm{Ca}^{2+}, \mathrm{Zn}^{2+} \mathrm{Fe}^{2+}, \mathrm{In}^{3+}$ and $\mathrm{Ga}^{3+}$ ) form an intermetallic alloy phase with lithium on its surface [58]. The intermetallic alloy phase has a lower conductivity than lithium and hence lithium diffuses into the layer instead of plating on top, suppressing dendritic deposition of the lithium [59].

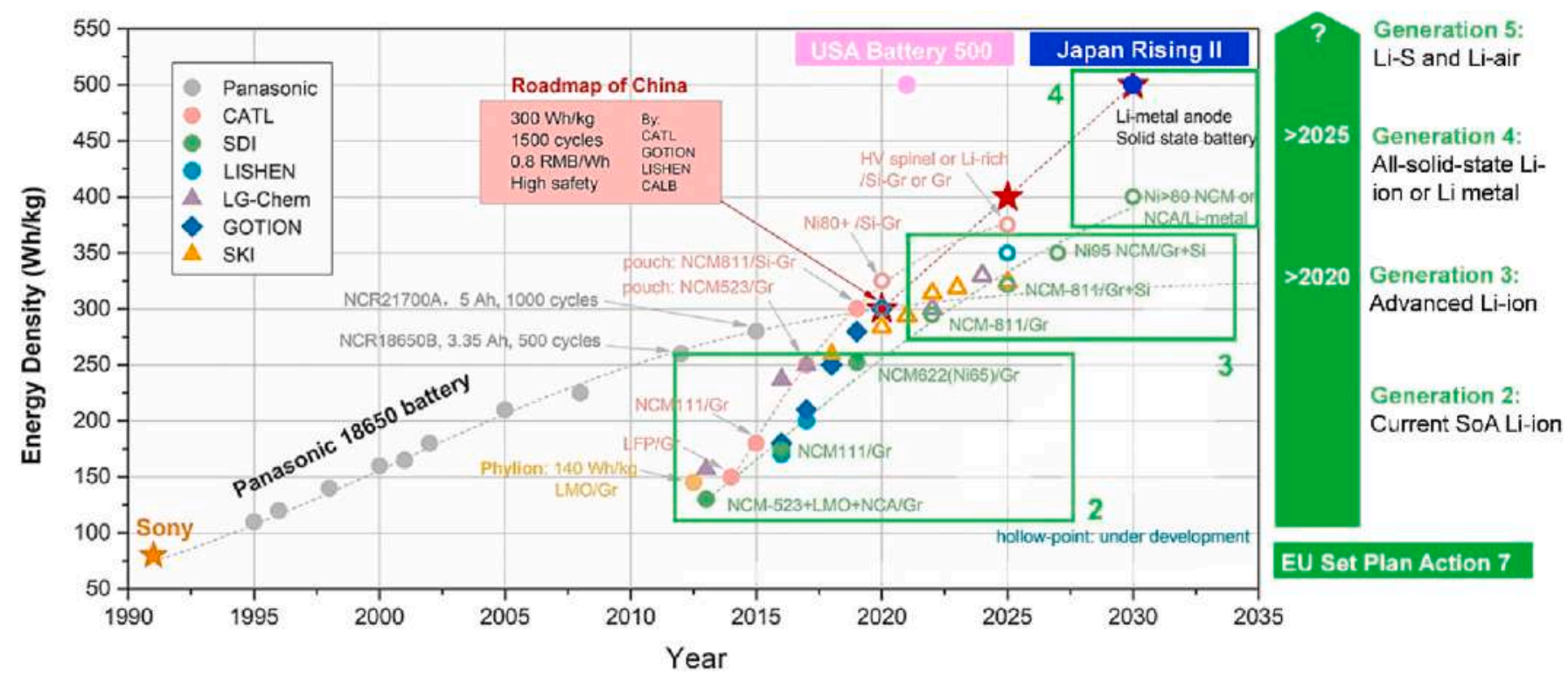

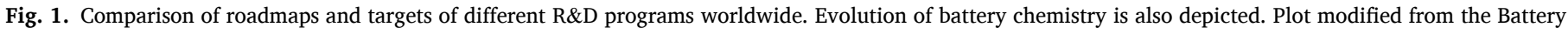
$2030+$ Roadmap [28]. Some of the data originally provided by Hong Li et al. [26]. 


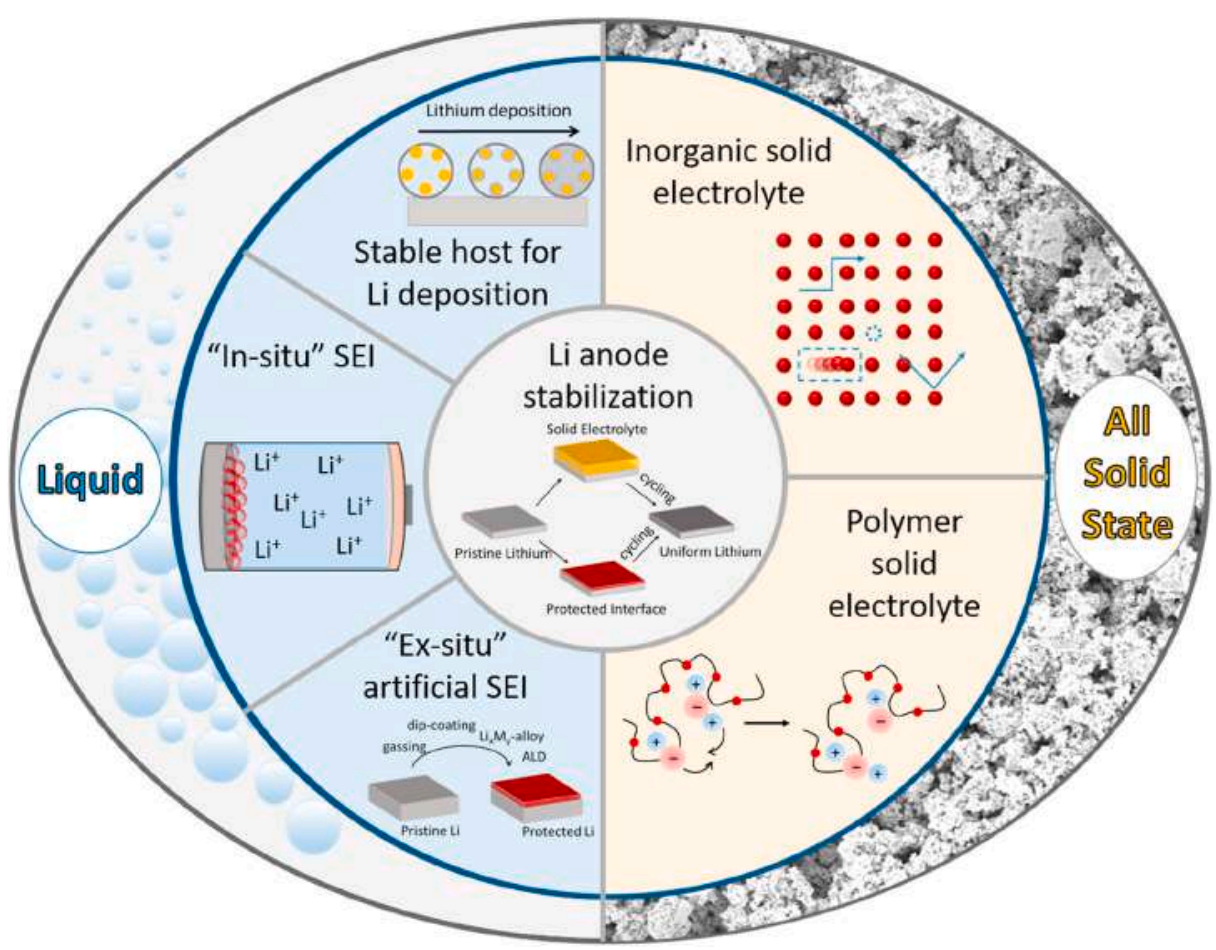

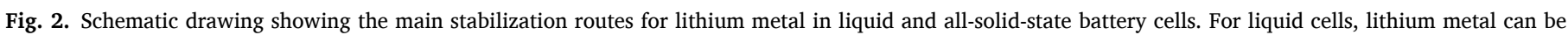

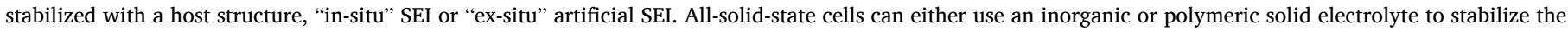
lithium metal anode.

Organic and inorganic hybrid SEIs have been also developed utilizing metal halides as electrolyte additives $[60,61]$. $\mathrm{AlI}_{3}$, for example, is able to stabilize the lithium metal anode surface by a multi-step, synergistic reaction. The initial reduction of the $\mathrm{AlI}_{3}$ salt leads to the formation of a stable LiI layer on top of the lithium metal surface, reducing the activation barrier for $\mathrm{Li}^{+}$transport across the electrode/electrolyte interphase. Additionally, aluminum metal will form the previously mentioned intermetallic alloy phase, suppressing dendrite growth. Finally $\mathrm{Al}^{3+}$, a strong Lewis acid, is an excellent initiator of the 1,3-Dioxolane (DOL) polymerization, producing a thin, protective, polymeric film on the lithium metal surface. The polymeric film protects from further unwanted side-reactions with the electrolyte, while maintaining a high $\mathrm{Li}^{+}$conductivity.

$\mathrm{LiAsF}_{6}$ has also been investigated as lithium salt additive for organic carbonate based electrolytes [62]. It is reduced in the electrolyte, forming a $\mathrm{Li}_{\mathrm{X}} \mathrm{As}$ alloy phase and $\mathrm{LiF}$ on the lithium anode, positively affecting lithium deposition and the surface morphology [63]. Overall, halogenated lithium salt additives are beneficial for improving long-term cyclability of LMBs. Lithium halides (LiF, LiBr and LiI) suppress dendrite formation. Even without good salt solubility, the anions $\left(\mathrm{F}^{-}, \mathrm{Br}^{-}\right.$and $\left.\mathrm{I}^{-}\right)$adsorb on the lithium surface and enhance the surface mobility of lithium ions $[64,65]$. Since halide salts cannot be reduced any further, they reduce or prevent reactions of lithium with other electrolyte components.

Ionic liquids (IL) have also been investigated as SEI precursors, yet many ionic liquids are not stable towards lithium metal (Fig. 3a-ii) [66, 67]. Generally, ionic liquids are reduced at a more positive potential with respect to the potential of lithium plating. Adding a lithium salt, such as $\mathrm{LiBF}_{4}, \mathrm{LiPF}_{6}$ and LiTFSI to an IL is beneficial. By using either the $\mathrm{FSI}^{-}$or $\mathrm{TFSI}^{-}$anion, the stability window of the electrolyte is extended and it can be combined with lithium metal $[66,67]$. Since ionic liquids do not contain solvents, the anion plays the deciding role in the SEI formation and can be tailored accordingly. In the case of LiFSI-IL, the SEI consists of $\mathrm{LiF}, \mathrm{Li}_{2} \mathrm{O}, \mathrm{LiOH}$ and $\mathrm{FSI}^{-}$decomposition products [68]. Once the cell is cycled, additional species associated with the cation are present.

Another example of safe electrolyte worth to be mentioned is the 1.2 M LiFSI in a mixture of triethyl phosphate (TEP) and bis(2,2,2trifluoroethyl) ether (BTFE) reported by Chen at al [69]. Besides being non-flammable, it produces a much thinner and dense SEI on Li metal compared to conventional carbonates, thus mitigating its continuous corrosion, which results in less surface being available for SEI formation and other parasitic reactions. As shown by Niu et al. [70], when employed in a $1 \mathrm{Ah} \mathrm{Li} \mid \mathrm{NMC}_{622}$ pouch cell a gravimetric energy of 300 $\mathrm{Wh} \mathrm{kg}^{-1}$, this electrolyte substantially mitigates cell swelling under applied external pressure.

\subsection{Artificial SEI}

As a measure to prevent dendrite formation and ensure long-term cycling stability artificial SEIs have been of particular interest. The artificial SEI is the passivate layer formed on top of the lithium metal anode before coming into contact with the electrolyte (Fig. 3b). Depending on the processing method, the artificial SEI forms on top of pristine lithium or the native SEI. Stabilizing the anode surface before cycling allows the regulation of the SEI considering the thickness, homogeneity and conformity. Artificial SEIs specifically for lithium metal electrodes are often formed by atomic-layer deposition, aeration or coating in a liquid [71-73].

Atomic layer deposition (ALD) is an advanced thin-film fabrication technique, producing homogenous, conform, and ultra-thin films at temperatures below the melting point of lithium (Fig. 3b-i) [74]. The surface film needs to be as thin as possible to preserve high ionic conductivity, but be thick enough to protect the lithium metal surface. ALD films based on $\mathrm{Al}_{2} \mathrm{O}_{3}$ result in the lithiation of $\mathrm{Al}_{2} \mathrm{O}_{3}$ and the formation of a stable, ionically conductive $\mathrm{Li}_{\mathrm{X}} \mathrm{Al}_{2} \mathrm{O}_{3}$ alloy layer [75]. According to Qin et al. the lithiation degree of a lithium aluminate layer increases upon consecutive cycling, which may be beneficial to guarantee a more homogeneous Li diffusion. Ultimately, it cannot be excluded that a Li-Al alloy is also formed [76]. Kozen et al. showed that a $14 \mathrm{~nm}$ thick film 


\section{a) In-situ SEI}

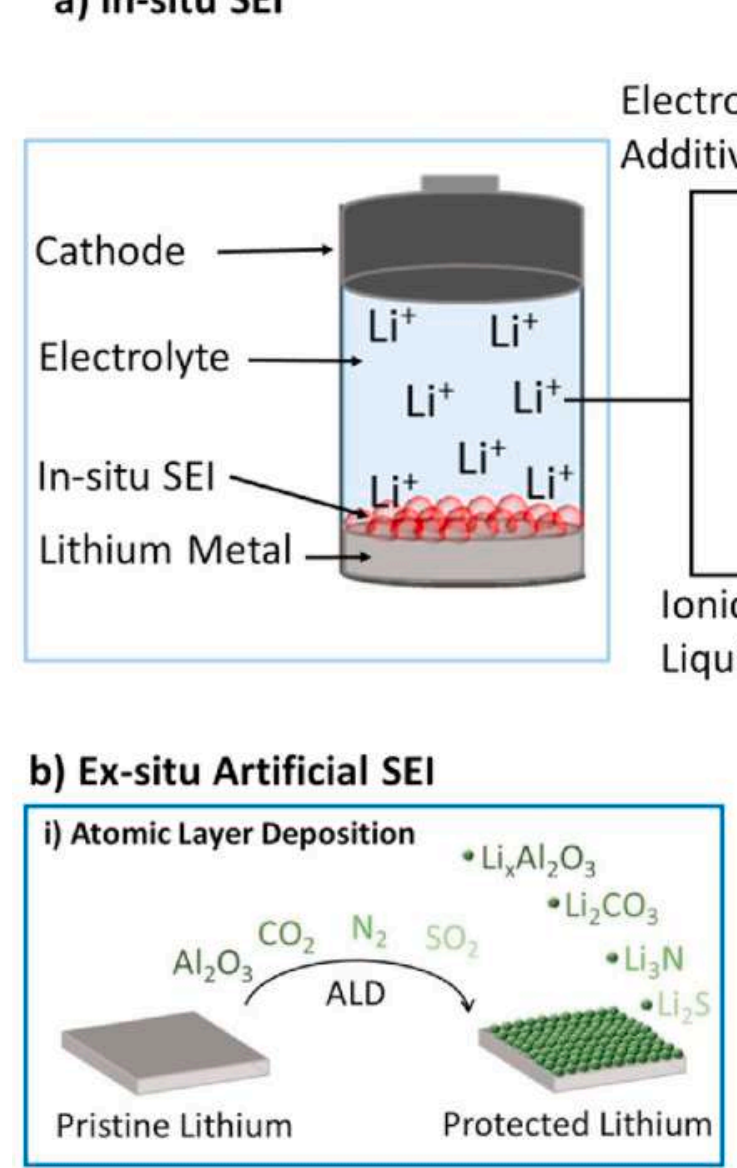

iii) Dip-coating
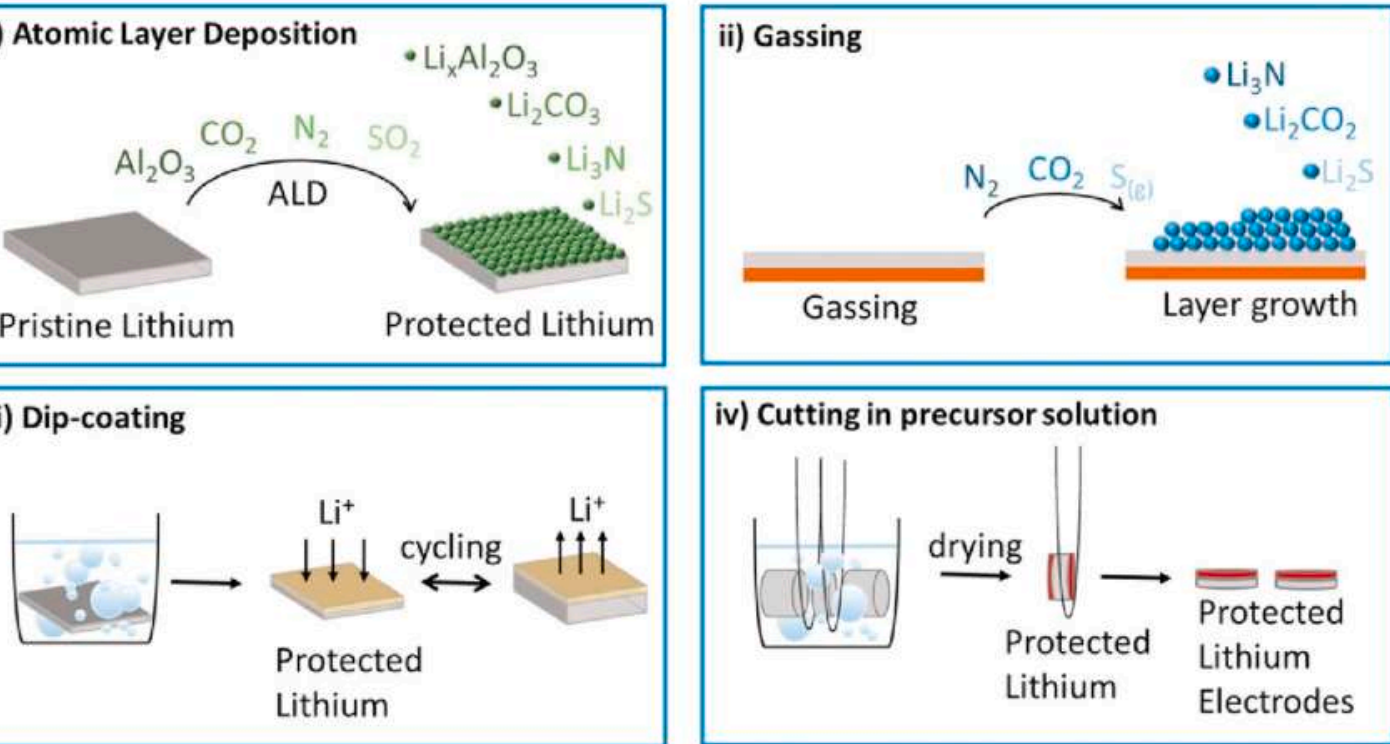

c) Host Structure
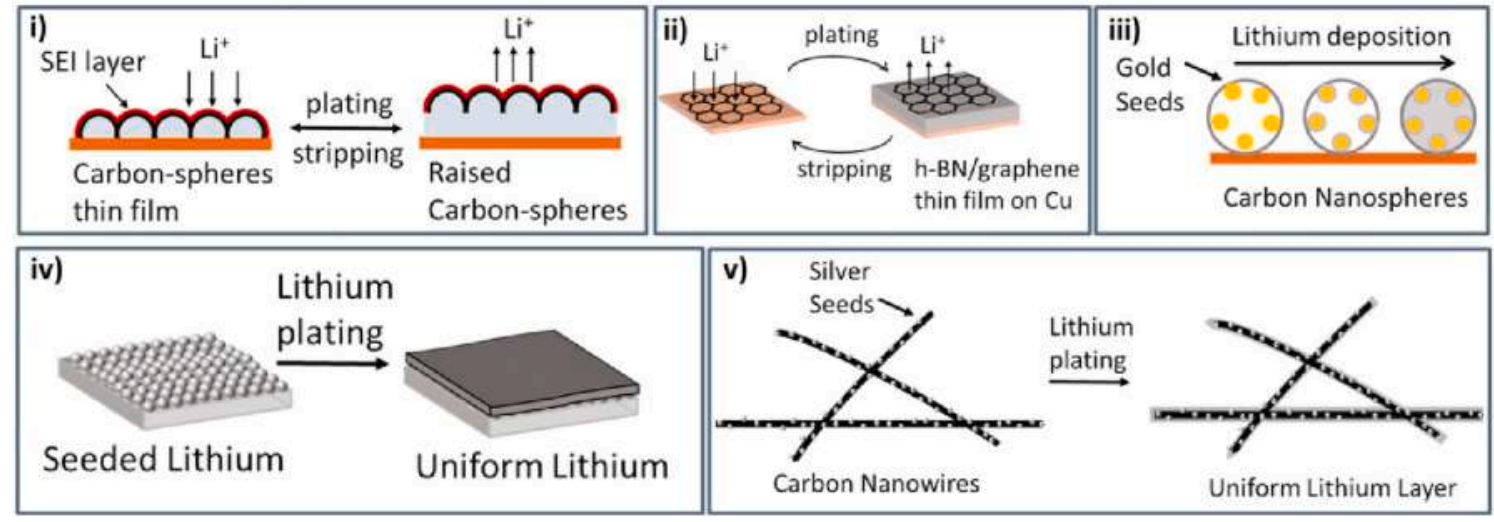

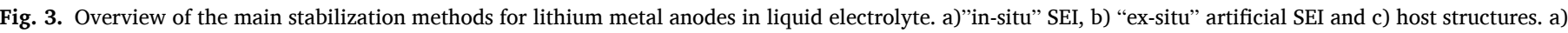

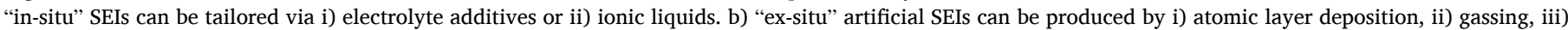

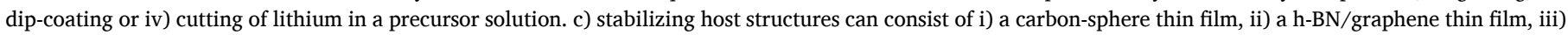
hollow carbon nanospheres, iv) an ultrafine lithium seed layer or v) seeded carbon nanowires. 
only contains the $\mathrm{Li}_{\mathrm{x}} \mathrm{Al}_{2} \mathrm{O}_{3}$ alloy phase in the $6 \mathrm{~nm}$ closest to the lithium metal surface. The top $8 \mathrm{~nm}$ consist of $\mathrm{Al}_{2} \mathrm{O}_{3}$ and undergo lithiation upon cycling, resulting in a pure $\mathrm{Li}_{\mathrm{x}} \mathrm{Al}_{2} \mathrm{O}_{3}$ alloy layer [77]. Combined with a sulfidic solid electrolyte the $\mathrm{ALD} \mathrm{Al}_{2} \mathrm{O}_{3}$ protective layer prevents self-discharge during the rest period and reduces capacity loss by $40 \%$ after 100 cycles [78]. A subsequent study by Kazyak et al. showed the beneficial effect of a significantly thinner $\mathrm{ALD} \mathrm{Al}_{2} \mathrm{O}_{3}$ film of only $2-3 \mathrm{~nm}$ [79]. This film was beneficial for suppressing dendrite propagation and doubled the lifetime of lithium metal electrodes before short-circuiting. Despite the reduction of the $\mathrm{Al}$ concentration on the lithium metal surface, the more homogenous current distribution on the surface reduces dendrite growth significantly. Chen et al. used low temperature ALD $\left(150{ }^{\circ} \mathrm{C}\right)$ to produce a homogenous, high purity ( $\left.>99 \%\right) \mathrm{LiF}$ film on top of a lithium metal surface. The LiF layer thickness is tailored by increasing its thickness by $0.8 \AA$ per ALD cycle. Its high shear modulus (58 GPa) suppressed dendrite growth and increased cycle life by four times in comparison to uncoated lithium electrodes, whilst showing a high Coulombic efficiency of 99.5\% [80].

Another method of creating an artificial SEI is via reaction of lithium metal with gaseous species (Fig. 3b-ii). The treatment with $\mathrm{N}_{2}$ at room temperature results in a stable and dense $\mathrm{Li}_{3} \mathrm{~N}$ protective film [81]. Wu et al. produced a highly conductive $\mathrm{Li}_{3} \mathrm{~N}$ layer with a thickness of 159 $\mathrm{nm}$. The protective layer effectively prevents side reactions between lithium metal and the electrolyte whilst $\mathrm{Li}_{3} \mathrm{~N}$, due to its high lithium ion conductivity, provides barely any resistance towards lithium ion mitigation [82]. After 100 cycles the passivating layer is still stable and without cracks. Importantly, the exposure time of lithium to $\mathrm{N}_{2}$ is the deciding factor towards performance and stability of the passivating $\mathrm{Li}_{3} \mathrm{~N}$ film. Alternatively, $\mathrm{CO}_{2}$ has been used to passivate the lithium metal surface. Lithium exposure to a $\mathrm{CO}_{2}$ atmosphere at room temper-

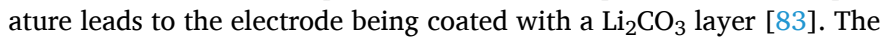
protective layer improved the ionic conductivity and resistance compared to the native SEI on lithium. For the $\mathrm{Li}_{2} \mathrm{CO}_{3}$ layer formation, the native SEI has to be removed from the lithium surface via mechanical brushing. Without this step, the surface film would be dominated by $\mathrm{Li}_{2} \mathrm{O}$, resulting in reduced ionic conductivity. The high lithium ion exchange rate for $\mathrm{Li}_{2} \mathrm{CO}_{3}$ is based on the charge centre in the carbonate shifting from one oxygen atom to another, due to orbital interaction and charge delocalization [84]. Due to low ionic resistance, the $\mathrm{Li}_{2} \mathrm{CO}_{3}$ layer itself is relatively stable and withstands high current densities of $20 \mathrm{~mA}$ $\mathrm{cm}^{-2}$ without cracking [83]. Sulfur gas has been also used to produce a stable $\mathrm{Li}_{2} \mathrm{~S}$ layer on lithium metal electrodes [85]. The gas phase reaction at elevated temperature $\left(170{ }^{\circ} \mathrm{C}\right)$ forms a homogenous and conductive layer. Due to its certain ionic conductivity $\left(10^{-5} \mathrm{~S} \mathrm{~cm}^{-1}\right)$, the $\mathrm{Li}_{2} \mathrm{~S}$ layer can mitigate inhomogeneous lithium ion flux. Upon cycling the artificial SEI preserves its protective function by converting into a layered SEI, containing $\mathrm{RCO}_{2} \mathrm{Li}, \mathrm{Li}_{2} \mathrm{CO}_{3}$, sulfonates and a $\mathrm{Li}_{2} \mathrm{~S} / \mathrm{Li}_{2} \mathrm{~S}_{2}$ mixture. The $\mathrm{Li}_{2} \mathrm{~S}$ protective triples the cycle life compared to unprotected lithium at $2 \mathrm{~mA} \mathrm{~cm}^{-2}$.

Additionally, an artificial SEI can be fabricated by exposing lithium metal to selected liquid chemicals. One method is dip-coating lithium metal in appropriate SEI precursors as initially proposed by Schechter et al. [86] (Fig. 3b-iii). For example, dip-coating with polyphosphoric acid solution ( $0.4 \mathrm{wt} \%$ in DMSO) leads to the formation of an artificial $\mathrm{Li}_{3} \mathrm{PO}_{4} \mathrm{SEI}$ layer [87]. This method replaces the native SEI on the lithium surface with a uniform $\mathrm{Li}_{3} \mathrm{PO}_{4} \mathrm{SEI}$, showing excellent chemical stability, a high Young's modulus (10-11 GPa) and high lithium ion conductivity. Dip-coating lithium metal in a metal chloride solution $\left(\mathrm{MCl}_{\mathrm{x}}\right.$ in THF, $\mathrm{M}$ $=\mathrm{In}, \mathrm{As}, \mathrm{Bi}, \mathrm{Zn}$ ) forms a $\mathrm{Li}_{\mathrm{x}} \mathrm{M}_{\mathrm{y}}$ alloy phase on the lithium surface [88]. This method utilizes the high lithium ion conductivity of the alloy phase and lithium ion from the underlying lithium metal. The formation of electronically insulating $\mathrm{LiCl}$ compensated the bulk alloy layer being electronically conductive, by establishing an electric field across the surface film, driving lithium mitigating through the protective layer. The layer prevents lithium reduction on the surface and suppresses dendrite growth sufficiently, allowing stable cycling at high current densities $\left(2 \mathrm{~mA} \mathrm{~cm}^{-2}\right)$ for up to $1000 \mathrm{~h}$. Using a dip-coating procedure to fabricate the artificial SEI has one major drawback: it produces the artificial SEI on top of the native SEI, making it difficult to unambiguously assign electrochemical properties. Furthermore, the composition of the native SEI depends on the lithium provider and storage conditions and can vary between lithium batches. Cutting the lithium directly in the precursor solution ensures the artificial SEI being produced on top of pristine lithium and enables improved investigation of the artificial SEI [89] (Fig. 3b-iv). This method was developed and used by Ding et al. to form a protective layer based on 1-pentylamine in pentane [90]. Pentane itself does not react with lithium; hence the resulting protective layer mainly consists of $\mathrm{Li}_{3} \mathrm{~N}$. $\mathrm{Li}_{3} \mathrm{~N}$ has an exceptionally high ionic conductivity, not hindering lithium transport, and produces a stable SEI with little resistivity, but it can also be a brittle solid which is less beneficial for the compensation of volume changes during plating/stripping [91]. It is important that the 1-pentylamine concentration is sufficiently high $(1 \mathrm{M})$ to produce a stable, homogenous surface prolonging cycling stability.

\section{3. - Host engineering}

A different approach is to alter the surface where Li is plated (either Li metal or directly the current collector) via nanoscale interfacial engineering. Mechanically and chemically stable frameworks are introduced to facilitate homogeneous deposition and to stabilize the SEI forming naturally during charge and discharge (Fig. 3c) [92,93].

Coating the lithium metal surface with a monolayer of interconnected amorphous hollow carbon nanospheres guides lithium deposition and its nucleation within the hollow carbon spheres and on the copper substrate underneath (Fig. 3c-i). During further lithium deposition, the layer lifts whilst remaining intact resulting in a continuously stable solid electrolyte interphase [94]. Additionally, lithium deposits in a column like structure rather than long filaments or protruding dendrites. The nanospheres layer enabled cycling at a current density of $1 \mathrm{~mA} \mathrm{~cm}{ }^{-2}$, whilst maintaining a coulombic efficiency of $97.5 \%$ for more than 150 cycles. Two-dimensional structures such as graphene or hexagonal boron have been proposed alternatively, as stabilizing structures directly on the copper current collector (Fig. 3c-ii) $[95,96]$. During lithium deposition, the ions travel through point and line defects of the 2D layer and deposit underneath on the copper substrate. Both layers are chemically inert and stable against lithium metal. Even a single atomic layer has sufficient mechanical strength to suppress dendrite formation, due to strong intra-layer bonds, resulting in a Young's modulus of up to $1.0 \mathrm{TPa}$, more than twice of lithium metal [97]. The graphene layer being a semimetal differs from the insulator hexagonal boron layer. Upon cycling the protective hexagonal boron layer mixes with the electrolyte producing a complex SEI and electrolyte layer. This mixing causes the Coulombic efficiency to rise from $87 \%$ to $97 \%$ within the first two cycles and remains stable for over 50 cycles at $0.5 \mathrm{~mA} \mathrm{~cm}^{-2}$. The hexagonal boron layer protects the lithium anode, but the coulombic efficiency is not yet sufficient for full cells. The graphene layer on the lithium metal anode also enables stable cycling, but the coulombic efficiency is lower ( $95 \%$ at $0.5 \mathrm{~mA} \mathrm{~cm}^{-2}$ for over 50 cycles), probably due to its reduced average thickness [98]. Also an as-engineered protective microstructure consisting of $\mathrm{LiZn}$ and $\mathrm{Li}_{3} \mathrm{PO}_{4}$ has resulted in a high cycling stability at high current densities (up to 5 $\mathrm{mA} \mathrm{cm}{ }^{-2}$ ) [99]. Alternatively, guided lithium deposition via pre-infusion or seeded growth has been examined. Pre-infusion host structures based on carbon [100-102], polymeric [103], ceramic [104] or others such as stable nickel foam [105] reduce the volumetric changes experienced by naturally hostless lithium metal and ensure homogenous lithium deposition. The host structure is infused with molten lithium driven by capillary force and provides an electrochemically and mechanically stable artificial interface. Lin et al. showed that such a composite anode has a reduced volumetric expansion of only $\sim 20 \%$, a low overpotential of $\sim 80 \mathrm{mV}$ at $3 \mathrm{~mA} \mathrm{~cm}^{-2}$ and is able to retain $\sim 3390 \mathrm{mAh}$ 
$\mathrm{g}^{-1}$ capacity [100]. Seeded growth entails guided lithium nucleation at chosen "seeds" placed directly on top of the current collector, aiding homogenous deposition [106]. A plethora of seeds have been investigated, including homogenous ultrafine lithium seeds (Fig. 3c-iv) [107] and heterogeneous seeds such as hollow, amorphous carbon spheres containing gold nanoparticles (Fig. 3b-iii) [108] or silver nanoparticles anchored onto carbon nanofibers (Fig. 3b-v) [109]. Pre-plated lithium seeds provide highly lithiophilic active sites, which significantly reduce the nucleation barrier promoting specific nucleation sites. The consequent homogenous lithium plating results in a dendrite-free surface for $350 \mathrm{~h}$ and low overvoltage of $20 \mathrm{mV}$ at $3 \mathrm{~mA} \mathrm{~cm}^{-2}$ [107]. Both the carbon spheres and carbon nanofibers provide a 3D matrix on top of the current collector in which the lithium nucleation occurs. In case of the amorphous carbon spheres, lithium initially alloys with the gold seeds, forming $\mathrm{Li}_{\mathrm{x}} \mathrm{Au}$, before completely filling the carbon sphere as lithium metal. The carbon spheres are able to alleviate the volumetric expansion as well as protect the lithium from unwanted side-reactions with the electrolyte [110].

\section{3. - Generation 4: all-solid-state batteries (ASSB)}

Conventional organic liquid electrolytes in rechargeable LIBs still pose one of the major safety hazard because of their flammability [111] and, with the development of up-scaled batteries for automotive or stationary application, the risk of fire and explosion has become a serious issue $[111,112]$. Replacing the flammable liquid solution with an inorganic solid electrolyte (ISE) or a solid polymer electrolyte (SPE) is considered an attractive strategy to mitigate the safety risks which impede the full commercialization of large-scale batteries [113,114]. Furthermore, the use of a solid electrolyte with higher thermal and mechanical stability would enable the use of lithium metal as anode, expediting the development of higher energy-dense batteries [113,114].

This new generation of all-solid-state batteries (ASSB), also known as generation 4 (or generation $4 \mathrm{~b}$ when a lithium metal anode is used), would potentially meet the demand for safer and higher energy-dense batteries for large-scale applications. However, several bottlenecks still impede the full commercialization [113,115-118]. Achieving an ionic conductivity comparable to classical liquid electrolyte systems (higher than $10^{-3} \mathrm{~S} \mathrm{~cm}^{-1}$ ) [119], and reducing the large impedance at the electrode-electrolyte interfaces are the main challenges to the full development. Furthermore, electrochemical stability against lithium metal is another major bottleneck in ASSBs.

\section{1. - ASSBs with inorganic electrolytes}

Inorganic solid electrolytes (ISEs) are considered the most attractive option for ASSBs, mainly because of their high thermal stability, ionic conductivity and cyclability [114]. Compared to solid polymer electrolytes (SPEs), ISEs can achieve a higher ionic conductivity at room temperature $\left(10^{-3}-10^{-4} \mathrm{~S} \mathrm{~cm}^{-1}\right.$ vs $\left.10^{-5}-10^{-7} \mathrm{~S} \mathrm{~cm}^{-1}\right)$ and high Li-ion transference number [120]. On the other hand, they are characterized by a higher interfacial impedance (caused by a poorer solid-solid contact at the electrode/electrolyte interface) and electrochemical instability toward lithium metal, which is dependent on the ISE chemistry [114, $121]$.

\subsection{1. - Inorganic solid electrolyte chemistries}

Sulfide-based electrolytes are among the most promising ISEs for ASSBs, because their lithium-ion conductivity is comparable to most organic liquid electrolytes [114,120,122,123]. A new class of superionic conductor, based on $\mathrm{Li}_{3} \mathrm{PS}_{4}$, has recently been developed as materials of choice for ASSB, not only for their extremely high ion conductivity but also for their mechanical properties allowing good solid-solid contact with the electrode interfaces [114,122]. $\mathrm{Li}_{10} \mathrm{GeP}_{2} \mathrm{~S}_{12}$ (LGPS), in particular, has one of the highest Li-ion conductivity ever achieved in solid electrolytes at room temperature $\left(12 \mathrm{mS} \mathrm{cm}^{-1}\right)$, which also exceeds the ionic conductivity of most conventional organic liquid electrolytes [120, 124]. Contrary to oxide-based systems, sulfide-based ISEs are softer and more deformable, and can be cold-pressed into pellets with tightly connected electrolyte particles. This densely packed configuration has relatively low grain boundary resistance, and does not require sintering as in many oxide-based electrolytes [122]. On the other hand, sulfide-based systems (as more thoroughly described in 3.1.2), are characterized by high reactivity toward both lithium metal and high voltage cathode materials and are extremely hygroscopic.

Oxide-based electrolytes constitute a wide family of ionic conductor for all-solid-state batteries. The most attractive crystalline Li-ion conductors are garnet-type [125], perovskite-type [126,127], Natrium Super Ionic Conductor (NASICON) and Lithium Super Ionic Conductor (LISICON) [119,128]. Even though their ionic conductivities are usually lower than sulfides, oxide-based systems are among the most investigated because of their better electrochemical stability with lithium metal and lower degradation at high voltage [114]. Garnet-type conductors are promising candidates to be used in solid state batteries [129], and are finding wider application as inorganic fillers to improve the ionic conductivity and mechanical properties of many solid polymer electrolytes [114]. Although lithium-garnet electrolytes like $\mathrm{Li}_{7} \mathrm{La}_{3} \mathrm{Zr}_{2} \mathrm{O}_{12}$ (LLZO) exhibit a relatively low ion conductivity $\left(10^{-6}\right.$ $10^{-4} \mathrm{~S} \mathrm{~cm}^{-1}$ ), this can be enhanced to $10^{-3} \mathrm{~S} \mathrm{~cm}^{-1}$ when the cubic phase is stabilized after Al-doping [114,130,131]. Contrary to many sulfides, Garnet solid electrolytes are stable at high voltage and when in contact with lithium metal [114]. They are also relatively stable in air, but are very sensitive to water and $\mathrm{CO}_{2}$ which usually cause the deposition of low-conducting side products on the surface (e.g. carbonates) [119, 120]. Unfortunately, they are characterized by high resistance at the grain boundaries, whose formation is hardly avoided when synthesized $[114,125]$. NASICON-type and perovskite-type conductors possess a relatively high ionic conductivity (in the order of $10^{-3} \mathrm{~S} \mathrm{~cm}^{-1}$ ) [119, 128]. Their fast lithium ion conductivity correlates strictly to their large lattice volume. However, modifications that cause an increase in the channel width for lithium transport are always needed. In a NASICON conductor like $\mathrm{LiZr}_{\mathrm{x}} \mathrm{Ti}_{2-\mathrm{x}}\left(\mathrm{PO}_{4}\right)_{3}$, lithium cannot diffuse fast in a framework mainly consisting of $\mathrm{ZrO}_{6}$ octahedra and $\mathrm{PO}_{4}$ tetrahedra, but, when $\mathrm{Zr}$ is replaced by Ti, the conductivity reaches $10^{-3} \mathrm{~S} \mathrm{~cm}^{-1}$ [132]. Increasing the lattice volume works well also for perovskite such as $\mathrm{Li}_{3 \mathrm{x}} \mathrm{La}_{2 / 3-\mathrm{x}} \mathrm{TiO}_{3}$ (LLTO) where partial substitution of La with larger Sr ions can enhance the ionic conductivity to $1.5 \times 10^{-3} \mathrm{~S} \mathrm{~cm}^{-1}[122,127]$. LISICON-type lithium conductors possess very high ionic conductivity at high temperature, but relatively poor at room temperature. $\mathrm{Li}_{3.5} \mathrm{Z}$ $\mathrm{n}_{0.25} \mathrm{GeO}_{4}$ is reported to have the highest conductivity $\left(0.125 \mathrm{Scm}^{-1}\right)$ at $300{ }^{\circ} \mathrm{C}$, but only $10^{-7} \mathrm{~S} \mathrm{~cm}^{-1}$ at room temperature [119]. Furthermore, LISICON electrolytes suffers from decrease of the ionic conductivity with time at low temperature because of the formation of $\mathrm{Li}_{4} \mathrm{GeO}_{4}$, a complex which traps the mobile lithium ions [119,122,133].

\subsubsection{Electrochemical and mechanical stability at the interfaces}

Several improvements were done in the enhancement of the ionic conductivity of many inorganic solid electrolytes and results comparable (or even higher) to conventional liquid electrolyte systems were reached for many ISEs such as thio-phosphates, NASICON and perovskiteconductor. However, many other challenges like poor electrode/electrolyte solid-solid contact and electrochemical instability of the solid electrolyte in contact with lithium metal or the high voltage cathode still hamper solid-state batteries full commercialization.

As already mentioned, reactivity toward lithium metal is one of the main drawbacks of sulfide-base solid electrolytes [114,122]. The solid electrolyte/lithium metal interface is very unstable and multiple solid phases (like $\mathrm{Li}_{2} \mathrm{~S}, \mathrm{Li}_{3} \mathrm{P}, \mathrm{Li}_{17} \mathrm{Ge}_{4}$, and polyphosphide compounds) with limited ionic transport properties are usually formed [134,135]. Furthermore, sulfides are extremely hygroscopic and can react with moisture producing toxic $\mathrm{H}_{2} \mathrm{~S}[114,136]$. Depositing surface coatings or artificially fabricated SEI layers on Li are the most common solution to 
stabilize the interface [114]. Many sulfides are also electrochemically unstable when in contact with high voltage cathode materials [114, 122]. Some glass-ceramics thiophosphates (LPS) like $\mathrm{Li}_{7} \mathrm{P}_{3} \mathrm{~S}_{11}$ can react with the layered oxide cathode to form metal sulfides (of Co, $\mathrm{Mn}$ and $\mathrm{Ni}$, e.g.) with consequent high interfacial impedance. The high electrode potential tends to deplete lithium ions, making the interface highly resistive. For this reason, sulfides need to be protected by the high cathode potential with the deposition at the interface of a buffer layer which needs to be electronically insulating and ionically conductive [114,122]. A thin film of an oxide-based electrolyte is usually used, acting as a buffer against lithium depletion and lowering the interfacial resistance $[114,122]$. The layer is deposited on the cathode active material surface, before contacting the electrolyte surface. Several ternary metal oxide buffer layers like $\mathrm{LiNbO}_{3}, \mathrm{Li}_{2} \mathrm{ZrO}_{3}, \mathrm{Li}_{2} \mathrm{SiO}_{3}$, and $\mathrm{LiTaO}_{3}$ have been successfully used as protective layers on the surface of $\mathrm{LiNi}_{0.5} \mathrm{Mn}_{1.5} \mathrm{O}_{4}$ (LNMO), $\mathrm{LiNi}_{\mathrm{x}} \mathrm{Mn}_{\mathrm{y}} \mathrm{Co}_{\mathrm{z}} \mathrm{O}_{2}$ (NMC), $\mathrm{LiNi}_{0.8} \mathrm{Co}_{0.15} \mathrm{Al}_{0.05} \mathrm{O}_{2}$ (NCA), and $\mathrm{LiCoO}_{2}$ (LCO), significantly reducing the electrode/electrolyte interfacial impedance [137-144]. However, a recent study from Zhang et al. [145] on an NMC-LPS system shows that lithium borates like $\mathrm{Li}_{3} \mathrm{~B}_{11} \mathrm{O}_{18}$ (LBO) have better stability at high voltage than lithium zirconate $\mathrm{Li}_{2} \mathrm{ZrO}_{3}$, being promising coatings for thiophosphate systems.

Similarly to sulfides-electrolytes, super ionic conductors like NASICON and perovskite-type electrolyte are also characterized by a bad stability at the lithium metal interface $[120,146]$. Electrolytes like $\mathrm{Li}_{1+\mathrm{x}} \mathrm{Al}_{\mathrm{x}} \mathrm{Ti}_{2-\mathrm{x}}\left(\mathrm{PO}_{4}\right)_{3}$ (LATP) and LLTO contain tetravalent Ti, which can easily be reduced when in contact with low-potential anodes. West et al. [147] found that a dark non-metallic insulating layer is usually formed on LATP when in contact with lithium metal. However, the deposition of $1 \mu \mathrm{m}$-thick lithium phosphorus oxynitride (LiPON) protective layers increases the chemical stability and reduces the reactivity with Li metal [119,147]. Zhou et al. [148] protected LATP from both cathode and lithium metal interface, preparing a ceramic membrane sandwiched with a cross-linked poly-(ethylene glycol) methyl ether acrylate (CPMEA), on both sides. The polymer layer at the solid electrolyte/lithium was observed to suppress dendrite formation, provide a higher wetting ability and protect LATP from Ti reduction caused by contact with lithium metal.

Garnet-type systems are among the most stable inorganic solids against lithium metal [125]. LLZO has a very low interfacial resistance with lithium metal $[114,125]$, but it has to be protected against humidity and $\mathrm{CO}_{2}$ during the synthesis, while the lithium surface has to be free of impurities (i.e. LiOH and carbonates) [114,149,150]. Another important aspect that needs to be considered is the mechanical stability at the $\mathrm{Li} /$ solid electrolyte interface. Scarce solid-solid contact caused by poor lithium wettability on the ISE surface, especially when Garnet-type electrolytes are used, results in high interfacial charge-transfer resistance which can negatively affect the lithium stripping and plating during battery operations [151]. Formation of macropores at the $\mathrm{Li}$ metal/ISE interface during anodic load can become a serious limitation to the battery cycle life and several strategies are currently employed to mitigate this effect [152]. Softening the lithium metal by heating it at $170-175{ }^{\circ} \mathrm{C}$ (about $5-10{ }^{\circ} \mathrm{C}$ below Li melting temperature) directly onto the surface of the ISE prior assembling is an interesting solution to improve the solid-solid contact [151-153]. Mitigation of macropores formation and lithium depletion during cycling can be obtained by application of external pressure (in the order of MPa) to the battery stack or increased operating temperature $\left(60^{\circ} \mathrm{C}\right.$ or above). However, these strategies can increase the weight and the operational cost of the battery [152]. Different approaches to improve the lithium wettability at room temperature are currently investigated. LLZO, like many ceramics, has poor lithium wettability but it can be improved by sputtering a "lithiophilic" coating as a buffer layer to maintain contact between the lithium anode and the oxide surface [154]. Interesting results were obtained after coating a dense/porous LLZO electrolyte with an ALD-deposited ZnO layer and infiltrating the molten lithium in the LLZO pores [155]. The lithium anode could be cycled for $300 \mathrm{~h}$ at $0.5 \mathrm{~mA} \mathrm{~cm}^{-2}$ without significant dendrite induced polarization. Utilization of a lithium-metal alloys (with $\mathrm{Mg}$ [152] or $\mathrm{Al}$ [156] as metals) in contact with LLZO is also an interesting strategy that showed a reduction of the contact loss at the solid-solid interface during lithium stripping. The garnet-cathode interface is not exempt by high interfacial resistance. Kato et al. [157] investigated the use of a thin Nb layer $(\sim 10 \mathrm{~nm})$ to reduce the resistance at the interface between LLZO and a $\mathrm{LiCoO}_{2}$ cathode. The $\mathrm{Nb}$ layer was observed to produce an amorphous $\mathrm{Li}-\mathrm{Nb}-\mathrm{O}$ structure, which is reported to be $\mathrm{Li}^{+}$conductive, reducing the interfacial resistance and improving both the battery cyclability and rate capability.

\subsection{3. - Fabrication of all-solid-state batteries with ISE}

In order to achieve the targets in terms of cycle life, volumetric and gravimetric energy densities defined for a battery cell by the European SET-Plan Action 7 for 2030 (2000 cycles for BEV, $>750 \mathrm{Wh} \mathrm{L}^{-1}$ and $>400 \mathrm{Wh} \mathrm{Kg}^{-1}$ ) several strategies are pursued to optimize the different components of the ASSBs, and to reduce materials synthesis costs when scaling-up. While components such as the solid electrolyte and the cathode can benefit from well established processing routes such as wet chemical processing or high-viscosity processing (solvent free), research on the anode is still undergoing to find cheaper routes for the large-scale production of electrochemical and mechanically stable lithium metal anodes for ASSBs [117].

Fabrication of a rational interface with the lithium metal anode is crucial for a high energy dense battery with long cycle life. Foil processing and layer joining are the most established routes for lithium anode foils production and subsequent interface fabrication. However, the increased cost to produce thinner lithium foils, the high interfacial resistance and the low mechanical stability caused by lithium depletion at the interface do not make this processing suitable for achieving the required cycle life target $[117,152]$. As already mentioned in 3.1.2, protective nano-coatings are necessary to protect lithium from reactive electrolytes or simply improve the wettability of the ceramic surface (schematically shown in Fig. 4a) rendering the lithium-ion flux at the interface more homogeneous, facilitating a more homogeneous deposition of lithium, with the final goal of preventing the formation of dendrites $[114,121,158]$. Expensive advanced fabrication methods like atomic layer deposition (ALD) or pulsed laser deposition (PLD) are usually employed to deposit inorganic nanolayers of $\mathrm{ZnO}$ [155], $\mathrm{Al}_{2} \mathrm{O}_{3}$ [159] or Si [160] on the electrolyte surface. However, alternative solutions like using a polymer/ceramic/polymer sandwich [148] can be interesting to improve the adherence to the lithium metal surface. Utilization of lithiophilic layers enables the melt processing route for designing structures with larger solid-solid contact surface and improves the mechanical stability of the lithium metal/ISE interface at room temperature, removing the need for high operational temperature and pressure [117]. Preparation of a composite lithium metal anode by melt infusion in a 3D scaffold is an attractive strategy for having a homogenous lithium-ion flux [161]. Wang et al. [155] successfully infiltrated melted lithium metal in a 3D garnet-based scaffold ALD coated with a lithiophilic ZnO layer (Fig. 4b). The tight contact between the lithium metal and the electrolyte significantly decreased the interfacial impedance (from $\sim 2000 \Omega \mathrm{cm}^{2}$ to $20 \Omega \mathrm{cm}^{2}$ ). While melt processing, in combination with lithiophilic thin layer deposition, can significantly improve the interfacial charge transfer resistance with beneficial effects on the cycle life, the process is very expensive and difficult to up-scale.

The plating processing route, which consists in developing a socalled "anode-free" cell [162-164] where the formation of a lithium metal anode occurs "in-situ" using the cathode as the only source of lithium while charging, is currently the most promising strategy for increasing the energy density and facilitate the cell manufacturing. Furthermore, removal of the relatively laborious lithium metal foil handling during the cell assembly process reduces the battery cost. Interesting studies were recently done on the in-situ growth of a lithium 
a)
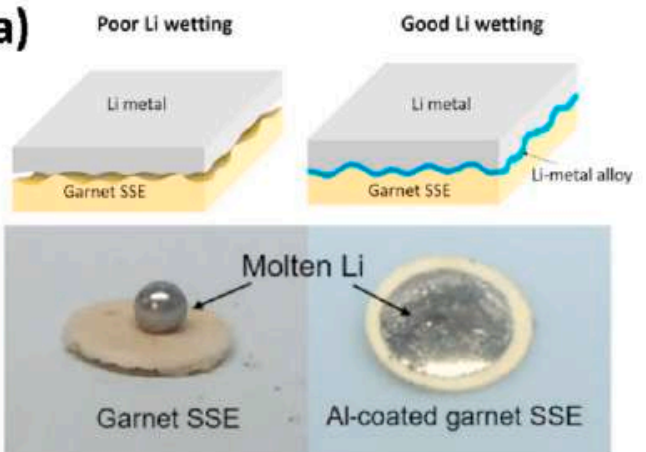

b)

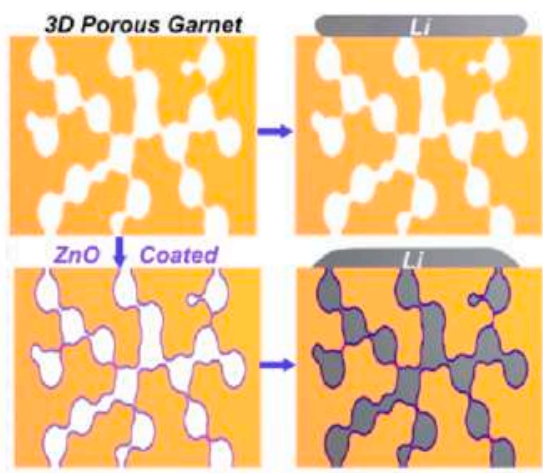

c)

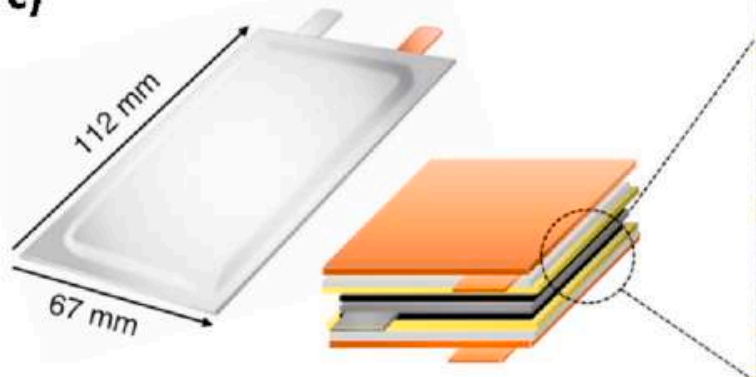

0.6 Ah class prototype pouch cell

d)
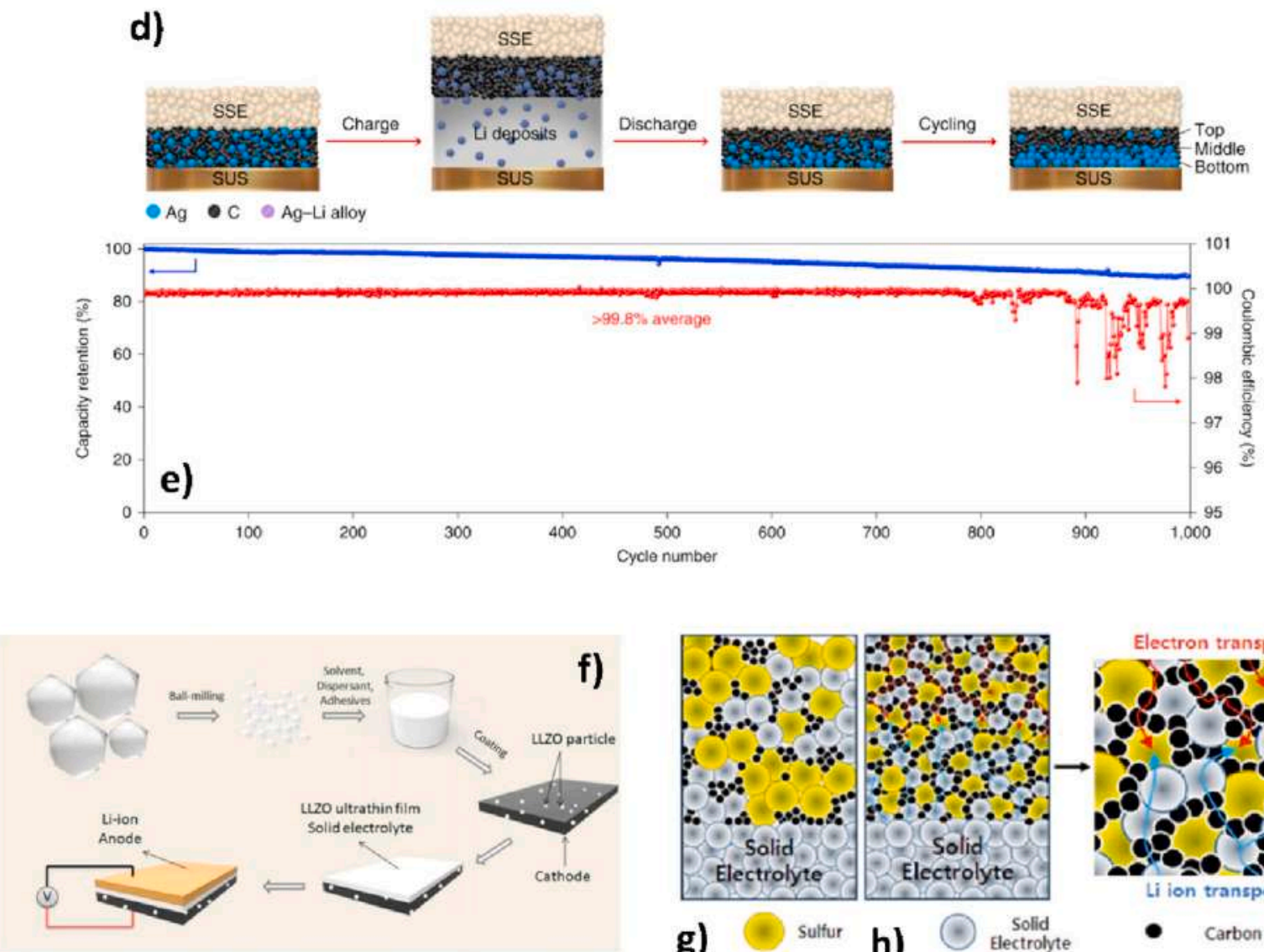

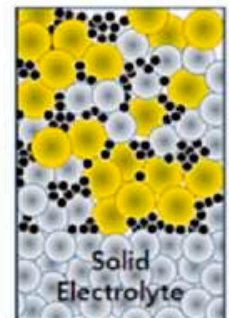

g)

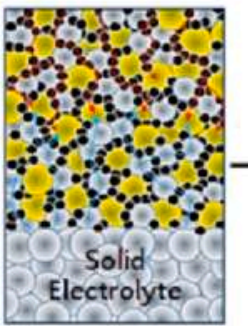

h)

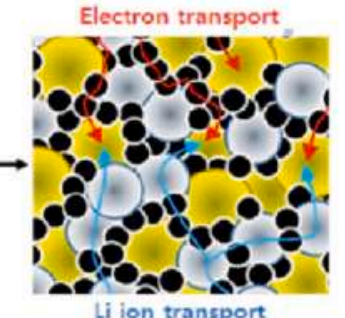

Li ion transport

- Carbon

(caption on next page) 


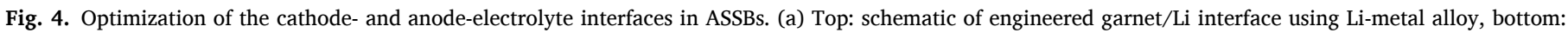

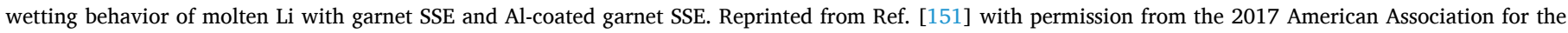

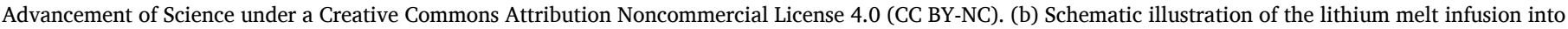

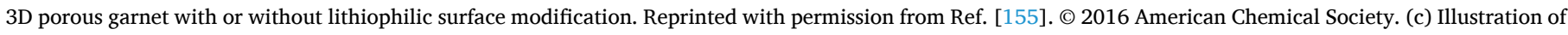

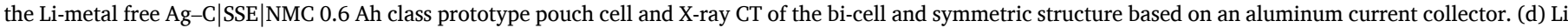

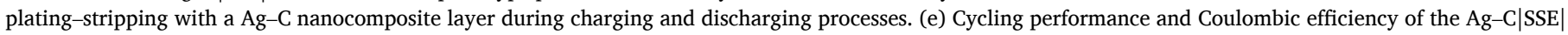

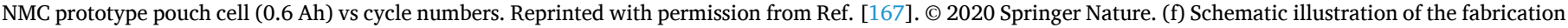

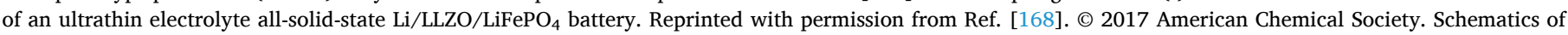

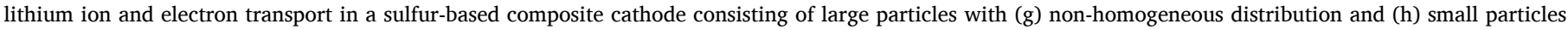
with homogeneous distribution. Reprinted with permission from Ref. [169]. ( 2017 Elsevier.

metal anode on different substrates $(\mathrm{Cu}, \mathrm{Au}$, or pre-existing $\mathrm{Li})$ using LLZO garnet-type [165] or LIPON electrolytes [166]. But the best results so far were obtained by Samsung, who developed a Li metal-free $\mathrm{Ag}-\mathrm{C} / \mathrm{Li}_{6} \mathrm{PS}_{5} \mathrm{Cl} / \mathrm{NMC} \mathrm{ASSB}$, where lithium is grown in-situ on the silver-carbon composite electrode (see Fig. 4c) [167]. The Ag-C layer regulates the Li deposition, leading to longer electrochemical cyclability (see Fig. 4d and e). The Samsung battery, with an impressive energy density $>900 \mathrm{Wh} \mathrm{L}^{-1}$, showed a stable Coulombic efficiency $>99.8 \%$ and long battery lifetime $>1000$ cycles. Despite many challenges still need to be faced for large-scale fabrication [117,118], these results prove that high energy densities and long battery lifetime are achievable by ASSB [167]. Additionally, as nicely outlined in the benchmark study published by Randau et al. [162], optimized cell designs are required to reduce internal cell resistance and improve the power density. Developing electrochemically compatible high conductive solid electrolyte ( $>10 \mathrm{mS} \mathrm{cm}^{-1}$, e.g. sulfide-based) with reduced thickness, accessing the full theoretical capacity of the cathode active material and implementing a new generation of anodes for in-situ lithium growth are the main pathways to follow [162].

Being the core of the solid-state battery, the dense solid electrolyte layer must also be carefully fabricated. It must be intimately in contact with the cathode materials, assure fast ionic conduction (while being an electron insulator), have a good wettability with the lithium anode and protect from dendrites growth and puncturing. At the same time, to achieve specific gravimetric energy $\left(\mathrm{Wh} \mathrm{kg}^{-1}\right.$ ) and volumetric energy density (Wh L ${ }^{-1}$ ) comparable to conventional liquid electrolyte LIBs, the solid electrolyte layer must be thinner than a critical value, called breakeven thickness $[118,170,171]$. The break-even thickness is usually dependent on the ionic conductivity of the electrolyte material and on the cathode material loading. It is indeed higher in sulfide-based electrolyte like LGPS $(\sim 70-250 \mu \mathrm{m})$ than in garnet-type conductors like LLZO $(\sim 25-80 \mu \mathrm{m})$ [170]. For instance, if a $60 \mu \mathrm{m}$-thick cathode with a $15 \mathrm{mg} \mathrm{cm}^{-2}$ loading is used, the break-even thicknesses for LLZO, LATP and LGPS would be $\sim 41 \mu \mathrm{m}, \sim 75 \mu \mathrm{m}$, and $\sim 115 \mu \mathrm{m}$, respectively [171]. Fabricating electrolyte thinner than the break-even thickness by traditional fabrication methods is rather challenging; however, Yan et al. [168] reported the preparation of an ultrathin nanoscale LLZO electrolyte for application in an all-solid-state $\mathrm{Li} / \mathrm{LLZO} / \mathrm{LiFePO}_{4}$ battery (Fig. 4f). They produced a solid electrolyte layer significantly thinner (3-5 $\mu \mathrm{m}$ ) than the break-even thickness for LLZO by conventional slurry ball billing and tape casting onto the composite $\mathrm{LiFePO}_{4} / \mathrm{LLZO}$ cathode, obtaining high performance in term of cyclability (capacity loss during cycles 2-100 was only $0.06 \%$ ). Production of even thinner dense electrolyte layers requires the use of advanced techniques such as PLD [172, 173], ALD [174], sol-gel [175,176], aerosol deposition [177,178]. Unfortunately, the main obstacle of these advanced methods is the high cost for up-scaled production.

Finally, optimization of the cathode-electrolyte interface is also necessary for the achievement of the high energy density targets for allsolid-state batteries. Contrary to conventional liquid electrolyte batteries with porous electrodes, all-solid-state batteries require dense electrolyte and electrode layers. While the energy density of the battery can benefit from this, assuring a good ionic and electronic transport becomes challenging. Fabricating the composite electrode containing cathode active material and solid electrolyte particles is one of the main strategies to provide an ionic and electronic network, while having an intimate contact between cathode and solid electrolyte. The difficulty of preparation of these composite electrodes can vary significantly according to the inorganic electrolyte chemistry. Sulfide-based electrolyte are easier to process because of their softness and deformability [122, 167,179-181], allowing cold-pressing of the composite electrode. The main drawback is the low mechanical strength to lithium dendrite growth [122]. Oxide-based electrolytes possess instead higher mechanical strength; however, they require high temperature sintering to reduce the grain boundary and electrode/electrolyte interface resistances [119,122].

In general, increasing the cathode/electrolyte contact area is crucial to ensure efficient solid-solid contact (Fig. $4 \mathrm{~g}$ and $\mathrm{h}$ ) [169], which is fundamental to achieve full active material utilization at high areal loadings (thick electrodes) [182-184], and reduces the amount of solid electrolyte required in the cathode composite. Obtaining a large contact area is possible thanks to mechanical ball milling of the active material, carbon black, and the inorganic solid electrolyte [118,169]. Infiltrating a solution of the soluble electrolyte, usually sulfide-based, in the porous electrode (with consequent removal of the solvent) is another interesting strategy for improved surface contact [118]. Alternatively, wetting agents can ensure intimate connection between particles when an insoluble compound like an oxide-based electrolyte is used. Materials like $\mathrm{Li}_{3} \mathrm{BO}_{3}$ (LBO) are used as wetting agents that, melting at $700{ }^{\circ} \mathrm{C}$, improve the interfacial contact between garnet-type electrolytes like LLZO [118,185]. Active material coating, as described in 3.1.2, is usually necessary to protect the electrolyte from degradation when in contact with high voltage cathodes (e.g. $\mathrm{LiNbO}_{3}$ at the $\mathrm{LiCoO}_{2} /$ sulfide interface [137]), or to create buffer layers with improved ionic transport (e.g. thin $\mathrm{Nb}$ layers on the garnet-conductors surface [157]). For example, PLD coating of sulfide electrolyte on cathode active material is an interesting technique that allow the preparation of densely packed electrodes with increased energy density [173].

\section{2. - ASSB with polymer electrolytes}

\subsection{1. - Science and technology}

Solid organic polymers dissolving lithium salts represent an alternative to ISE, ensuring adequate safety level and possibly, better scalability [186]. Dry polymer membranes with suitable physicochemical characteristics may be indeed processed into thin separators acting as host for lithium ions, which can move under an electric field [187]. These so-called solid polymer electrolytes (SPEs) allow dissociation of the lithium salt due to favorable coordination of the electrolyte species and $\mathrm{a} \mathrm{Li}^{+}$transport assisted by segmental motion of the organic chains [188]. Accordingly, the cation motion mostly occurs within the amorphous fraction of the polymer matrix above the glass transition temperature $\left(T_{g}\right)$ [188], although a few studies described lithium-ion conductivity in crystalline polymer phases [189,190].

Among the SPEs, those based on poly(ethylene oxide) (PEO) [191] revealed the most promising features in terms of applicability and scalability. Indeed, PEO with solid amorphous state dissolves a large variety of LiX salts, where $\mathrm{X}$ is typically a voluminous anion such as perchlorate $\left(\mathrm{ClO}_{4}^{-}\right)$[192], trifluoromethanesulfonate $\left(\mathrm{CF}_{3} \mathrm{SO}_{3}^{-}\right)$[193], bis(oxalato)borate $\left(\mathrm{BOB}^{-}\right.$) [194], and bis(trifluoromethansulfonyl) 
imide $\left(\mathrm{TFSI}^{-}\right.$) $[195,196]$. These salts form complexes with PEO in which the anion is almost trapped by the polymer backbone, while lithium cation can move through the helicoidal ether chains as well as between them by hopping, thus allowing the ion migration through the membrane under an electric field [196,197]. These solid solutions may exhibit relatively high ionic conductivity (above $10^{-4} \mathrm{~S} \mathrm{~cm}^{-1}$ ) at temperatures higher than the polymer transition point from crystalline to amorphous state $[198,199]$, which can range from 60 to $75{ }^{\circ} \mathrm{C}$ depending on the PEOs' chain length [200,201]. Improved conductivity and mechanical stability can be actually achieved by employing ceramic fillers of various nature [202], e.g., Lewis acid or bases, such as $\mathrm{Al}_{2} \mathrm{O}_{3}$ [197], $\mathrm{ZrO}_{2}$ [203], $\mathrm{TiO}_{2}$ [204], and $\mathrm{SiO}_{2}$ [205], as well as functionalized fillers [206] and nano-sized oxides, to obtain nanocomposite polymer electrolytes (NCPEs, Fig. 5a.) [207]. Fillers can in fact enhance the membrane strength [208], facilitate self-standing configuration, and increase at the same time the amorphous fraction into the polymer, thereby definitively improving the ionic conductivity and the lithium transference number of the electrolyte [186]. Following this trend, inert inorganic fillers may be replaced with either crystalline or glassy lithium-ion conducting nanoparticles or nanowires to decrease the operating temperature, as demonstrated by promising results obtained in laboratory-scale cells [40]. However, solid PEO electrolytes normally achieve an amorphous condition with ionic conductivity suitable for use in a battery only at medium-high temperatures (typically exceeding $65{ }^{\circ} \mathrm{C}$ ) [209], thus limiting the application range. The inclusion of plasticizers such as organic [210] and ionic liquids [211,212] to the polymer electrolytes (Fig. 5b) [213] allows an increase of the room-temperature conductivity, in spite of a decrease in mechanical strength.

It is worth mentioning that gelled membranes with similar characteristics to typical liquid solutions, also named as gel polymer electrolytes (GPEs), are widely employed in commercial Li-ion configurations [218]. GPEs are commonly carbonate-based membranes, in which the liquid phase being responsible for the ion conduction (such as a EC:DMC - $\mathrm{LiPF}_{6}$ solution) is embedded into a polymer matrix, e.g., based on polyvinylidene fluoride (PVDF), PVDF-hexafluoropropylene (PVDF-HFP) or polymethyl methacrylate (PMMA) [219]. Accordingly, these electrolytes suffer from similar safety issues to conventional polypropylene separators trapping liquid carbonate solutions, thereby hindering a possible application in Li-metal batteries [220].

Solvent-free polymers can increase the safety level, and allow scaling up to high-energy, laminated systems by partially exploiting the current roll-to-roll lithium-ion battery manufacturing line [221]. According to the abovementioned approach, polymer electrolyte and cathode slurries are deposited onto a polypropylene support and a current collector foil, respectively, and laminated after drying. The polymer cell is then assembled using ultra-thin lithium foils prepared by extrusion and rolling/calendaring [221]. However, various issues beside the high operating temperature still hinder the large-scale diffusion of such an attracting battery system. These are: i) relatively low cation transference numbers, ii) possible dendrite growth at the lithium anode leading to decay in efficiency and poor cycle life [215,222], and iii) electrochemical instability above $4-4.1 \mathrm{~V}$ along with poor film forming properties, particularly beyond $65{ }^{\circ} \mathrm{C}$ [223], which currently prevent using high-voltage layered $\mathrm{LiCoO}_{2}$ as well as its high-energy analogues (e.g., NMC materials with various compositions ranging from 1:1:1 to $8: 1: 1$ and NCA) [224]. In this regard, layered cathodes may undergo phase change, release oxygen, and delaminate on charge in PEO-based electrolytes. On the other hand, $\mathrm{LiFePO}_{4}$, working at $3.5 \mathrm{~V} \mathrm{vs} \mathrm{Li}^{+} / \mathrm{Li}$, is fully compatible with the lithium-metal polymer configuration, further benefiting from a high thermal stability due to the strong polyanionic framework, which fully enables application at elevated temperatures [225]. In particular, PEO-based solvent-free polymers have shown suitable practical features in $\mathrm{Li} \mid \mathrm{LiFePO}_{4}$ batteries with a maximum specific capacity of $170 \mathrm{mAh} \mathrm{g}^{-1}$ as referred to the cathode mass [226]. Notably, lithium-metal polymer batteries may ensure a gravimetric energy density as high as $300 \mathrm{Wh} \mathrm{kg}^{-1}$, that is, a value approaching that of high-performance lithium-ion systems [227,228], despite the use of low-voltage $\mathrm{LiFePO}_{4}$ and a relatively low volumetric energy density ranging from 500 to $600 \mathrm{Wh} \mathrm{L}^{-1}$ [227]. Indeed, cell thickness and weight may be reduced by moving from the conventional lithium-ion configuration to a dry-polymer, laminated geometry employing thin electrode and electrolyte foils [221]; furthermore, the high-capacity metal anode does not require a heavy $\mathrm{Cu}$ current collector [227]. Therefore, the use of high-energy NCA and NMC 811 electrodes in a lithium-metal polymer cell might lead to gravimetric energy density values within 400 and $450 \mathrm{Wh} \mathrm{kg}^{-1}$, as well as volumetric energy density between 700 and $850 \mathrm{Wh} \mathrm{L}^{-1}$ [227]. Significant enhancement might be also achieved by solid polymer batteries using $\mathrm{LiMn}_{2} \mathrm{O}_{4}$ and $\mathrm{LiNi}_{0.5} \mathrm{Mn}_{1.5} \mathrm{O}_{4}$, that is, within approximate ranges of $300-400 \mathrm{Wh} \mathrm{kg}^{-1}$ and $600-700 \mathrm{Wh} \mathrm{L}^{-1}$ [227]. However, the abovementioned limited anodic stability of the electrolyte represents a serious drawback to be addressed for boosting the cell performance up to that required in long-range electric cars.

The $\mathrm{Li}^{+}$transport within dry SPEs may be enhanced by controlled copolymerization of selected monomers that can ensure anion immobilization along with suitable mechanical and electrochemical properties (Fig. 5c) [214,223]. Moreover, appropriated amorphous polymeric interlayers may improve the lithium-metal plating/stripping process, thus enhancing cyclability and coulombic efficiency of the $\mathrm{Li} \mid \mathrm{LiFePO}_{4}$ cell at $70{ }^{\circ} \mathrm{C}$ (Fig. 5d) [215]. While the high operating temperature matches the typical requirements of the automotive and stationary storage markets, a widespread application in portable electronics is currently less realistic. Notably, high molecular weight end-capped glymes, that is, short-chain polymers and oligomers based on the ethylene oxide group, are characterized by a lower melting point compared to that of conventional PEO [216]. Despite suffering from limited mechanical stability, solid glyme-based solutions can be actually considered as a possible polymer electrolyte enabling a relatively low operating temperature to the lithium cell (Fig. 5e) [216]. Several other chemistries, including poly(methyl methacrylate) (PMMA) [229] as well as cross-linked polymers and copolymers [230], have been proposed for allowing a lithium metal ASSB; however, various issues, such as low conductivity, modest chemical stability, and scarce mechanical strength, hindered their diffusion and practical application. Among the alternatives to PEO, polyethylene carbonate (PEC) [231] is one of the most promising candidates since it is characterized by similar physicochemical features and higher ionic conductivity at lower temperatures. Furthermore, PEC-based electrolytes are more stable than PEO against high voltage layered cathode, as shown in Fig. $5 f$ [217]. However, issues in terms of mechanical and chemical stability, as well as relevant dendrite growth at the lithium side, still prevent a practical application of these electrolytes [232]. It is worth mentioning that a possible approach to mitigate the low chemical and/or electrochemical stability of SPEs, as well as uneven lithium plating, mainly observed in solid poly-glymes, PEC, PAN and PMMA, is represented by the addition of a sacrificial film-forming agent, such as $\mathrm{LiNO}_{3}$, for protecting the metal surface from side processes [216]. In contrast, increasing the battery voltage above $4 \mathrm{~V}$ [223] appears much more challenging, since it may involve a considerable change of the chemical nature of the SPE both to allow a wide electrochemical stability window and to ensure a stable cathode/electrolyte interphase.

\subsection{2. - The lithium metal polymer battery: a practical reality}

In spite of a great deal of efforts from both academia and industries for achieving commercially viable LMBs, a few practical demonstrations have been reported to date [228]. Indeed, scaling up from laboratory-prototype coin and pouch cells to more realistic configurations, as well as module and battery packs, often faces substantial barriers [233]. Suitable mathematical models may assist an evaluation of the actual applicability of innovative cell chemistries so far investigated in proof-of-concept and fundamental studies, although various 


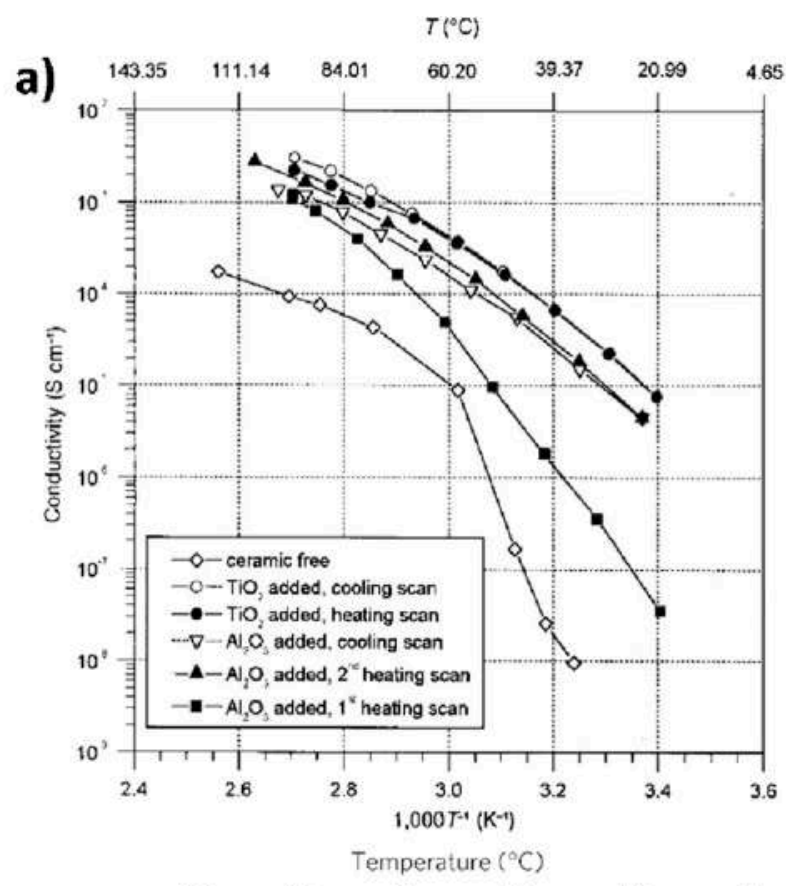

b)
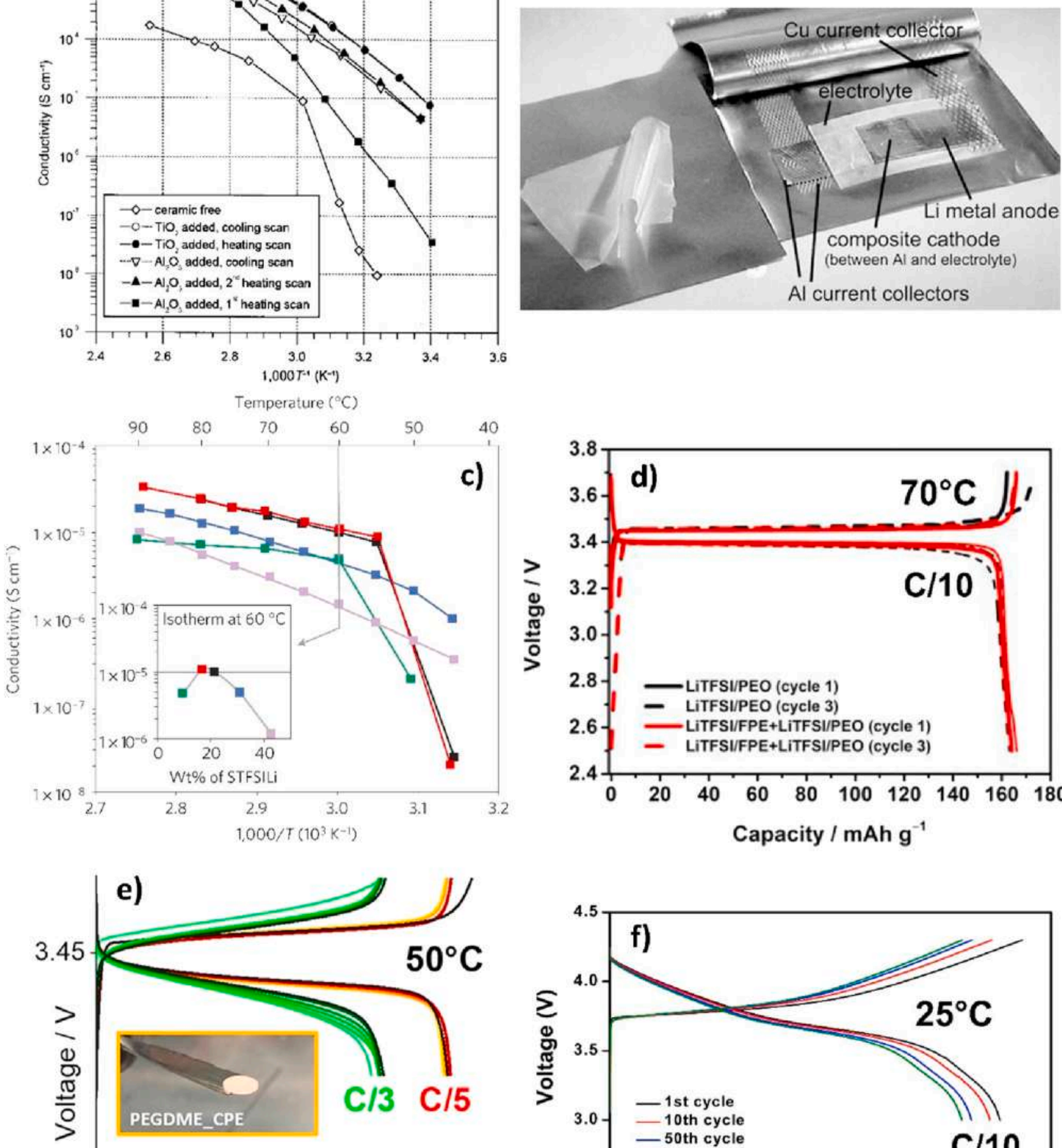

Li / PEGDME_CPE / $\mathrm{LiFePO}_{4}$

Capacity / mAh g ${ }^{-1} 125150$
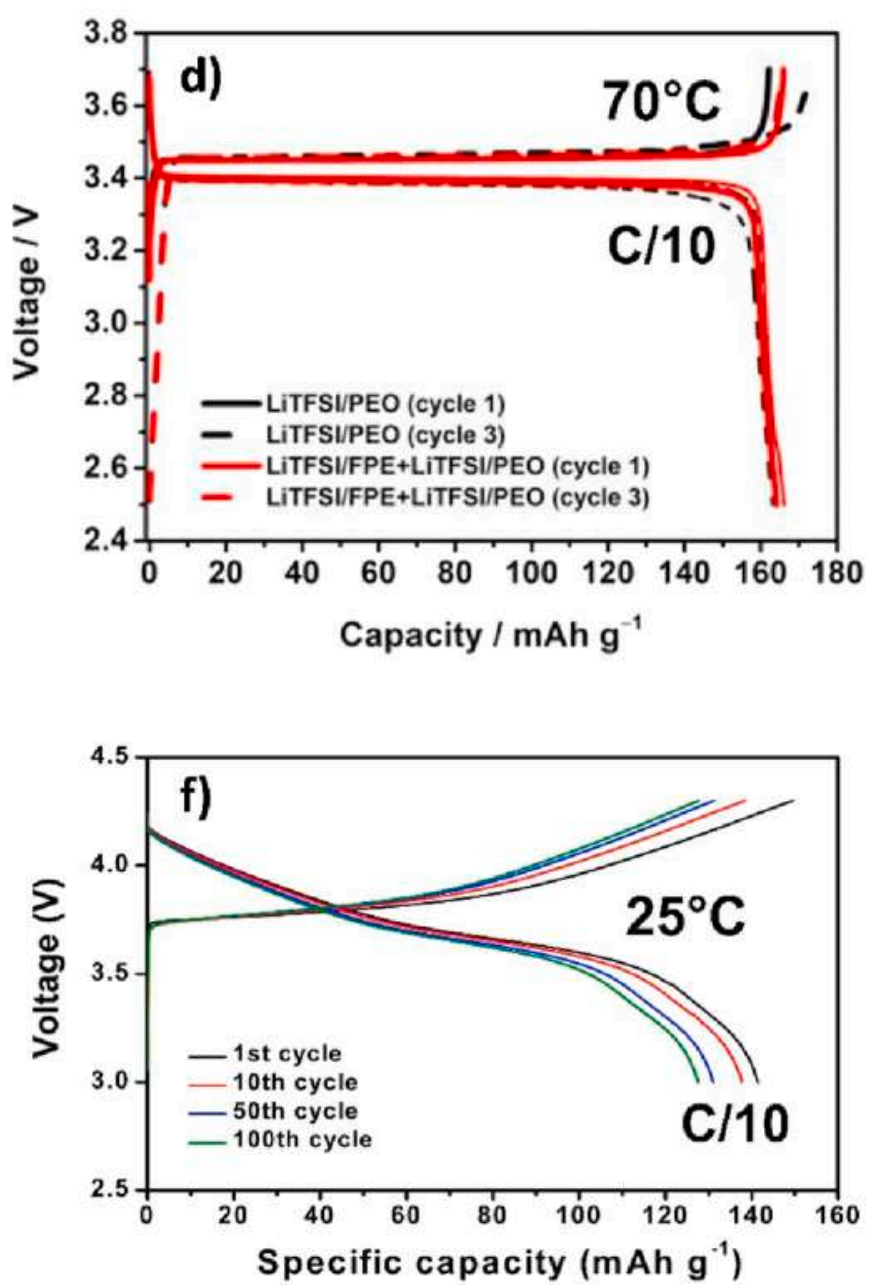

(caption on next page) 


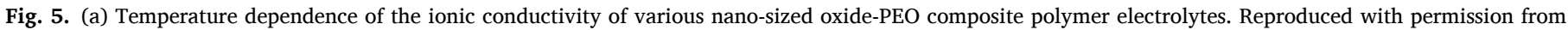

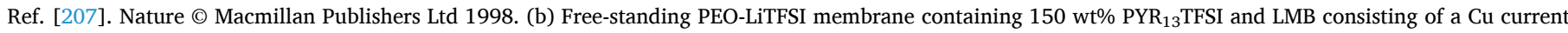

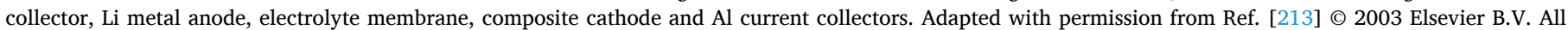

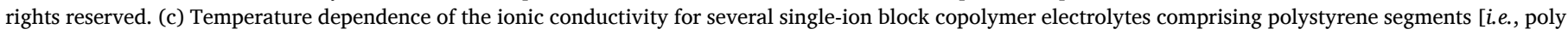

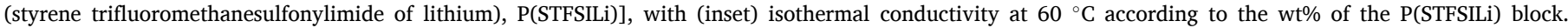

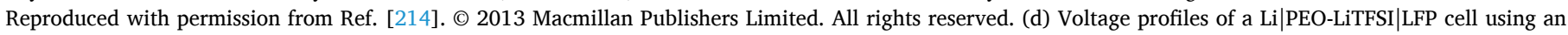

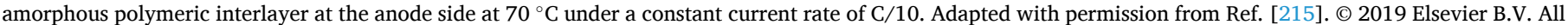

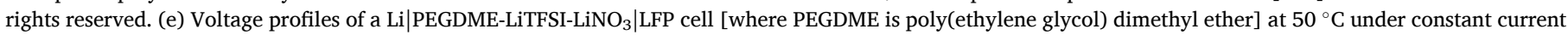

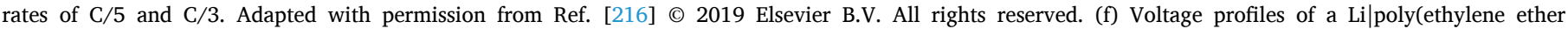

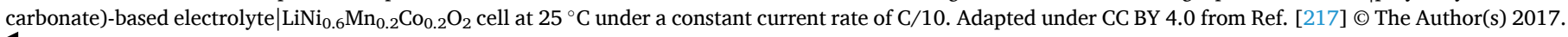

assumptions based on the current lithium-ion battery market may affect their long-term reliability [227]. Moreover, pre-commercial cells and emerging technologies lately on the market represent useful examples to identify the main obstacles that have to be overcome in the short-to-medium term for matching the economic and environmental targets of the European SET Plan. In 2015 Sion Power Corp. (US) announced a transition of their activity from Li-S batteries to a rechargeable lithium-metal oxide technology [234]. Interestingly, their Licerion ${ }^{\circledR}$ cell employs an ionically conductive ceramic/polymer barrier for protecting the lithium electrode and enabling reversible metal plating within a wide current range due to low interphase resistance, as well as a high-voltage metal-oxide intercalation cathode [234]. Sion Power Corp. demonstrated an energy density exceeding $500 \mathrm{Wh} \mathrm{kg}^{-1}$ and $1000 \mathrm{Wh} \mathrm{L}^{-1}$ in $0.4 \mathrm{Ah}$ cells in 2018 [234], as well as 800 full depth-of-discharge cycles to $70 \%$ of the nominal capacity for $1.8 \mathrm{Ah}$ cells in 2020, estimating an energy density for EV applications of $420 \mathrm{Wh}$ $\mathrm{kg}^{-1}$ and $700 \mathrm{Wh} \mathrm{L}^{-1}$ when scaled to commercial designs [235].

ASSBs based on the above discussed $\mathrm{Li}|\mathrm{PEO}| \mathrm{LiFePO}_{4}$ technology have been successfully launched onto the market as Lithium Metal Polymer (LMP $®$ ) batteries by the Bolloré Group (France) over the past decade [221]. This battery is an evolution of a prototype developed in the 1990s by Hydro-Québec (Canada) and 3 M (US) [221], which involved a Li metal anode, a PEO membrane dissolving $\mathrm{LiClO}_{4} / \mathrm{LiTFSI}$, and a $\mathrm{VO}_{\mathrm{x}}$ cathode (see Fig. 6a) [236], thus ensuring an energy density of the order of $100 \mathrm{Wh} \mathrm{kg}^{-1}$ with a life of 600 cycles at $80 \%$ depth of discharge [221]. A Bolloré's subsidiary, Blue Solutions, commercialized a Li|PEO|LiFePO 4 battery with an energy density of $180 \mathrm{Wh} \mathrm{kg}^{-1}$ which delivers over 1300 cycles within 60 and $80{ }^{\circ} \mathrm{C}$, formed by ultrathin cathode, polymer electrolyte, and anode films. Cells are connected in series in a module; several modules are then connected in series in a full battery pack as shown in Fig. 6b [221]. This technology is suitable for the automotive market, as demonstrated by the successful launch in 2011 of a car sharing program called Bluecar [221], employing small EVs (Fig. 6c) [237] with a maximum speed of $120 \mathrm{~km} \mathrm{~h}^{-1}$ and drive range from 150 to $250 \mathrm{~km}$ [238]. Recently, the Bolloré Group commercialized through its Brittany division a bus in two formats ( 6 and $12 \mathrm{~m}$ long, see Fig. 6d) [237], named Bluebus, using an LMP battery [239]. The automotive applications of the LMP battery suggest the ASSBs with polymeric electrolytes for diverse applications that do not require low-temperature. Although, the targets established in the European SET Plan could be hardily achieved with the current $\mathrm{Li} \mid \mathrm{LiFePO}_{4}$ chemistry ( $>400 \mathrm{Wh} \mathrm{kg}^{-1}$ and $>750 \mathrm{Wh} \mathrm{L}^{-1}$ at the cell level as well as $>250 \mathrm{Wh} \mathrm{kg}^{-1}$ and $>500 \mathrm{Wh} \mathrm{L}^{-1}$ at the pack level by 2030). For instance, the LMP 63 pack proposed by the Bolloré Group is formed by 9 ASSB modules and has an operating voltage range from 450 to $648 \mathrm{~V}$, an energy of $63 \mathrm{kWh}$, and an overall weight of $450 \mathrm{~kg}$ (42 kg per module) [240]. The same company developed through its Bluestorage division battery packs for stationary energy storage, i.e., the Blue LMP 250 and Blue LMP 400, which can store 252 and $392 \mathrm{kWh}$ with overall weight of about 2250 and $3270 \mathrm{~kg}$, respectively, (corresponding to $740 \mathrm{~kg}$ and $920 \mathrm{~kg}$ per rack and $42 \mathrm{~kg}$ per module) [241]. Therefore, the relevant safety and high-thermal stability of lithium-metal polymer configurations appear particularly adequate for developing load-balancing battery packs integrated in smart grids as well as power storage systems coupled with intermittent renewable energy sources and off-grid generators. The replacement of $\mathrm{LiFePO}_{4}$ with high-voltage insertio$\mathrm{n}$ /intercalation compounds, to date only demonstrated in proof-of-concept studies (see Fig. 5f), might further extend the applicability of ASSBs using polymeric electrolytes, possibly matching the present requirements for long range electric cars in terms of both energy a)

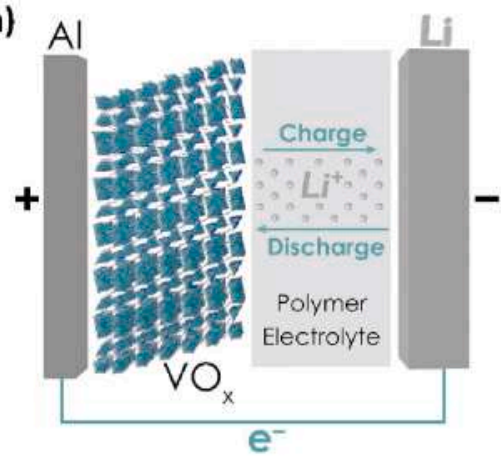

c)

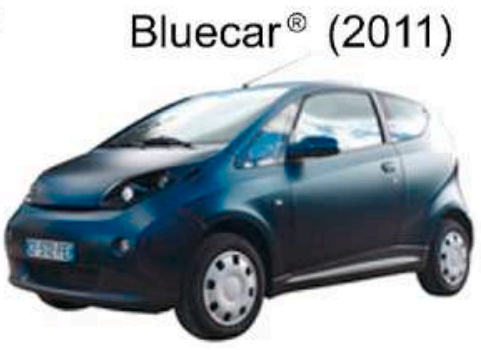

b)
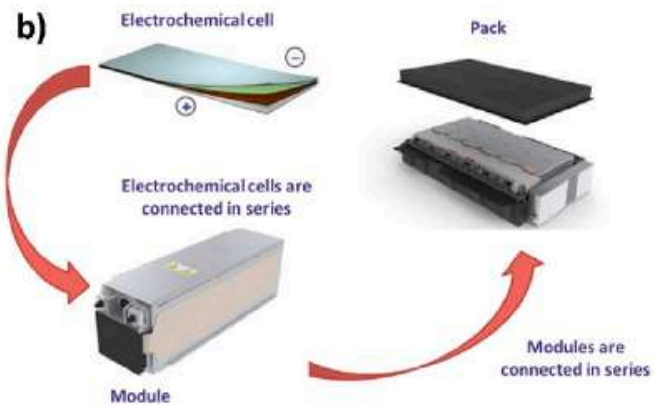

d)

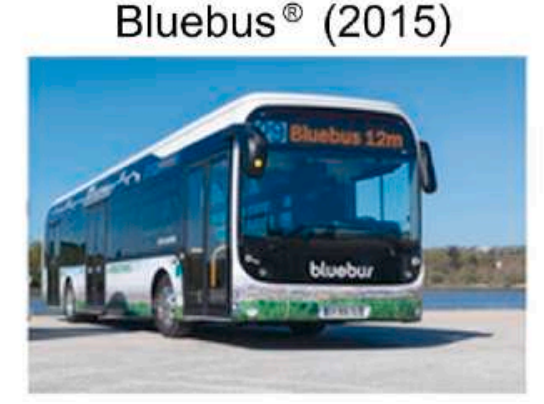

Fig. 6. (a) Schematic of the lithium-metal battery prototype developed in the 1990s, comprising a $\mathrm{Li}$ anode, a PEO-LiClO 4 /LiTFSI electrolyte, and a $\mathrm{VO}_{x}$ cathode [236]. (b) Schematic of assembly of an LMP ${ }^{\circledR}$ battery pack (developed and commercialized by the Bolloré Group) from the cell level. Reproduced with permission from Refs. [221]. () Springer Nature Switzerland AG 2019. (c) Bluecar and (d) Bluebus (using the LMP $®$ technology) commercialized by the Bolloré Group. Reproduced with permission from Ref. [237]. (C) 2020 Wiley-VCH Verlag GmbH \&Co. KGaA, Weinheim. 
density and cost, as well as the European SET Plan targets. In this regard, a remarkable breakthrough in the upcoming years might be achieved by developing lithium-sulfur cells using high-viscosity glyme oligomers or solid low-molecular-weight glyme polymers. However, as discussed in the following section, the current Li-S technology suffers from various shortcomings needing substantial efforts to obtain commercially relevant results.

\section{Generation 5: LMBs based on conversion cathodes}

\section{1. - Li-S batteries}

Li-S batteries can achieve high specific energies $\left(>450 \mathrm{Wh} \mathrm{kg}^{-1}\right.$ [242]), are based on low cost raw materials and thus, are a highly attractive generation 5 cell technology [243]. Li-S-cells use lithium metal anodes, liquid electrolytes and conversion cathodes based on elemental sulfur mixed with carbon. The overall reaction is $\mathrm{S}_{8}+16 \mathrm{e}^{-}+$ $16 \mathrm{Li}^{+} \leftrightarrows 8 \mathrm{Li}_{2} \mathrm{~S}$ with an equilibrium potential of $2.1 \mathrm{~V}$ vs. $\mathrm{Li} / \mathrm{Li}^{+}$. Typically cells are assembled in the charged state, and during discharge, lithium is stripped while sulfur is converted to lithium sulfide involving several electrochemical steps and various intermediate sulfur species (polysulfides). During charging, the $\mathrm{Li}_{2} \mathrm{~S}$ in the cathode is converted back to elemental sulfur and lithium is plated on the anode. Hence, the anode chemistry in Li-S batteries is per se very comparable to other LMBs. However, the sulfur conversion chemistry causes several specific characteristics, which need to be considered for lithium anode design. Electrolytes are typically based on LiTFSI in ether based solvents (DME, DOL), while carbonate solvents are mostly avoided due to decomposition via nucleophilic attack by polysulfides in case they are not confined in the cathode pores. Furthermore, polysulfides are soluble in the electrolyte and can diffuse and participate in side reactions on the anode surface. This involves continuous passivation of the lithium surface and the reduction of dissolved long-chain polysulfides to short-chain species causing self-discharge and low charge efficiency of the cells, also known as "polysulfide shuttle" [244-247]. Lithium nitrate was found to be an effective additive in participating in anode surface passivation, thereby reducing the polysulfide shuttle current and enabling high coulombic efficiencies [248]. Thus, the combination of DME/DOL, LiTFSI, and $\mathrm{LiNO}_{3}$ is a well-established electrolyte system for exploring Li-S batteries. Under lean electrolyte conditions ( $<3 \mu \mathrm{l} / \mathrm{mg}$ sulfur), Li-S cells suffer from a rapid capacity fade, and prototype cells typically do not achieve more than 100 charge/discharge cycles. The low cycle life is still the major shortcoming hampering the technology breakthrough.

Consumption of electrolyte components in general and polysulfides in particular through reduction at the anode surface and the structural anode degradation are known to be the major failure mechanisms [249]. For these reasons, innovations in anode protection or structural design are of high relevance for improving Li-S cell performance. This section provides a review on the most promising lithium anode concepts from a holistic point of view and assesses critical parameters to be considered for application-relevant cells.

Several review articles on metallic lithium anodes for Li-S cells have been published [250-257] describing the major obstacles and first approaches how to tackle the complex issue of a highly reactive anode and sulfidic intermediate species intrinsically derived from to the conversion mechanism. It is vital, however, to evaluate the proposed strategies in regard of a multi-layered cell as a system comprising both active and inactive components [258-261]. In addition, comparability of results is frequently hampered as the electrochemical evaluation is often performed in coin cells with varying electrolyte amounts (frequently with electrolyte excess), separator types \& thicknesses, and cathode porosities [260].

\subsection{1. - Concepts for lithium metal anodes in Li-S batteries}

4.1.1.1. - Electrolyte adaption and in-situ SEI. In contrast to state-of-theart LIBs, the electrolyte weight fraction of recently developed Li-S batteries is as high as $\sim 50 \mathrm{wt} \%$ [260]. Additionally, the ether electrolyte dissolves a high fraction of very reactive polysulfides that indirectly stress the anode. It is known that $\mathrm{LiNO}_{3}$ in combination with the lithium polysulfide play an important role to passivate the lithium anode [262-266]. This effect also depends on the sulfur loading in the cathode [267]: below a certain threshold concentration of sulfur species, polysulfide do have a beneficial effect, similar as already mentioned in chapter 2.2 describing $\mathrm{Li}_{2} \mathrm{~S}$ to form a stabilizing interface. Above a certain sulfur loading, the overall current density both on anode and cathode is increased, so the probability of local concentration depletion rises where the electric field is increased and cannot be fully compensated by the anions and cations of the electrolyte [268]. Thus, dendrite formation or mossy lithium growth is accelerated [260]. Electrolyte additives such as lanthanum nitrate have a certain beneficial effect on the lithium stability as well given that it decreases the reducibility of metallic lithium and slows down the electrochemical dissolution/deposition reaction [257]. Hence, adapting the electrolyte is a key parameter to indirectly reduce anode corrosion by employing new solvents and new additives beyond lithium nitrate (Fig. 7a). So-called "sparingly (polysulfide) solvating electrolytes" are discussed as a sensible and effective approach in order to reduce the corrosive species on the anode side [269-274]. Significant improvement of the cycle stability due to fluorinated ether [275], has been successfully demonstrated even in multi-layered pouch cells [276]. However, fluorinated solvents usually have a high mass density being detrimental for the overall specific energy. Nevertheless, electrolytes with high mass density can potentially tackle the issue of a low volumetric energy density of Li-S cells. Moreover, in order to implement a more stable carbonate-based electrolyte and to utilize the sulfur almost at the theoretical maximum, confining of sulfur into polymers like polyacrylnitrile (PAN) [277,278] or microporous carbons [279] is possible (Fig. 7a), but mostly reaches only low sulfur weight fractions resulting in an overall low energy density of prototype cells. A prototype cell using carbonates reaching $280 \mathrm{Wh} \mathrm{kg}^{-1}$ was reported [280]. On the one hand, ether-based electrolyte comprising $\mathrm{LiNO}_{3}$ is known for gas evolution during cycling [244,281]. However, this system also leads to passivation of the lithium metal anode being safer in nail penetration and bullet tests when compared to conventional LIBs [282-284]. A $\mathrm{LiNO}_{3}$-free electrolyte in lean electrolyte regime and limited polysulfide solubility based on DOL was implemented in a multi-layered pouch cell reaching $300 \mathrm{Wh} \mathrm{kg}^{-1}$ [285]. The combination of symmetric and "non-symmetric" ethers with varying alkyl chain lengths may also be useful to adjust the polysulfide solubility [286]. A special case of sparingly polysulfide electrolytes are solid state concepts, the most promising ones are sulfide-based inorganic glasses $\left(\mathrm{P}_{2} \mathrm{~S}_{5}-\mathrm{Li}_{2} \mathrm{~S}\right)$ leading to almost theoretical sulfur utilization [287] and reasonable power capability [288] (Fig. 7a.).

Alternatives for LiTFSI, such as lithium trifluoromethyl-4,5dicyanoimidazole were found to restrict the solubility of polysulfides as well [289], and lithium bis(perfluoroethylsulfonyl)imide LiBETI [290] is known to form more stable thin and compact SEI films containing mainly LiF on lithium [291]. The beneficial effect of lithium halides, especially LiF, was already discussed in chapter 2.1. In addition, in PEO-based electrolytes, a beneficial effect of (difluoromethanesulfonyl) (trifluoromethanesulfonyl)imide anion [N $\left.\left(\mathrm{SO}_{2} \mathrm{CF}_{2} \mathrm{H}\right)\left(\mathrm{SO}_{2} \mathrm{CF}_{3}\right)\right]^{-}$DFTFSI $^{-}$on the anode stability was reported [292]. Moreover, the unsymmetrical (fluorosulfonyl) (trifluoromethanesulfonyl)imide anion [293] was presented as a promising alternative imide-containing salt. It combines the good thermal and chemical stability of TSI $^{-}$and the high-quality SEI building properties of the $\mathrm{FSI}^{-}$anion. In addition, Lithium 1,1,2,2,3,3-hexafluoropropane-1, 3-disulfonimide (LiHFDF) forms highly fluorinated interphases at both 


\section{a) In-situ SEI}

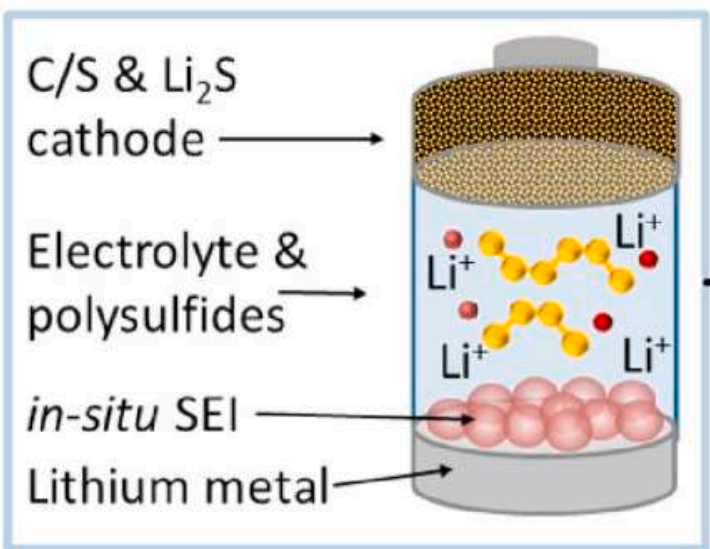

\section{b) Ex-situ Artificial SEI}

Additives for invivo $\mathrm{SEI}$ formation
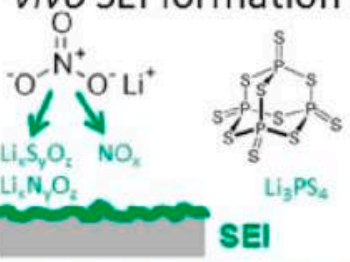

Carbonates (confined $\left.\mathrm{S}_{8} \& \mathrm{~S}-\mathrm{PAN}\right)$

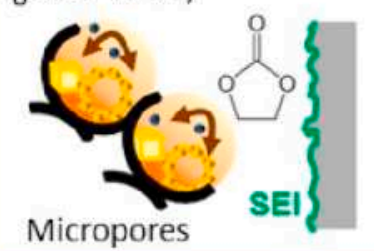

Sparingly PS solvating

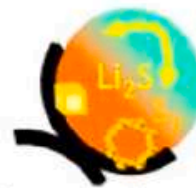

Meso- and

Macropores

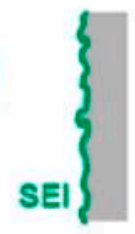

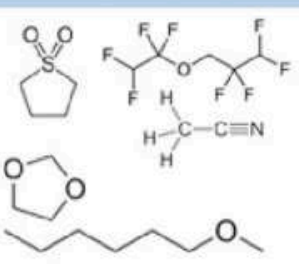

$\mathrm{Li}_{2} \mathrm{~S} \cdot \mathrm{P}_{2} \mathrm{~S}_{5}$ solid electrolyte

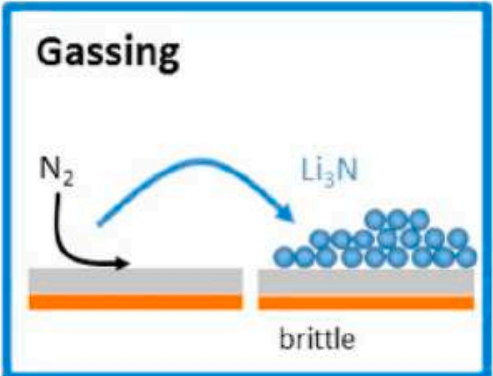

\section{Sputtering of inorganic layers}

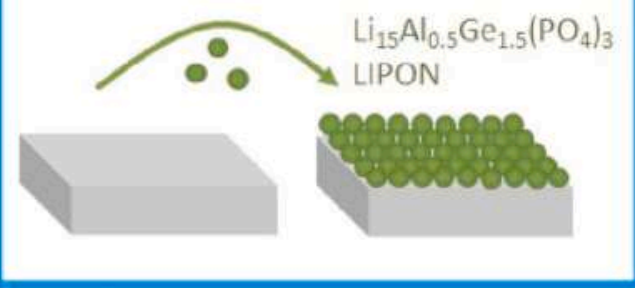

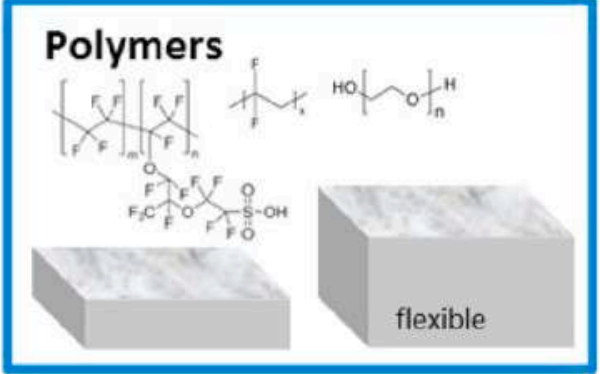

\section{c) Host engineering}

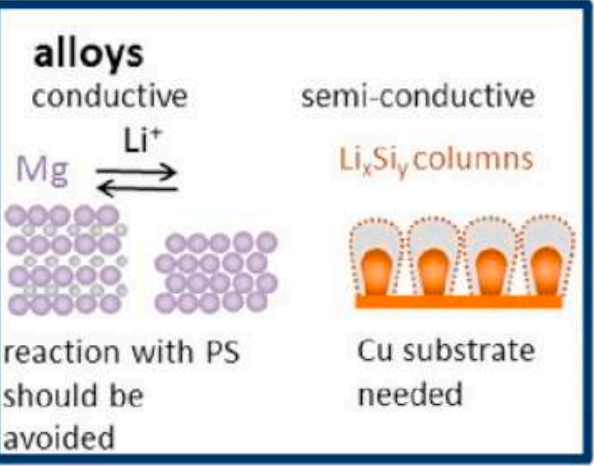

\section{Frameworks / scaffolds}

conductive non-conductive
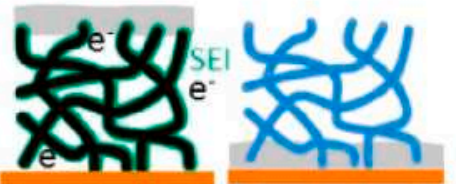

Dead volume \& filling with electrolyte needs to be considered for gravimetric energy
Spacer concepts

particles/ fillers

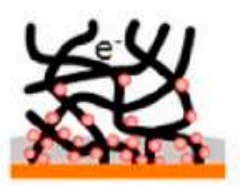

Particle mass density \& reaction with PS needs consideration

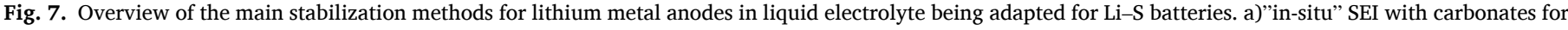

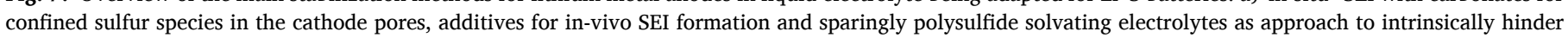

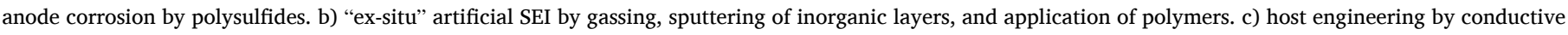
and non-conductive frameworks, spacer concepts, and alloys.

anode and cathode surfaces, which effectively suppress formation of Li-dendrites and dissolution/shuttling of polysulfides [294]. As fluorine-free noble salt anion, tricyanomethanide $\left[\mathrm{C}(\mathrm{CN})_{3}\right]^{-} \mathrm{TCM}^{-}$has shown promising results as it leads to a $\mathrm{Li}_{3} \mathrm{~N}$ rich SEI [295]. Lithium azide $\mathrm{LiN}_{3}$ results in the formation of a thin, compact and highly conductive passivation layer on the Li degrees anode, thereby avoiding dendrite formation, and polysulfide shuttling [296]. Summarizing, for the holistic development of enhanced Li-S cells the electrolyte plays a highly complex role. Besides interacting with the anode interface, possible limitations for maximum content and utilization of sulfur need to be considered. The power capability may be limited by the electrolyte conductivity depending on temperature and might vary over state of charge. Furthermore, the content and the specific mass density of electrolytes may have a drastic impact on the specific energy of Li-S cells.

4.1.1.2. Coatings and ex-situ artificial SEI concepts. Inorganic ceramic coatings on lithium anodes - Intuitively, one approach is to generate a dense electrically insulating but ion-conductive protection layer on metallic lithium. $\mathrm{Li}_{3} \mathrm{~N}$ is a potential candidate (compare chapter 2.2, Fig. 7b) and can be applied via reaction with dry nitrogen at room 
temperature [297]. However, $\mathrm{Li}_{3} \mathrm{~N}$ is quite sensitive towards humidity and needs to be carefully handled. In addition, it is also a quite brittle solid leading to cracks during stripping and plating of lithium. Likewise, $\mathrm{P}_{4} \mathrm{~S}_{10}$ was reported to cause a positive effect on the lithium anode in $\mathrm{Li}-\mathrm{S}$ cells [298]. However, the employed electrolyte excess used in this study should be critically considered as well. The in-vivo generation of $\mathrm{Li}_{3} \mathrm{PS}_{4}$ by using polysulfides and $\mathrm{P}_{2} \mathrm{~S}_{5}$ had a beneficial effect on the cycling stability in symmetric cells [299] (Fig. 7a). A further candidate is $\mathrm{Li}_{1.5} \mathrm{Al}_{0.5} \mathrm{Ge}_{1.5}\left(\mathrm{PO}_{4}\right)_{3}$ being already implemented in a single-layered pouch cell [300]. LIPON (lithium phophorus oxynitrides) as system was implemented in a multi-layered pouch cell reaching promising 300 Wh kg ${ }^{-1}$ [301]. In addition, mixed ion- and electron-conductive layers are discussed for Li-S cells, although the electrolyte amount was not stated and this approach might not be generally applicable to compensate the volume change during plating and stripping [302].

Polymeric or polymer-like coatings with and without fillers - In order to cope with the volume changes during lithium plating/stripping, the application of a polymeric protecting film is obvious. Nafion-coated separators are known to prevent polysulfide diffusion to the anode at least partially [303], and dual-functional polymer coating consisting of Nafion/polyvinylidene difluoride (PVDF) minimized leakage currents leading to decreasing diffusion of soluble polysulfides and thereby suppressed self-discharge [304]. Other successful separator coatings are for one a Ketjen Black-MnO composite [305], a thin coating of highly porous, conductive nitrogen-rich carbon material [306] as well as vapor deposition (CVD)-grown graphene interlayer on top of a conventional polypropylene separator [307], both promising for preventing the shuttling of polysulfide and enhancing the utilization of sulfur. Also for these approaches, a holistic point of view on cell level is crucial. Thick, porous, and heavy coatings are detrimental for the overall energy density as they potentially cause dead volume that must be filled with inactive electrolyte mass/volume. In addition, the increased sulfur utilization could be mostly attributed to the distribution of the sulfur mass content to a higher surface area, especially when highly porous coatings are employed.

In order to transfer these films into $\mathrm{a} \mathrm{Li}^{+}$-ion-conductive film, usually, lithium conductive salts are implemented. LiTFSI and PEO is a very established combination [308], however, those films per se can only operate at elevated temperatures [308]. Then, the PEO chains show similar discharge slopes like an ether based solvent which is a strong hint that they dissolve lithium polysulfides very well. The beneficial role of ceramic fillers, both ion-conductive and non-conductive [309-312], has not been fully understood yet. It should be pointed out that fillers with high mass density increase the ionic conductivity, but might lower the overall energy density of the final prototype cell [313]. In combination with liquid electrolyte [314], polymers can also swell and might not provide decent protection then [315]. A further approach is to use lithium surfaces being treated with polysiloxane [316], with a crown ether [317], or with a organosulfide-plasticized solid electrolyte interphase [318] leading to improved cycle stability at least compared to the respective reference materials.

Lithium alloys with other elements - In addition to recurrent electrolyte depletion and SEI formation, the volume change during plating and stripping causes breathing of the cells and generate dead lithium. Metallic lithium can electrochemically alloy with the other elements in organic electrolyte at ambient temperature [319], and various alloys of lithium have been extensively investigated as anode materials in many years [320]. In order to balance the high electrochemical capacity of $\mathrm{Li}_{2} \mathrm{~S}$, lithiated silicon was discussed as one promising material [321]. The $\mathrm{Li}_{\mathrm{x}} \mathrm{Si}_{\mathrm{y}}$ alloy is stable versus polysulfides as the balanced cell with only a small lithium excess could be run for 50 cycles being a hint for only few side-reactions. However, pre-lithiation is a laborious process, and an all-over $\mathrm{Cu}$ foil current collector needs to be employed limiting the specific energy on Li-S battery pouch cell level. Therefore, employing alloys of lithium with metals, such as magnesium [322], can have a beneficial effect on the lithium stripping and plating as a generic concept for lithium metal-based batteries (Fig. 7c). However, it should be noted that alloys increase the anode potential and lower the overall voltage window, so coating only the lithium metal anode's surface with the alloy impacts less the overall energy density than using a completely alloyed anode. In addition, the electrolyte excess being employed during these studies might mask effects as well. Especially for the Li-S battery system, the alloyed anode (coating) needs to be compatible with the sulfur-species being dissolved in the electrolyte, as investigated e.g. by Kong et al. [322]. The alloying element should not leak into solution and the resulting passivation layer should provide certain lithium ion conductivity.

Scaffold, spacer, and filler concepts - As already mentioned in chapter 2, plain metallic lithium has the intrinsic above-mentioned properties, such as continuous electrolyte depletion and SEI formation due to the highly reactive surface and volume changes during cycling. It is known from the Sand equation (vide supra) that the time for lithium dendrite formation is inverse proportional to the current density. Hence, a homogeneous distribution of the current is crucial to balance space-charge and to avoid local electric field build-up. Consequently, functional frameworks have been discussed as stabilizing scaffolds to facilitate lithium plating. These scaffolds can be divided into two main different types: (i) electrically non-conductive frameworks and (ii) electrically conductive frameworks (Fig. 7c). Non-conductive frameworks have the beneficial effect that no SEI is formed due to the framework material itself and that the lithium can be plated on the bottom. For example, a fibrous $\mathrm{Li}_{7} \mathrm{~B}_{6}$ matrix was presented in order to entrap lithium [323]. However, no decrease of the areal current density takes place and the lithium can push away those frameworks like a separator. Consequently, electronically conductive frameworks have some benefits despite the SEI formation. Conductive frameworks potentially enable a decrease of the areal current, and they are also potentially able to activate dead lithium [249]. However, plating solely on top of the framework is very likely and should be inhibited. In order to keep the mass fraction of inactive materials as low as possible, carbonaceous materials are ideal candidates in particular carbon fibers [324-329], graphene [327], graphene oxide [328] or hard carbon/stabilized lithium particle composites [330,331]. Hybrid lithiophilic and lithiophobic gradients have been already presented in single-layered pouch cells [332]. Very often, the deposition of lithiophilic sides, such as zinc oxides or silver are needed though. In contrast to sulfur-free battery systems, these frameworks should be compatible with the sulfur species in the electrolyte when implemented in Li-S cells. Moreover, the framework porosity should not take up additional excess of electrolyte resulting in a lower overall energy density on cell level.

$\mathrm{Li}_{2} \mathrm{~S}$-based "anode free" concept - Lithium anode foils are commercially only available in thickness exceeding $50 \mu \mathrm{m}$. In addition, the handling and processing of the foil causes issues due to high ductility of this metal. For lithiated nickel-manganese-cobalt-oxides, it is known that lithium can be plated from this cathode material onto a lithiophilic anode current collector (vide supra). A similar approach was published using $\mathrm{Li}_{2} \mathrm{~S}$ as lithium source [333]. Especially the volumetric energy density could be increased by plating only the required amount of lithium, however, the handling and/or encapsulation of $\mathrm{Li}_{2} \mathrm{~S}$ is challenging and the lithium ion loss during first charging for the SEI formation on anode side needs to be compensated. $\mathrm{Li}_{2} \mathrm{~S}$ can be also formed via depletion of the electrolyte which might lead to dry out of the cell.

\subsubsection{Critical parameters for Li anode design in Li-S-Batteries}

As explained above, the lithium anode design has a crucial impact on Li-S cell performance and often determines cycle life, power capability and energy efficiency. On the other hand, lithium excess as well as protective coatings, frameworks, new electrolytes etc. may impact the energy density of the cells. Therefore, the anode needs to be tailored considering the application-specific requirements.

Limiting factors for specific energy are inactive materials that have a high mass fraction in Li-S-cells, e.g. any copper/nickel current collector, 
especially when employed all over. In addition, electrolytes with high salt concentrations, high density solvents or rather fillers, and high overall electrolyte content drastically decrease the specific energy.

Limiting factors for volumetric energy density are inactive materials having a high volume fraction. For example, thin current collectors $(\mathrm{Ni}$, $\mathrm{Cu})$, even when used all-over the area, can enhance the volumetric energy density, as they allow a minimization of Li excess. The reaction between heavy metals such as copper with the polysulfide should be considered though. In addition, $\mathrm{Li}$ and electrolyte excess limit the volumetric energy density of today's Li-S-cells. First reports on "Li-free" anodes demonstrate the feasibility and potential of that concept, especially for established (lithiated) nickel-manganese-cobalt-oxide cathodes. The applicability of using $\mathrm{Li}_{2} \mathrm{~S}$ as single lithium source still needs to be further evaluated. a)

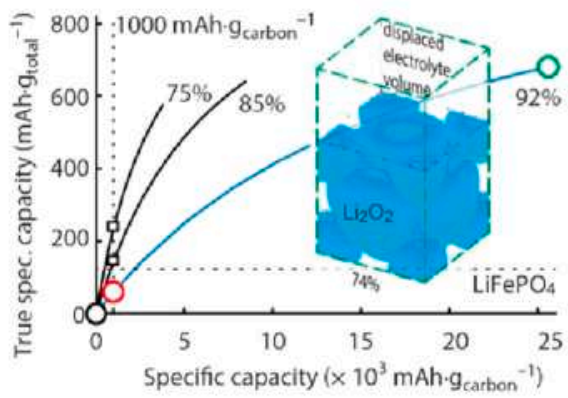

b)

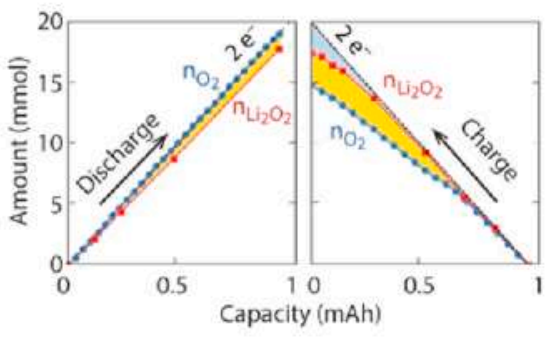

c)

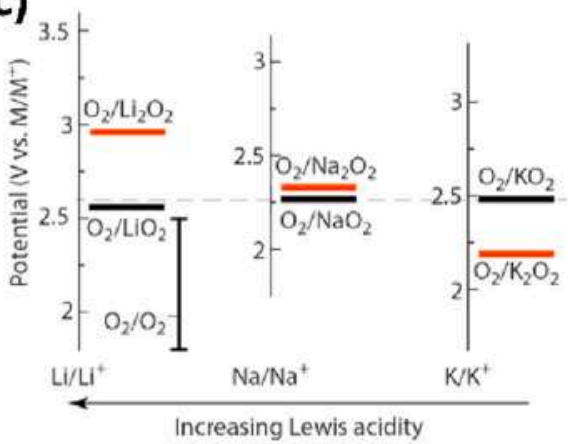

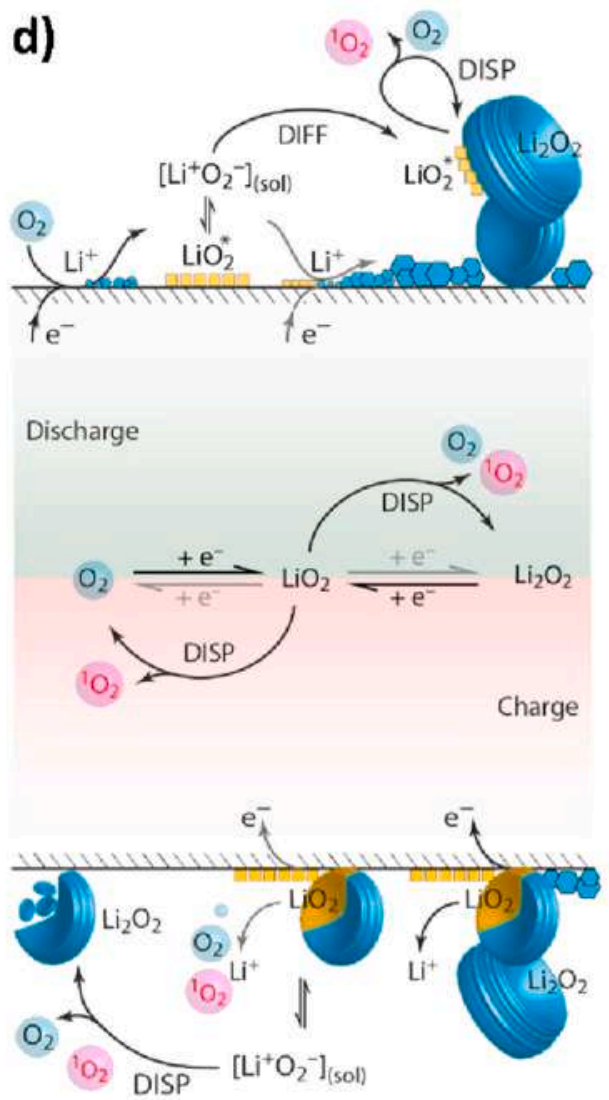

e)
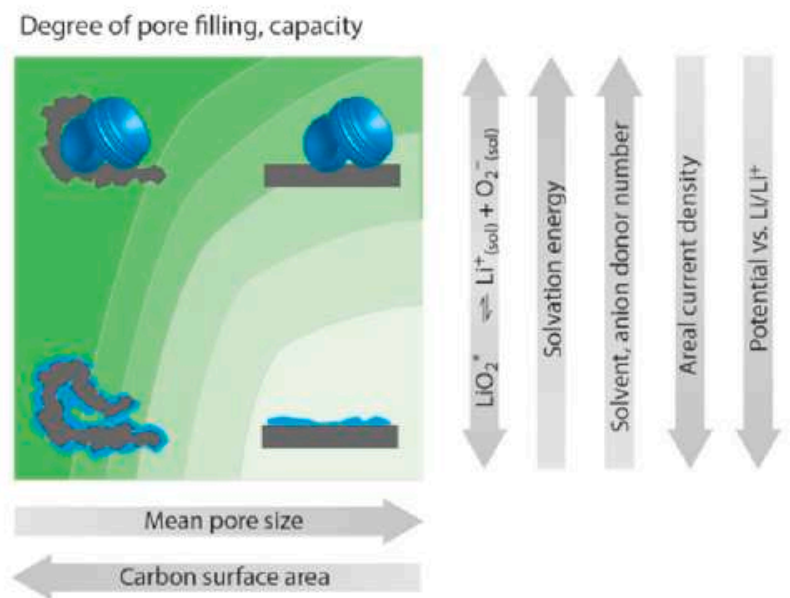

f)

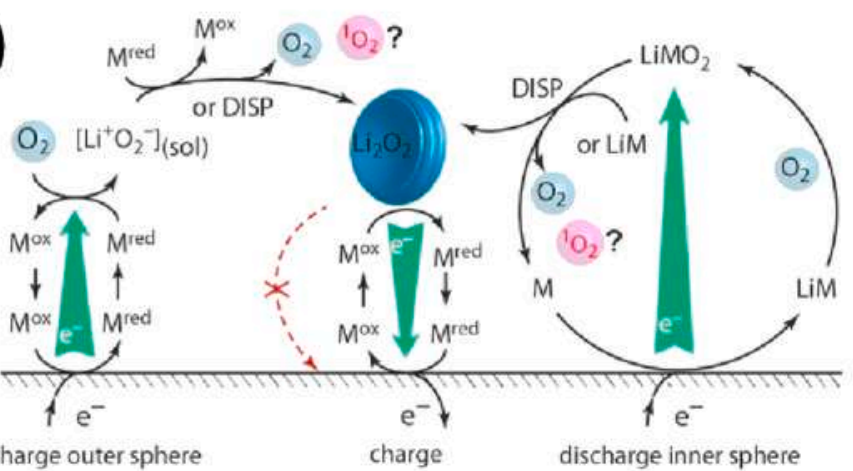

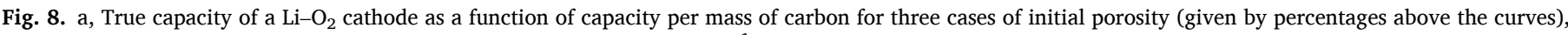

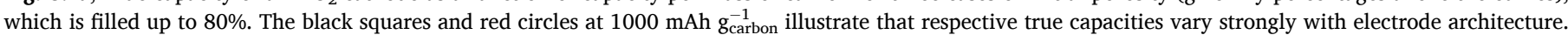

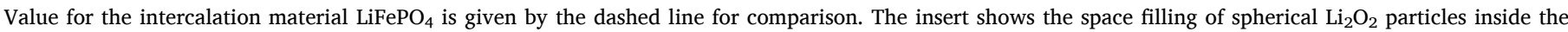

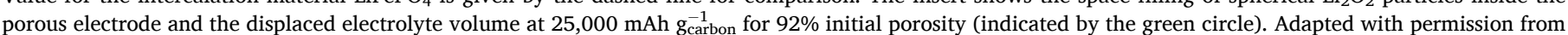

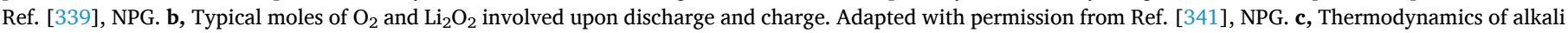

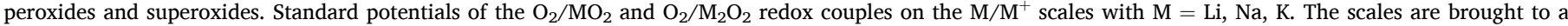

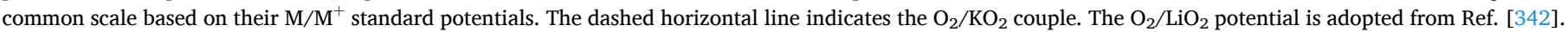

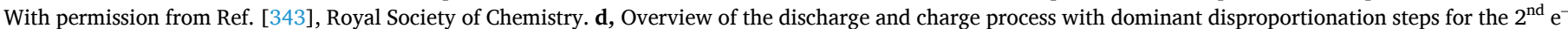

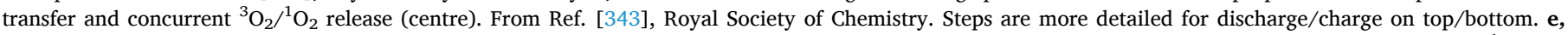

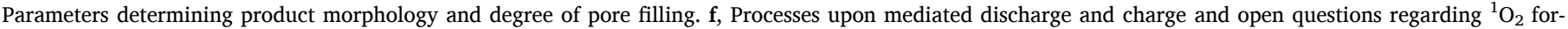
mation. (For interpretation of the references to colour in this figure legend, the reader is referred to the Web version of this article.) 
Limiting factors for power density is mossy lithium growth that depends on a critical areal charging current and eventually limits the charging rate of Li-S-cells. The 3D-framework-concepts discussed above are promising, however, the impact on energy density needs to be estimated as porous frameworks contribute significantly to weight and volume of the cell. Moreover, filling the pores with inactive electrolyte may increase mass and practical implementation in the prototype cells need to be considered. In particular, the limiting current density and depletion of electrolyte impair the cycling stability of lithium anodes. The limiting factors for production are techniques for thin or 3D Li film application as Li-S requires a specific range of film thickness (15-30 $\mu \mathrm{m})$. Importantly, handling of sensitive films requires further development. Lithium passivation coatings for a better handling might differ from those suggested for other battery types to enhance the anode performance and in particular require compatibility with polysulfides. In addition, the reactivity of developed alloys towards polysulfides should be considered and analysed. More importantly, processing of anode pre-lithiation should be viable and the decrease of the overall voltage window must be carefully evaluated.

\subsection{Lithium-air $\left(\mathrm{Li}-\mathrm{O}_{2}\right)$ batteries}

Lithium-air $\left(\mathrm{Li}-\mathrm{O}_{2}\right)$ batteries operate by reversibly forming/dissolving lithium peroxide $\left(\mathrm{Li}_{2} \mathrm{O}_{2}\right)$ in the pores of a carbon cathode, while drawing/releasing oxygen $\left(\mathrm{O}_{2}\right)$ from air. The overall reaction is $\mathrm{O}_{2}+2$ $\mathrm{e}^{-}+2 \mathrm{Li}^{+} \leftrightarrows \mathrm{Li}_{2} \mathrm{O}_{2}$ with an equilibrium potential of $2.96 \mathrm{~V} \mathrm{vs.} \mathrm{Li} / \mathrm{Li}^{+}[21$ 334-336]. Besides poor rechargeability due to parasitic reactions [337, 338], practical realization relies on fully using the high theoretical capacity of $\mathrm{Li}_{2} \mathrm{O}_{2}$ [339]. Only if the electrode porosity is filled by a large fraction with active material, significant capacity improvements can be achieved [339,340]. Yet, large $\mathrm{Li}_{2} \mathrm{O}_{2}$ pore occupation impedes mass and electron transfer. Achieving high reversible capacity requires maximizing $\mathrm{Li}_{2} \mathrm{O}_{2}$ packing densities through a detailed understanding of the oxygen reduction and evolution mechanism. Equally, parasitic chemistry is now understood to be curbed only through understanding its mechanism.

\subsection{1. $\mathrm{Li}-\mathrm{O}_{2}$ performance}

Realistic capacities of $\mathrm{Li}-\mathrm{O}_{2}$ cathodes cause lots of confusion. This is because formal capacity (1168 $\left.\mathrm{mAh} \mathrm{g}^{-1}, 2500 \mathrm{mAh} \mathrm{cm} \mathrm{cm}_{2}^{-3} \mathrm{~L}_{2}\right)$ is confused with theoretical capacity $\left(\mathrm{Li}_{2} \mathrm{O}_{2}\right.$ including the minimum electron and ion conductor for $\mathrm{Li}_{2} \mathrm{O}_{2}$ to take place) and achieved true capacity $\left(\mathrm{Li}_{2} \mathrm{O}_{2}\right.$ including the used electron and ion conductor) [339]. Given that the positive active material $\mathrm{O}_{2}$ is absent in the as-made charged cathode, relating the capacity to the mass of carbon has become habitual, resulting often in more than $10,000 \mathrm{mAh} \mathrm{g}_{\mathrm{C}}^{-1}$. As full capacity cycling is difficult, cyclability is often shown at, e.g., a fixed $1000 \mathrm{mAh} \mathrm{g}^{-1}$, i.e., often $<10 \%$ depth-of-discharge. However, highly porous cathodes are back-filled with electrolyte. Fig. 8a shows the true capacity per total electrode mass for three initial porosities, which are filled up to $80 \%$ with $\mathrm{Li}_{2} \mathrm{O}_{2}$. To achieve truly higher capacity than intercalation cathodes, filling the available pore space to the widest possible extent is crucial. Overly restricted depth-of-cycling results in no advantage. Fairly assessing true energy and cyclability requires values reported with respect to full electrode mass and volume. $\mathrm{Li}-\mathrm{O}_{2}$ cathodes could achieve higher true capacity than intercalation also in practice; key is high active material packing density and a small inactive/active material ratio.

\subsection{2. $\mathrm{Li}-\mathrm{O}_{2}$ discharge}

$\mathrm{O}_{2}$ reduction during discharge in $\mathrm{Li}-\mathrm{O}_{2}$ batteries proceeds in two consecutive steps (Fig. 8d) [344,345]. First, $\mathrm{O}_{2}$ is reduced to superoxide $\left(\mathrm{O}_{2}^{-}\right)$at the carbon-electrolyte interface to $\mathrm{O}_{2}^{-*}$, which associates with $\mathrm{Li}^{+}$to form the surface species $\mathrm{LiO}_{2}{ }^{*}$. The desorption/adsorption equilibrium $\mathrm{LiO}_{2}^{*} \rightleftharpoons \mathrm{Li}_{(\text {sol })}^{+}+\mathrm{O}_{2 \text { (sol) }}^{-}$defines the extent to which associated $\mathrm{LiO}_{2} *$ is adsorbed at the surface or dissolved as $\left[\mathrm{Li}^{+} \ldots \mathrm{O}_{2}^{-}\right]_{(\text {sol })}$, which can be anything between solvated free ions and solvated ion pairs or clusters [344]. Second, solid $\mathrm{Li}_{2} \mathrm{O}_{2}$ is believed to either form via electroreduction of $\mathrm{LiO}_{2}{ }^{*}$ or via disproportionation of the dissolved species. The former leads to a conformal $\mathrm{Li}_{2} \mathrm{O}_{2}$ coating up to a few nanometers in thickness [346], the latter to disc-like $\mathrm{Li}_{2} \mathrm{O}_{2}$ crystallites [347] that may assemble to toroidal particles of several hundred nanometers in size [348,349]. Disproportionation takes place via associated $\mathrm{LiO}_{2}$ or clusters in solution or adsorbed on existing $\mathrm{Li}_{2} \mathrm{O}_{2}$ crystals [350,351]. While chemical experiments suggest that disc-like crystallites are a unique signature for disproportionation [352], the exact mechanism of toroidal particle formation remains to be clarified.

Increasing discharge capacities relies on facilitating solution growth since the $\mathrm{Li}_{2} \mathrm{O}_{2}$ volume formed via electrochemical reduction is limited by $\mathrm{Li}_{2} \mathrm{O}_{2}$ 's poor electronic conductivity [334,337,345,353]. Using planar or low surface area electrodes, the capacity correlates directly with the formal $\mathrm{Li}_{2} \mathrm{O}_{2}$ layer thickness. In carbon cathodes with smaller pores, the $\mathrm{Li}_{2} \mathrm{O}_{2}$ particle size is limited to the pore size (Fig. 8e). Whether the second electron transfer (surface mechanism) or solution mediated disproportionation (solution mechanism) prevails, is currently understood to be primarily controlled by the electrolyte's solvation energy [344,345,354]. A high Gutman donor number (DN) of the solvent will drive $\mathrm{Li}^{+}$solvation and consequently the solution mechanism [344]. Similarly, high DN anions [354] or trace $\mathrm{H}_{2} \mathrm{O}$ [345] in the electrolyte shift the adsorption/desorption equilibrium towards dissolved species. In all cases, microscopy shows larger and less numerous $\mathrm{Li}_{2} \mathrm{O}_{2}$ particles in electrolytes with stronger solvation [345,354]. With decreasing current density, $\mathrm{Li}_{2} \mathrm{O}_{2}$ particles become larger and less numerous in line with nucleation and growth theory. At low currents or low overpotentials, solution mediated disproportionation generally dominates [355,356].

Concerning the surface mechanism, much speculation has been going on whether the higher conductivity in defect-rich or amorphous $\mathrm{Li}_{2} \mathrm{O}_{2}$ [357-359] could explain particle sizes of few tens of nanometers formed by electrochemical reduction. Actual electrochemical discharge, however, at realistic current densities and in prototype electrolytes for surface discharge [346,353] have established a maximum formal film thickness of about 5-10 nm, depending on the applied current. Theoretical studies explain the electron transfer by polaron-hole conduction and electron tunnelling through crystalline $\mathrm{Li}_{2} \mathrm{O}_{2}[346,353,360]$. Given the exponential tunnelling resistance increase with $\mathrm{Li}_{2} \mathrm{O}_{2}$ thickness $[346,361]$, particle growth by electrochemical reduction is self-limited, indicating that $\mathrm{Li}_{2} \mathrm{O}_{2}$ formed via the surface mechanism would always results in film-like morphologies.

Capacity of $\mathrm{Li}-\mathrm{O}_{2}$ batteries is primarily electron transport limited, i. e., electrode passivation with $\mathrm{Li}_{2} \mathrm{O}_{2}$ formed via the surface mechanism. At the end of galvanostatic discharge, widely $\mathrm{Li}_{2} \mathrm{O}_{2}$ covered carbon surface increases the local current density and the electrode potential drops [355,362]. The contribution of the surface mechanism would rise until all carbon surface is $\mathrm{Li}_{2} \mathrm{O}_{2}$ covered up to the maximum tunnelling thickness. In electrolytes promoting solution discharge, also mass transport limitation through the increasingly tortuous network of $\mathrm{Li}_{2} \mathrm{O}_{2}$ and carbon is considered [363]. This suggests next to electrolyte solvation and current density the species mobility $\left(\mathrm{O}_{2}^{-}, \mathrm{Li}^{+}, \mathrm{O}_{2}\right)$ as a third parameter to control discharge capacities [364,415].

An interesting aspect arises from how the size and number density of $\mathrm{Li}_{2} \mathrm{O}_{2}$ particles varies with increasing solvation (solvent or anion DN, $\mathrm{H}_{2} \mathrm{O}$ content), which is usually explained by the shifting partition from surface to solution mechanism. Less numerous, but larger particles are many times associated with an increased fraction of solution mechanism and accelerated disproportionation. However, this explanation contradicts nucleation and growth theory, if only homogenous nucleation in solution is considered: the concentration of dissolved $\mathrm{Li}^{+}$and $\mathrm{O}_{2}^{-}$and homogenous nucleation rates are highest in strongly solvating electrolytes. Consequently, the $\mathrm{Li}_{2} \mathrm{O}_{2}$ particle number density should be highest and the $\mathrm{Li}_{2} \mathrm{O}_{2}$ particle size smallest in strongly solvating electrolytes. Yet, just the opposite is observed [344,345,354,415]. In a multiscale 
modelling study Franco et al. [362] give a reasonable explanation for that: $\mathrm{Li}_{2} \mathrm{O}_{2}$ nucleation takes place via heterogeneous nucleation at the carbon surface, where nuclei form via the surface mechanism. $\mathrm{Li}_{2} \mathrm{O}_{2}$ particle growth above the tunnelling limit takes place via solution mediated disproportionation. Hence, an increasing fraction of the surface mechanism would lead to more numerous and smaller $\mathrm{Li}_{2} \mathrm{O}_{2}$ particles, as observed experimentally.

Interestingly, some recent SEM [365-368] and TEM [348,349] studies raise doubts about the prevalence of the surface mechanism in low donor number electrolytes, although they were not interpreted this way. SEM and TEM micrographs of electrodes after discharge in supposedly prototype electrolytes for surface mechanism (dry DME, MeCN) show particles from tens to hundreds of $\mathrm{nm}$, contradicting that they could have formed via the surface mechanism [415].

\subsection{3. - $\mathrm{Li}-\mathrm{O}_{2}$ charge}

Only recently, knowledge about the recharge mechanism has seen progress to a similar level as discharge. Generally, $\mathrm{O}_{2}$ evolution starts just above $2.96 \mathrm{~V}$ with steadily rising voltage, sometimes with plateaus. It is agreed that oxidation has low kinetic barrier, and that the voltage rise stems mostly from accumulating side products and to a lesser extent from increasingly difficult electron transfer. Most recent understanding settled at a two-step process: First, formation of a superoxide intermediate, which may either be a Li-deficient $\mathrm{Li}_{2-\mathrm{x}} \mathrm{O}_{2}$ phase or $\mathrm{LiO}_{2}$. Second, $\mathrm{O}_{2}$ evolution via superoxide disproportionation (Fig. 8d). Superoxide formation on charge can proceed at low voltages and has been proposed theoretically [369] and shown experimentally via XRD [370], PITT [371,372], XANES [373], and RRDE [372,373].

Whether $\mathrm{O}_{2}$ evolution from the superoxide intermediate involves a second electron transfer or only disproportionation is still controversial, although evidence accumulates that the latter can fully explain things $[343,372,373] .{ }^{1} \mathrm{O}_{2}$ forms from the onset of charge and its fraction, being sensitive to the cations present (see next section), can only be explained with disproportionation [343]. While also solid superoxide may disproportionate [351], kinetically relevant appears soluble $\mathrm{LiO}_{2}$. Hence, similar to discharge, the solvent becomes the governing factor as reported by Lu et al. [372,373]. RRDE has shown that even in low DN electrolytes dissolved $\mathrm{LiO}_{2 \text { (sol) }}$ forms. XANES showed surface $\mathrm{LiO}_{2}$ in high DN solvents but its absence in low DN solvents. Disproportionation in high DN solvents was shown via SEM, where after charging large $\mathrm{Li}_{2} \mathrm{O}_{2}$ particles, nanocrystalline, lamellar $\mathrm{Li}_{2} \mathrm{O}_{2}$ was seen. Similar recrystallization to nanocrystalline $\mathrm{Li}_{2} \mathrm{O}_{2}$ was also seen for low DN solvents by XANES [373]. Disproportionation as the $\mathrm{O}_{2}$ release step is paramount for understanding parasitic chemistry, as discussed in the following.

\subsection{4. - $\mathrm{Li}-\mathrm{O}_{2}$ parasitic chemistry}

Parasitic chemistry keeps buzzling the community. The equation 2 $\mathrm{Li}^{+}+\mathrm{O}_{2}+2 \mathrm{e}^{-} \leftrightarrow \mathrm{Li}_{2} \mathrm{O}_{2}$ directly describes the ratios of charge passed and species converted, which have to match during discharge and charge. However, as illustrated in Fig. 8c, typically the $\mathrm{e}^{-} / \mathrm{O}_{2}$ ratio on discharge is $\sim 2$ while only $\sim 50-95 \% \mathrm{Li}_{2} \mathrm{O}_{2}$ form [343,374]. On charge, substantially less $\mathrm{O}_{2}$ evolves as expected from the charge passed and the $\mathrm{Li}_{2} \mathrm{O}_{2}$ consumed. These discrepancies have for long been ascribed to the potential reactivity of superoxide and peroxide. However, theoretical calculations revealed prohibitively high barriers for the potential onset reactions: nucleophilic substitution, $\mathrm{H}$-atom abstraction and $\mathrm{H}^{+}$ abstraction. Strategies to mitigate the irreversibilities using materials with higher stability against superoxide and peroxide proved only partially successful [375-378].

Singlet oxygen $\left({ }^{1} \mathrm{O}_{2}\right)$ could be the missing reactive species as first suggested by Hassoun et al. to possibly form upon $\mathrm{Li}_{2} \mathrm{O}_{2}$ oxidation at high voltages [379]. ${ }^{1} \mathrm{O}_{2}$ is the first excited state of ground state triplet oxygen being $\sim 1 \mathrm{eV}$ higher in energy. This idea was occasionally picked up, but experimental proof was hindered by the difficulty to detect ${ }^{1} \mathrm{O}_{2}$. Small amounts could first be shown to form upon charging between 3.55 and 3.75 V using operando EPR [380]. The used spin trap was, however, unable to measure during discharge and higher charge voltages. The finding could partly explain parasitic chemistry beyond $3.55 \mathrm{~V}$. On discharge and from the onset of charge (where always less than $1 \mathrm{~mol} \mathrm{O}_{2}$ evolved per $1 \mathrm{~mol}$ of $\mathrm{Li}_{2} \mathrm{O}_{2}$ oxidized), parasitic chemistry could not be clarified [374,377,381].

To comprehensively investigate involvement of ${ }^{1} \mathrm{O}_{2}$, Freunberger et al. developed methods to sensitively and quantitatively detect ${ }^{1} \mathrm{O}_{2}$ over the entire relevant voltage range during discharge and charge of metal- $\mathrm{O}_{2}$ cells [338]. The $1270 \mathrm{~nm}$ emission during the ${ }^{1} \mathrm{O}_{2}$ to ${ }^{3} \mathrm{O}_{2}$ decay gave direct unambiguous proof for ${ }^{1} \mathrm{O}_{2}$. To be more sensitive and quantifiable, 9,10-dimethylanthracene (DMA) was identified as a suitable ${ }^{1} \mathrm{O}_{2}$ trap, fulfilling all requirements in the cell environment. DMA forms with ${ }^{1} \mathrm{O}_{2}$ selectively its endoperoxide form (DMA-O ${ }_{2}$ ); both species are stable in the relevant voltage range between 2 and $\sim 4 \mathrm{~V}$ vs $\mathrm{Li} / \mathrm{Li}^{+}$; and the conversion can be measured using ex-situ HPLC of extracted electrolyte or by in-situ fluorescence.

${ }^{1} \mathrm{O}_{2}$ has been shown to form both during discharge and from the onset of charge and with growing rate as the charge voltage rises, which resembles the rates at which parasitic reactions occur in $\mathrm{Li}-\mathrm{O}_{2}$ cells, Fig. 8b. Given that ${ }^{1} \mathrm{O}_{2}$ accounts for the majority of parasitic reaction products on discharge and charge, ${ }^{1} \mathrm{O}_{2}$ arises as the biggest hurdle to cycle $\mathrm{Li}-\mathrm{O}_{2}$ cells by reversibly forming/decomposing $\mathrm{Li}_{2} \mathrm{O}_{2} \cdot{ }^{1} \mathrm{O}_{2}$ not only decomposes the electrolyte [338,382], but also carbon [377,383] and redox mediators [384]. As a means to counter ${ }^{1} \mathrm{O}_{2}$-related side reactions, DMA was shown to reduce parasitic products on discharge and charge by trapping ${ }^{1} \mathrm{O}_{2}$. Further, the ${ }^{1} \mathrm{O}_{2}$ quencher 1,4-diazabicyclo[2.2.2] octane (DABCO) was shown to even more strongly reduce parasitic chemistry by physically deactivating ${ }^{1} \mathrm{O}_{2}$. However, DABCO is unstable above 3.6 V. The mono-alkylated DABCOnium was proven as an effective, more oxidation stable quencher [385].

Formation of ${ }^{1} \mathrm{O}_{2}$ is now understood to predominantly stem from superoxide disproportionation

$2 \mathrm{O}_{2}^{-} \rightarrow \mathrm{O}_{2}^{2-}+x{ }^{3} \mathrm{O}_{2}+(1-x){ }^{1} \mathrm{O}_{2}$

Rather than direct $2 \mathrm{e}^{-}$oxidation of $\mathrm{Li}_{2} \mathrm{O}_{2}$ [343]. Another source is superoxide oxidation above $\mathrm{E}_{\mathrm{O}_{2} / \mathrm{LiO}_{2}}^{0}+\mathrm{E}\left(\mathrm{O}_{12} \leftarrow \mathrm{O}_{32}\right) \sim 3.26 \ldots 3.56 \mathrm{~V}$ [338] as well as $\mathrm{Li}_{2} \mathrm{CO}_{3}$ oxidation [386]. Superoxide disproportionation is involved on discharge and charge as discussed above, Fig. $8 \mathrm{c}$ and $\mathrm{d}$. With this recognition, a unified mechanism of ${ }^{1} \mathrm{O}_{2}$ generation has been established with the Lewis acidity of the cations involved in the disproportionation reaction governing the ${ }^{1} \mathrm{O}_{2}$ yield [343]. The cation controls the relative thermodynamic stability of (su)peroxide and hence the fate of the initial one-electron reduction product superoxide (Fig. 8c). $\mathrm{Li}^{+}$or $\mathrm{Na}^{+}$as strong Lewis acids favour peroxide, albeit only slightly in the case of sodium [387]. $\mathrm{K}^{+}$and even weaker Lewis acids (e. g., quaternary ammoniums like tetrabutylammonium $\left(\mathrm{TBA}^{+}\right)$and imidazolium) favour the superoxide [388]. The latter constitute often-used ionic liquid electrolytes.

While stronger Lewis acids drive disproportionation, the ${ }^{1} \mathrm{O}_{2}$ fraction grows with decreasing Lewis acidity of the cation, causing insignificant ${ }^{1} \mathrm{O}_{2}$ with $\mathrm{H}^{+}$and strongly growing fractions with $\mathrm{Li}^{+}$and $\mathrm{Na}^{+}$. Importantly, weakly Lewis acidic cations that alone do not drive disproportionation boost ${ }^{1} \mathrm{O}_{2}$ fractions when combined with strong Lewis acids. DFT calculations revealed that weak Lewis acids open pathways that bypass the otherwise most unfavourable reaction steps towards ${ }^{1} \mathrm{O}_{2}$. This allows $\mathrm{TBA}^{+}$to be used as a probe for disproportionation steps. Disproportionation must be involved if presence of $\mathrm{TBA}^{+}$increases the ${ }^{1} \mathrm{O}_{2}$ yield. This way, larger ${ }^{1} \mathrm{O}_{2}$ yields in mixed $\mathrm{Li}^{+} / \mathrm{TBA}^{+}$electrolytes as compared to pure $\mathrm{Li}^{+}$electrolytes verified that disproportionation is the $\mathrm{O}_{2}$ evolving step on both discharge and charge (Fig. 8d) [343].

So far, parasitic chemistry remains the major concern in $\mathrm{Li}-\mathrm{O}_{2}$ batteries. Concluding about the impact of any measures (electrolytes, electrodes, catalysts, mediators, ...) requires multiple quantitative analyses of the $\mathrm{O}_{2}$ and $\mathrm{Li}_{2} \mathrm{O}_{2}$ inventory and of side products [337]. 
Qualitative measures cannot replace quantitative integral methods and cannot support claims of reversibility.

\subsection{5. - Mediated $\mathrm{Li}-\mathrm{O}_{2}$ chemistry}

The difficulties to reversibly fill the pore space with insulating $\mathrm{Li}_{2} \mathrm{O}_{2}$ at high rates and associated side reactions require countermeasures. Redox mediators could potentially mitigate all these problems by shuttling electrons between carbon surface and $\mathrm{O}_{2}$ or $\mathrm{Li}_{2} \mathrm{O}_{2}$, thereby forming/decomposing $\mathrm{Li}_{2} \mathrm{O}_{2}$ distant from the surface at high rate and low overpotentials (Fig. 8f) [389-392]. Upon discharge, mediators may act via outer or inner sphere pathways that differ in whether or not free superoxide is involved [392,393]. The relative absence of superoxide was suggested to mitigate side reactions on discharge. On charge mediators were suggested to reduce side reactions by reducing the recharge potential [394]. Classes and some features of reduction and oxidation mediators have been reviewed comprehensively in, e.g., Refs. [391, 395]. However, the major open questions remain in the role of ${ }^{1} \mathrm{O}_{2}$ during mediated $\mathrm{O}_{2}$ reduction and evolution. It is unknown whether inner sphere reduction that forms $\mathrm{Li}_{2} \mathrm{O}_{2}$ via disproportionation of $\mathrm{LiMO}_{2}$ intermediates ( $2 \mathrm{LiMO}_{2} \rightarrow \mathrm{Li}_{2} \mathrm{O}_{2}+2 \mathrm{M}+{ }^{\mathrm{x}} \mathrm{O}_{2}$ ) [392] forms ${ }^{1} \mathrm{O}_{2}$ and, if yes, what governs its fraction. Equally, the mediated peroxide oxidation mechanism is unknown and whether the nature of the mediator may allow to suppress ${ }^{1} \mathrm{O}_{2}$ generation therefrom. More or less severe decay of the mediation effect suggests that ${ }^{1} \mathrm{O}_{2}$ is to some extent involved with both oxidation and reduction mediators [384]. Only detailed knowledge of the underpinning mechanisms will allow progress towards fully reversible $\mathrm{Li}-\mathrm{O}_{2}$ cells.

\subsection{6. - The lithium metal anode in $\mathrm{Li}-\mathrm{O}_{2}$ cells}

The lithium metal anode in $\mathrm{Li}-\mathrm{O}_{2}$ cells poses some additional challenges beyond those discussed in Section 2 for the metal anode in general. Given that at present the by far biggest hurdle for the $\mathrm{Li}-\mathrm{O}_{2}$ cell is the cathode, we focused heavily on it and restrict ourselves to discussing cornerstones of particularities of the lithium metal with $\mathrm{Li}-\mathrm{O}_{2}$. The additional issues are (i) electrolyte requirements for the cathode may exclude some solvents/additives that were per se beneficial for the anode; (ii) cross over of $\mathrm{O}_{2}, \mathrm{CO}_{2}, \mathrm{H}_{2} \mathrm{O}, \mathrm{N}_{2}$ from the cathode feed stream, and (iii) reactivity of electrolyte additives motivated by the cathode chemistry, such as redox mediators or singlet oxygen quenchers, may be incompatible with the anode. Approaches to tackle these issues go broadly along those stabilizing the lithium metal in general (Fig. 2). These are (i) inorganic or polymeric separators that are impermeable to cathode specific species (e.g., $\mathrm{O}_{2}, \mathrm{CO}_{2}, \mathrm{H}_{2} \mathrm{O}$, redox mediators), (ii) additives to form a stable SEI, (iii) a preformed artificial SEI, (iv) adapted Li host structures.

More or less complete separation of the catholyte from the anode may be achieved using either inorganic $\mathrm{Li}^{+}$conducting ceramics or solid polymer electrolytes. The former is widely considered as suitable for lab cells but less so for practical cells due to cost and mechanical issues [396, 397]. $\mathrm{Li}^{+}$conducting polymer films may be more practical and have been shown to prevent ingress of, e.g., $\mathrm{O}_{2}$ or redox mediators to the anode [398,399].

Li plating/stripping in presence of species from air may as such not necessarily be detrimental compared to Ar atmosphere. Several groups found synergies between the SEI formed by classical electrolyte reduction and the presence of $\mathrm{O}_{2}$ or $\mathrm{N}_{2}$ [400-402]. For example, the SEI in glyme/LiTFSI electrolyte has been found more uniform in presence of $\mathrm{O}_{2}$ and $\mathrm{N}_{2}$ than with Ar, giving rise to higher coulombic efficiency. $\mathrm{LiNO}_{3}$ as salt in dimethylacetamide electrolyte was found to require $\mathrm{O}_{2}$ to allow for long term cycling of lithium metal, something impossible with this solvent with other salt or without $\mathrm{O}_{2}[400,401]$. $\mathrm{LiNO}_{3}$ as additive affects both anode and cathode chemistry beneficially [403]. Further bifunctional electrolyte additives proposed were $\mathrm{InI}_{3}$ and LiI [404], or $\mathrm{LiBr}[394,405]$. Highly-concentrated electrolytes have shown benefits for both electrodes. Examples include 3 M LiTFSI/DME [406], 4 M $\mathrm{LiNO}_{3} / \mathrm{DMSO}$ [407] and more recently localized high-concentration electrolytes [408], which employ fluorinated diluents to improve viscosity, cost, $\mathrm{O}_{2}$ solubility, and stability against ${ }^{1} \mathrm{O}_{2}$. They all have been shown to cycle lithium metal well under $\mathrm{O}_{2}$ atmosphere. Artificial SEIs often involve dipping the metal into carbonates such as FEC [409] or PC [410]. Furthermore, lithium metal cycling may be enhanced by using it in alloys such as with Na together with dioxolane as additive [411] or by integrating it into a carbon host structure [412].

\section{5. - Final considerations towards SET plan targets for $\mathbf{2 0 3 0}$}

To enable the widespread commercialization of Li metal batteries, substantial efforts are required, in particular to stabilize the Li anode. Despite the multitude of protection strategies proposed so far, using highly reactive metallic Li in liquid cells still appears very challenging. Particularly because the safety issues associated with the presence of the flammable organic electrolytes remain. To guarantee safe operation of Li metal anodes, using non-flammable solid electrolytes is planned starting from 2025 with Generation 4 ASSBs.

Lithium metal ASSBs with ISEs are considered one of the most promising energy storage technologies for automotive and stationary applications. Implementing an ISE with higher mechanical and electrochemical stability than organic liquid electrolytes would enable to use lithium metal as an anode or so-called "anode-free" concepts (coupled with a high voltage cathode material), expediting the development of high voltage battery systems with enhanced energy density. The Interuniversity Microelectronics Centre (IMEC) of Leuven Belgium, after recently presenting an ASSB with a volumetric energy density of $400 \mathrm{Wh} \mathrm{L}^{-1}$ at a charging speed of $0.5 \mathrm{C}$, aims to produce by 2024 a solidstate battery with an energy density of $1000 \mathrm{Wh} \mathrm{L}^{-1}$ at 2-3 C (charging time of 20-30 $\mathrm{min}$ ) [413]. These results bode well for the achievement of the performance targets in terms of charging time (12 min for $70-80 \%$ $\Delta$ SOC), volumetric $\left(>750 \mathrm{Wh} \mathrm{L}^{-1}\right)$ and gravimetric $\left(>400 \mathrm{Wh} \mathrm{kg}^{-1}\right.$ ) energy densities defined for a battery cell by the European SET-Plan Action 7 for 2030. Despite the significant improvements, the main challenge remains to stabilize the lithium metal and high-voltage cathode/electrolyte interfaces, considered crucial for long battery lifetimes. As highlighted by Randau et al. [162], further research is required to develop protective coatings for high voltage cathodes. Furthermore, achieving an electrolyte thickness below $50 \mu \mathrm{m}$, in-situ generation of the anode, and areal capacities higher than $5 \mathrm{mAh} \mathrm{cm}^{-2}$ would be necessary to further improve the battery performance. An exceptional result was recently achieved by Samsung [167], where a 0.6 Ah pouch lithium metal cell (using a Ag-C nanocomposite anode for in-situ uniform deposition of Li metal) was recently developed. A record energy density of $900 \mathrm{Wh} \mathrm{L}^{-1}$, areal capacity $>6.8 \mathrm{mAh} \mathrm{cm}^{-2}$, and lifetime of 1000 cycles was achieved. As previously described, several techniques (coatings, nanocomposite electrodes and alloys) are already available to obtain uniform lithium metal deposition. However, their high costs still hamper the scalability of the process, making challenging to simultaneous achieve the cost targets $(75 € / \mathrm{kWh}$ for an automotive battery pack, or $0.05 € / \mathrm{kWh} /$ cycle for stationary) and battery lifetime (2000 cycles for BEV, or 10000 cycles for stationary). ASSBs using lithium metal and a polymer electrolyte represent a very attractive energy storage system since it holds the potentialities for achieving high gravimetric and volumetric energy, long cycle life and remarkable safety. The favorable characteristics of this technology have been suggested by a large number of studies on laboratory-scale cells, which might achieve about $300 \mathrm{Wh} \mathrm{kg}^{-1}$ and 500-600 $\mathrm{Wh} \mathrm{L}^{-1}$ in optimized conditions. Scaling up to practical solid-state LMP cells by various companies (i.e., Hydro-Quebéc, $3 \mathrm{M}$, and Bolloré Group) has led to actual commercialization for automotive applications. Yet, the European SET Plan targets for 2020 (i.e., $350 \mathrm{Wh} \mathrm{kg}^{-1}$ and $750 \mathrm{Wh} \mathrm{L}^{-1}$ at cell level as well as $235 \mathrm{Wh} \mathrm{kg}^{-1}$ and $500 \mathrm{Wh} \mathrm{L}^{-1}$ at the pack level) have not been achieved. Despite promising results suggesting large room for improvement by optimizing cathode, electrolyte, and anode interphase, the targets expected for 2030 (i.e., $>400 \mathrm{Wh} \mathrm{kg}^{-1}$ and $>750 \mathrm{Wh} \mathrm{L}^{-1}$ at 
the cell level as well as $>250 \mathrm{Wh} \mathrm{kg}^{-1}$ and $>500 \mathrm{Wh} \mathrm{L}^{-1}$ at the pack level) appear to be even more challenging.

Generation 5 batteries relying on conversion cathodes may be the key to achieve and, in theory, well exceed the performance target of the SET plan. Li-S batteries have been successfully demonstrated for an UAV application in 2014 with a specific energy of $350 \mathrm{Wh} \mathrm{kg}^{-1}$ [414]. Since then, further improvement led to specific energies up to $470 \mathrm{Wh} \mathrm{kg}^{-1}$ in prototype cells [22]. Thus, Li-S-technology clearly surpasses the SET plan targets in terms of specific energy. Considering the high content of excess electrolyte and lithium, further energy density enhancement is expected by improving the cell chemistry. While the volumetric energy of today's Li-S-cells is limited to below $500 \mathrm{Wh} \mathrm{L}^{-1}$, reducing this excess and the amount of passive materials may lead towards $700 \mathrm{Wh} \mathrm{L}^{-1}$ in the future. Another major challenge is the limited cycle life $(<100$ for high energy cells) which is mainly caused by electrolyte and/or lithium depletion. Consequently, stabilizing the anode/electrolyte interphase is key for progressing the Li-S-technology towards the SET targets in 2030. Novel electrolytes, protective coatings, and/or innovative electrode design are expected to be enablers for enhanced future Li-S-cells. On the other hand, Lithium-air $\left(\mathrm{Li}-\mathrm{O}_{2}\right)$ batteries, which operate by reversibly forming/dissolving $\mathrm{Li}_{2} \mathrm{O}_{2}$ at the cathode are in a much lower state of development. They have the highest formal energy amongst all battery systems. Sometime quoted figures of $3500 \mathrm{Wh} \mathrm{kg}^{-1}$ are based on pure $\mathrm{Li}_{2} \mathrm{O}_{2}$ and hence unrealistic. As outlined in Section 4.2.1, key for truly higher capacities compared to Li-ion is to achieve at the end of discharge a maximum of $\mathrm{Li}_{2} \mathrm{O}_{2}$ volume occupation and hence high active-to-inactive volume and mass ratios. When doing so (e.g., $80 \%$ volume occupation of the initial pore space) and when accounting for the total mass and volume of cathode (active, binder, carbon, electrolyte), separator and anode, theoretical limits of $1700 \mathrm{Wh} \mathrm{kg}^{-1}$ and 1850 Wh $\mathrm{L}^{-1}$ excluding housing are obtained [339]. The main challenges to realize at least part of this promise are: First, reversibly electrodepositing insulating $\mathrm{Li}_{2} \mathrm{O}_{2}$ and filling the porous electrode to the largest possible extent at high rates. Second, avoiding parasitic chemistry, which decomposes cell components and causes poor energy efficiency and cycle life, is crucial. These problems are interrelated and can only be solved in conjunction. Controlling superoxide disproportionation is key for large discharge capacities and efficient recharge. At the same time, disproportionation is the major step forming singlet oxygen, which is now recognized to cause the vast majority of side reactions. Mediated $\mathrm{Li}-\mathrm{O}_{2}$ chemistry may mitigate all these problems in conjunction, but only if the mechanisms are clarified in detail. Overall, only detailed knowledge of the underpinning mechanisms will allow progress towards fully reversible $\mathrm{Li}-\mathrm{O}_{2}$ cells.

For sake of clarity, the current status of LMBs compared to the performance targets of the EU Integrated Strategic Energy Technology Plan (SET-Plan) Action 7 for 2030 is summarized in Table 1.

Finally, a general consideration should be done regarding upscaling of LMBs. Although specific targets per unit of weight or volume may be met with laboratory scale prototypes, the transition to large cell formats suitable for EV application presents additional obstacles. Firstly, a stable $\mathrm{Li} /$ electrolyte interface is a generic challenge for cycle life and high

Table 1

Current status of Li-metal batteries compared to the performance targets of the EU Integrated Strategic Energy Technology Plan (SET-Plan) Action 7 for 2030 [27]. Considering the relatively low TRL of some cell chemistries, cost and manufacturing targets are omitted. For the same reason calendar life is omitted from the performance targets and only values at the cell level are compared.

\begin{tabular}{|c|c|c|c|c|c|}
\hline \multirow{3}{*}{$\frac{\text { SET Plan Targets }}{2030}$} & \multirow[t]{3}{*}{ Current Status } & \multicolumn{4}{|l|}{ Li Metal Batteries } \\
\hline & & \multicolumn{2}{|l|}{ Generation 4: ASSB } & \multicolumn{2}{|c|}{ Generation 5: conversion cathodes } \\
\hline & & inorganic & polymeric & $\mathrm{Li}-\mathrm{S}$ & Li-air \\
\hline & TRL & $4-6$ & commercial & $5-7$ & $1-4$ \\
\hline \multirow{4}{*}{$\begin{array}{l}\text { ENERGY } \\
\text { Gr. }\left(\mathrm{Wh} \mathrm{kg}^{-1}\right) \text { : } \\
>400 \\
\text { Vol. }\left(\mathrm{Wh} \mathrm{L}^{-1}\right) \text { : } \\
>750\end{array}$} & Performance & $\begin{array}{l}>\text { Gr: } 450 \mathrm{Wh} \mathrm{kg}^{-1} \\
>\text { Vol: } 900 \mathrm{Wh} \mathrm{L}^{-1}\end{array}$ & $\begin{array}{l}\text { Estimated (laboratory scale): } \\
>\text { Gr: } 300 \mathrm{Wh} \mathrm{kg}^{-1}\end{array}$ & $\begin{array}{l}>\mathrm{Gr}:>450 \mathrm{Wh} \mathrm{kg}^{-1} \\
>\mathrm{Vol}:<700 \mathrm{Wh} \mathrm{L}^{-1}\end{array}$ & $\begin{array}{l}\text { Theoretical limits (no housing): } \\
>\text { Gr: } 1700 \mathrm{Wh} \mathrm{kg}^{-1}\end{array}$ \\
\hline & & & $\begin{array}{l}>\text { Vol: } 500-600 \mathrm{Wh} \mathrm{L}^{-1} \\
\text { Practical (EVs): } \\
>\text { Gr: } 100-180 \mathrm{Wh} \mathrm{kg}^{-1} \\
>\text { Vol:100 Wh L }\end{array}$ & & $>$ Vol: $1850 \mathrm{Wh} \mathrm{L}^{-1}$ \\
\hline & $\begin{array}{l}\text { Most limiting } \\
\text { factor(s) }\end{array}$ & $\begin{array}{l}>\text { ISE stability towards high } \\
\text { voltage cathodes }\end{array}$ & $\begin{aligned}> & \text { Operating temperature }> \\
& 60^{\circ} \mathrm{C} \\
> & \text { SPE stability towards high } \\
& \text { voltage cathodes }\end{aligned}$ & $\begin{array}{l}>\text { Electrolyte excess } \\
\text { required }\end{array}$ & $\begin{aligned}> & \mathrm{Li}_{2} \mathrm{O}_{2} \text { deposition and dissolution } \\
& \text { mechanism }\end{aligned}$ \\
\hline & $\begin{array}{l}\text { Suggested } \\
\text { measures }\end{array}$ & $\begin{array}{l}>\text { Develop more effective } \\
\text { coatings }\end{array}$ & $\begin{array}{l}>\text { Electrolyte additives } \\
>\text { New cell chemistries }\end{array}$ & $\begin{aligned}> & \text { New electrolytes } \\
> & \text { Improved Electrolyte- } \\
& \text { Anode interphase }\end{aligned}$ & $\begin{array}{l}>\text { New electrolytes/additives based } \\
\text { on mechanistic studies }\end{array}$ \\
\hline $\begin{array}{l}\frac{\text { POWER }}{\text { Gr. }\left(\text { Wh } \mathrm{kg}^{-1}\right):} \\
>700\end{array}$ & Performance & $\begin{array}{l}>\mathrm{Gr}:<500 \mathrm{~W} \mathrm{~kg}^{-1} \\
>\mathrm{Vol}:<1000 \mathrm{~W} \mathrm{~L}^{-1}\end{array}$ & $\begin{array}{l}>\text { Practical (EV) } \\
\text { Gr: }<200 \mathrm{~W} \mathrm{~kg}^{-1} \\
\text { Vol: }<200 \mathrm{~W} \mathrm{~L}^{-1}\end{array}$ & $\begin{array}{l}>\mathrm{Gr}:<500 \mathrm{~W} \mathrm{~kg}^{-1} \\
>\mathrm{Vol}:<1000 \mathrm{~W} \mathrm{~L}^{-1}\end{array}$ & $\begin{array}{l}>\text { No realistic numbers possible } \\
\text { now }\end{array}$ \\
\hline $\begin{array}{l}\text { Vol. }\left(\mathrm{Wh} \mathrm{L}^{-1}\right) \text { : } \\
>1500 \\
\text { Charge time }\end{array}$ & $\begin{array}{l}\text { Most limiting } \\
\text { factor(s) }\end{array}$ & $\triangleright$ High cell impedance & $\begin{array}{l}>\text { Low } \mathrm{Li}^{+} \text {transference } \\
\text { number }\end{array}$ & $\begin{aligned}> & \text { Cathode conversion } \\
& \text { kinetics } \\
> & \text { Electrolyte resistance }\end{aligned}$ & $\begin{aligned}> & \mathrm{Li}_{2} \mathrm{O}_{2} \text { deposition and dissolution } \\
& \text { mechanism }\end{aligned}$ \\
\hline$(\min ): 12$ & $\begin{array}{l}\text { Suggested } \\
\text { measures }\end{array}$ & $>$ Reduction of SE thickness & $\begin{aligned}> & \text { New electrolyte } \\
& \text { formulations }\end{aligned}$ & $\begin{array}{l}>\text { Improved electrolytes } \\
>\text { Electrode design }\end{array}$ & $\begin{aligned}> & \text { New electrolytes/additives based } \\
& \text { on mechanistic studies }\end{aligned}$ \\
\hline$\frac{\text { CYCLE LIFE }}{\text { (to } 80 \% \text { DOD) }}$ & Performance & $>1000$ & $>$ ca. 1300 & $\begin{aligned}> & <1000(<100 \text { for high } \\
& \text { energy cells })\end{aligned}$ & $\begin{array}{l}>\text { No realistic numbers possible } \\
\text { now }\end{array}$ \\
\hline $\begin{array}{l}\text { BEV: } 2000 \\
\text { Stationary: }\end{array}$ & $\begin{array}{l}\text { Most limiting } \\
\text { factor(s) }\end{array}$ & $\begin{array}{l}>\text { Contact issue at interfaces } \\
>\text { Dendrite growth }\end{array}$ & $\begin{array}{l}>\text { Stability of electrode/ } \\
\text { electrolyte interphase }\end{array}$ & $\begin{array}{l}>\text { Electrolyte } \\
>\text { Anode depletion }\end{array}$ & $>$ Parasitic chemistry at cathode \\
\hline 10000 & $\begin{array}{l}\text { Suggested } \\
\text { measures }\end{array}$ & $\begin{aligned}> & \text { Stable interlayers } \\
& \text { (hybrid) } \\
> & \text { Highly dense SE }\end{aligned}$ & $\begin{aligned}> & \text { Electrolyte additives } \\
> & \text { New electrolyte } \\
& \text { formulations }\end{aligned}$ & $\begin{aligned}> & \text { New electrolytes } \\
> & \text { Improved Electrolyte- } \\
& \text { Anode interphase }\end{aligned}$ & $\begin{aligned} &> \text { Detailed understanding of }{ }^{1} \mathrm{O}_{2} \\
& \text { formation mechanisms. } \\
&>\text { New electrolytes/additives based } \\
& \text { on mechanistic studies }\end{aligned}$ \\
\hline
\end{tabular}


power of LMBs. Secondly, the fabrication of thin $(<20 \mu \mathrm{m})$, wide, homogeneous and current collector-free Li metal foils is another big obstacle. While a lithium metal film or foil are required for present cell chemistries featuring a conversion cathode (Li-S and Li-air), the "anodefree" configuration appears to date the most emerging approach to bring LMBs (with a lithiated cathode, of course) into EVs. Combined with solid electrolytes enabling bipolar stacking, this can potentially result in reduced manufacturing costs (no handling of Li metal during cell production) and increased energy density of high voltage systems (less packaging needed to connect cells in series).

\section{Credit author statement}

A.V: Writing - original draft, conceived the manuscript structure, wrote section 1, conceived Figure 1 and 2 and Table 1, and coordinated the writing of entire manuscript, K.T: Writing - original draft, wrote section 2, conceived and realized Figure 3 and realized Figure 2, R.S: Writing - original draft, wrote sections 3 and 3.1 and conceived and realized Figure 5, D.D: Writing - original draft, wrote section 3.2 and conceived and realized Figure 5 and 6, J.H: Writing - original draft, wrote section 3.2 and conceived and realized Figure 5 and 6, S. D: Writing - original draft, wrote section 4.1, revised section $1-4.1$, and conceived and realized Figure 7, H. A: Writing - original draft, Writing review \& editing, revised the entire manuscript, and implemented values for Table 1 and wrote section 4.1, S. K: Writing - original draft, coordinated and revised the entire manuscript, C.P: Writing - original draft, wrote section 4.2, realized Figure 8. S.A.F: Writing - original draft, Writing - review \& editing, wrote section 4.2, realized Figure 8. All authors have contributed to section 5 , revised the entire manuscript and approved the final version of before submission.

\section{Declaration of competing interest}

The authors declare that they have no known competing financial interests or personal relationships that could have appeared to influence the work reported in this paper.

\section{Acknowledgments}

A.V. and K.T. acknowledge, respectively, the financial support of the Helmholtz Association and BMW AG. J.H. acknowledges the collaboration project "Accordo di Collaborazione Quadro 2015" between University of Ferrara (Department of Chemical and Pharmaceutical Sciences) and Sapienza University of Rome (Department of Chemistry). S.D., H.A. and S.K. thank the Fraunhofer Gesellschaft, Technische Universität Dresden and would like to acknowledge European Union's Horizon 2020 research and innovation programme under grant agreement No 814471. S.A.F. and C.P. are indebted to the European Research Council (ERC) under the European Union's Horizon 2020 research and innovation program (grant agreement no. 636069) and IST Austria.

\section{References}

[1] W. Xu, J. Wang, F. Ding, X. Chen, E. Nasybulin, Y. Zhang, J.-G. Zhang, Energy Environ. Sci. 7 (2014) 513.

[2] D. Lin, Y. Liu, Y. Cui, Nat. Nanotechnol. 12 (2017) 194.

[3] M. Winter, B. Barnett, K. Xu, Chem. Rev. 118 (2018) 11433.

[4] H. Zhang, C. Li, G.G. Eshetu, S. Laruelle, S. Grugeon, K. Zaghib, C. Julien, A. Mauger, D. Guyomard, T. Rojo, N. Gisbert-Trejo, S. Passerini, X. Huang, Z. Zhou, P. Johansson, M. Forsyth, Angew. Chem. Int. Ed. 59 (2020) 534.

[5] M.V. Reddy, A. Mauger, C.M. Julien, A. Paolella, K. Zaghib, Materials 13 (2020) 1884.

[6] M.S. Whittingham, Science 84192 (1976) 1126.

[7] K. Brandt, Solid State Ionics 69 (1994) 173.

[8] F.C. Laman, K. Brandt, J. Power Sources 24 (1988) 195.

[9] K.B.R.R. Haering, J.A. Stiles, Lithium Molybdenum Disulphide Battery Cathode, US4224390, 1980

[10] D. Lin, Y. Liu, Y. Cui, Nat. Nanotechnol. 12 (2017) 194.

[11] J.B. Goodenough, Y. Kim, Chem. Mater. 22 (2010) 587.

[12] E. Peled, D. Golodnitsky, G. Ardel, J. Electrochem. Soc. 144 (1997) L208.
[13] E. Peled, J. Electrochem. Soc. 126 (1979) 2047.

[14] M. Ishikawa, M. Morita, Current Issues of Metallic Lithium Anode, Springer US, Boston, 2003.

[15] H. Kim, G. Jeong, Y.U. Kim, J.H. Kim, C.M. Park, H.J. Sohn, Chem. Soc. Rev. 42 (2013) 9011.

[16] G. Pistoia, Lithium Batteries: New Materials, Developments and Perspectives (Book), ETDEWEB, 1993.

[17] D. Aurbach, E. Zinigrad, Y. Cohen, H. Teller, Solid State Ionics 148 (3-4) (2002) 405-416.

[18] J.M. Tarascon, M. Armand, Nature 414 (2001) 359.

[19] M.S. Whittingham, Chem. Rev. 104 (2004) 4271.

[20] L. Carbone, S.G. Greenbaum, J. Hassoun, Sustain. Energy Fuels 1 (2017) 228.

[21] J.W. Choi, D. Aurbach, Nat. Rev. Mater. 1 (2016) 1.

[22] (n.d.), https://oxisenergy.com/products/.

[23] Https://oxisenergy.com/wp-content-uploads-2020-05-oxis-mbb-final-pressorpdf-pdf/, (n.d.).

[24] Https://www.forbes.com/sites/emanuelabarbiroglio/2020/05/29/a-new32gwh-gigafactory-will-build-sustainable-batteries-in-norway/\#8ad340e2f686, (n.d.).

[25] M. Marinaro, D. Bresser, E. Beyer, P. Faguy, K. Hosoi, H. Li, J. Sakovica, K. Amine, M. Wohlfahrt-Mehrens, S. Passerini, J. Power Sources 459 (2020).

[26] Y. Lu, X. Rong, Y.S. Hu, L. Chen, H. Li, Energy Storage Mater 23 (2019) 144.

[27] "Become Competitive in the Global Battery Sector to Drive E-Mobility and Stationary Storage Forward" Integrated SET-Plan Action 7, 2016, p. 1. Implementation Plan.

[28] BATTERY 2030+ Roadmap, Inventing the Sustainable Batteries of the Future, Research Needs and Future Actions, 2020.

[29] M.S. Park, W.Y. Yoon, J. Power Sources 114 (2003) 237.

[30] W.S. Kim, W.Y. Yoon, Electrochim. Acta 50 (2-3) (2004) 541-545.

[31] J.H. Chung, W.S. Kim, W.Y. Yoon, S.W. Min, B.W. Cho, J. Power Sources 163 (2006) 191.

[32] A. Kolesnikov, M. Kolek, J.F. Dohmann, F. Horsthemke, M. Börner, P. Bieker, M. Winter, M.C. Stan, Adv. Energy Mater. (2020) 2000017.

[33] Y.-S. Lee, J.H. Lee, J.-A. Choi, W.Y. Yoon, D.-W. Kim, Adv. Funct. Mater. 23 (2013) 1019.

[34] D.J. David, M.H. Froning, T.N. Wittberg, W.E. Moddeman, Appl. Surf. Sci. 7 (3) (1981) 185-195.

[35] M.L. Meyerson, J.K. Sheavly, A. Dolocan, M.P. Griffin, A.H. Pandit, R. Rodriguez, R.M. Stephens, D.A. Vanden Bout, A. Heller, C.B. Mullins, J. Mater. Chem. 7 (2019) 14882.

[36] R. Schmitz, R. Müller, S. Krüger, R.W. Schmitz, S. Nowak, S. Passerini, M. Winter, C. Schreiner, J. Power Sources 217 (2012) 98.

[37] D. Wang, W. Zhang, W. Zheng, X. Cui, T. Rojo, Q. Zhang, Adv. Sci. 4 (2017) 1600168.

[38] S.J. An, J. Li, C. Daniel, D. Mohanty, S. Nagpure, D.L. Wood, Carbon N. Y. 105 (2016) 52.

[39] P. Verma, P. Maire, P. Novák, Electrochim. Acta 55 (2010) 6332.

[40] M. Keller, A. Varzi, S. Passerini, J. Power Sources 392 (2018) 206.

[41] S.S. Zhang, J. Power Sources 162 (2006) 1379.

[42] J.-P. Boeuve, Rechargeable Lithium Electrochemical Cell, 1995.

[43] H. Ota, K. Shima, M. Ue, J. ichi Yamaki, Electrochim. Acta 49 (2004) 565.

[44] R. Mogi, M. Inaba, S.-K. Jeong, Y. Iriyama, T. Abe, Z. Ogumi, J. Electrochem. Soc. 149 (2002) A1578.

[45] Y. Yang, J. Xiong, S. Lai, R. Zhou, M. Zhao, H. Geng, Y. Zhang, Y. Fang, C. Li, J. Zhao, ACS Appl. Mater. Interfaces 11 (6) (2019).

[46] S. Chen, C. Niu, H. Lee, Q. Li, L. Yu, W. Xu, J.G. Zhang, E.J. Dufek, M. S. Whittingham, S. Meng, J. Xiao, J. Liu, Joule 3 (2019) 1094.

[47] A. Lewandowski, A. Swiderska-Mocek, L. Waliszewski, J. Solid State Electrochem. 16 (2012) 3391.

[48] M. Yamada, N. Awano, N. Kubota, Nonaqueous electrolytic solution and nonaqueous secondary battery E, ASE 8.2 (75) (2001). Inventors.

[49] D. Aurbach, J. Electrochem. Soc. 142 (1995) 687.

[50] Y. Matsuda, J. Electrochem. Soc. 132 (1985) 2538.

[51] R.D. Rauh, S.B. Brummer, Electrochim. Acta 22 (1977) 85.

[52] J. Pires, L. Timperman, A. Castets, J.S. Peña, E. Dumont, S. Levasseur, R. Dedryvère, C. Tessier, M. Anouti, RSC Adv. 5 (2015) 42088.

[53] J.G. Han, M.Y. Jeong, K. Kim, C. Park, C.H. Sung, D.W. Bak, K.H. Kim, K. M. Jeong, N.S. Choi, J. Power Sources 446 (2020) 227366.

[54] S.S. Zhang, K. Xu, T.R. Jow, J. Power Sources 113 (2003) 166.

[55] M.H. Choo, C.C. Nguyen, S. Hong, Y.H. Kwon, S.W. Woo, J.Y. Kim, S.W. Song, Electrochim. Acta 112 (2013) 252.

[56] J.G. Han, K. Kim, Y. Lee, N.S. Choi, Adv. Mater. 31 (2019).

[57] T. Yim, K.S. Kang, J.S. Yu, K.J. Kim, M.S. Park, S.G. Woo, G. Jeong, Y.N. Jo, K. Y. Im, J.H. Kim, Y.J. Kim, in: Jpn. J. Appl. Phys., Japan Society of Applied Physics, 2014, 08NK01.

[58] W. Zeng, M.M.C. Cheng, S.K.Y. Ng, Electrochim. Acta 319 (2019) 511.

[59] Y. Matsuda, J. Power Sources 43 (1993) 1.

[60] L. Ma, M.S. Kim, L.A. Archer, Chem. Mater. 29 (2017) 4181.

[61] Q. Pang, X. Liang, I.R. Kochetkov, P. Hartmann, L.F. Nazar, Angew. Chem. 130 (2018) 9943.

[62] J. Zheng, M.H. Engelhard, D. Mei, S. Jiao, B.J. Polzin, J.G. Zhang, W. Xu, Nat. Energy 2 (2017) 1.

[63] X. Ren, Y. Zhang, M.H. Engelhard, Q. Li, J.G. Zhang, W. Xu, ACS Energy Lett 3 (2018) 14.

[64] Y. Lu, Z. Tu, L.A. Archer, Nat. Mater. 13 (2014) 961.

[65] Y. Lu, Z. Tu, J. Shu, L.A. Archer, J. Power Sources 279 (2015) 413. 
[66] A.S. Best, A.I. Bhatt, A.F. Hollenkamp, J. Electrochem. Soc. 157 (2010) A903.

[67] H. Matsumoto, H. Sakaebe, K. Tatsumi, M. Kikuta, E. Ishiko, M. Kono, J. Powe Sources 160 (2006) 1308.

[68] A. Budi, A. Basile, G. Opletal, A.F. Hollenkamp, A.S. Best, R.J. Rees, A.I. Bhatt, A. P. O'Mullane, S.P. Russo, J. Phys. Chem. C 116 (2012) 19789.

[69] S. Chen, J. Zheng, L. Yu, X. Ren, M.H. Engelhard, C. Niu, H. Lee, W. Xu, J. Xiao, J. Liu, J.G. Zhang, Joule 2 (2018) 1548.

[70] C. Niu, H. Lee, S. Chen, Q. Li, J. Du, W. Xu, J.G. Zhang, M.S. Whittingham, J. Xiao, J. Liu, Nat. Energy 4 (2019) 551.

[71] H.-Y. Wang, F.-M. Wang, J. Power Sources 233 (2013) 1.

[72] W.J. Li, Q. Li, J. Huang, J.Y. Peng, G. Chu, Y.X. Lu, J.Y. Zheng, H. Li, Chin. Phys. B 26 (2017).

[73] R.S. Thompson, D.J. Schroeder, C.M. López, S. Neuhold, J.T. Vaughey, Electrochem. Commun. 13 (12) (2011) 1369-1372.

[74] S.M. George, Chem. Rev. 110 (2010) 111.

[75] S.C. Jung, Y.K. Han, J. Phys. Chem. Lett. 4 (2013) 2681.

[76] B. Qin, T. Diemant, H. Zhang, A. Hoefling, R.J. Behm, J. Tübke, A. Varzi, S. Passerini, ChemSusChem 12 (2019) 2609.

[77] A.C. Kozen, C.F. Lin, A.J. Pearse, M.A. Schroeder, X. Han, L. Hu, S.B. Lee, G. W. Rubloff, M. Noked, ACS Nano 9 (2015) 5884.

[78] A.C. Kozen, C.F. Lin, A.J. Pearse, M.A. Schroeder, X. Han, L. Hu, S.B. Lee, G. W. Rubloff, M. Noked, ACS Nano 9 (2015) 5884.

[79] E. Kazyak, K.N. Wood, N.P. Dasgupta, Chem. Mater. 27 (2015) 6457.

[80] L. Chen, K.S. Chen, X. Chen, G. Ramirez, Z. Huang, N.R. Geise, H.G. Steinrück, B. L. Fisher, R. Shahbazian-Yassar, M.F. Toney, M.C. Hersam, J.W. Elam, ACS Appl Mater. Interfaces 10 (2018) 26972.

[81] M. Wu, Z. Wen, Y. Liu, X. Wang, L. Huang, J. Power Sources 196 (2011) 8091.

[82] Y.J. Zhang, W. Wang, H. Tang, W.Q. Bai, X. Ge, X.L. Wang, C.D. Gu, J.P. Tu, J. Power Sources 277 (2015) 304-311.

[83] H. Gan, E.S. Takeuchi, J. Power Sources 62 (1996) 45.

[84] J. Xu, J. Electrochem. Soc. 142 (1995) 3303.

[85] H. Chen, A. Pei, D. Lin, J. Xie, A. Yang, J. Xu, K. Lin, J. Wang, H. Wang, F. Shi, D. Boyle, Y. Cui, Adv. Energy Mater. 9 (2019) 1900858

[86] A. Schechter, D. Aurbach, H. Cohen, Langmuir 15 (1999) 3334.

[87] N.-W. Li, Y.-X. Yin, C.-P. Yang, Y.-G. Guo, Adv. Mater. 28 (2016) 1853.

[88] X. Liang, Q. Pang, I.R. Kochetkov, M.S. Sempere, H. Huang, X. Sun, L.F. Nazar, Nat. Energy 6 (2017) 17119.

[89] K. Thanner, A. Varzi, D. Buchholz, S.J. Sedlmaier, S. Passerini, ACS Appl. Mater. Interfaces 12 (2020) 32851.

[90] M.S. Ding, S.L. Koch, S. Passerini, Electrochim. Acta 240 (2017) 408.

[91] G. Ma, Z. Wen, M. Wu, C. Shen, Q. Wang, J. Jin, X. Wu, Chem. Commun. 50 (2014) 14209.

[92] G. Zheng, S.W. Lee, Z. Liang, H.-W. Lee, K. Yan, H. Yao, H. Wang, W. Li, S. Chu, Y. Cui, Nat. Nanotechnol. 9 (2014) 618.

[93] Q. Li, T. Yi, X. Wang, H. Pan, B. Quan, T. Liang, X. Guo, X. Yu, H. Wang, X. Huang L. Chen, H. Li, Nanomater. Energy 63 (2019) 103895.

[94] G. Zheng, S.W. Lee, Z. Liang, H.W. Lee, K. Yan, H. Yao, H. Wang, W. Li, S. Chu, Y. Cui, Nat. Nanotechnol. 9 (2014) 618.

[95] K. Yan, H.W. Lee, T. Gao, G. Zheng, H. Yao, H. Wang, Z. Lu, Y. Zhou, Z. Liang, Z. Liu, S. Chu, Y. Cui, Nano Lett. 14 (2014) 6016.

[96] Y. Xu, T. Li, L. Wang, Y. Kang, Adv. Mater. 31 (2019) 1901662.

[97] C. Lee, X. Wei, J.W. Kysar, J. Hone, Science 84321 (2008) 385.

[98] X. Li, W. Cai, J. An, S. Kim, J. Nah, D. Yang, R. Piner, A. Velamakanni, I. Jung, E. Tutuc, S.K. Banerjee, L. Colombo, R.S. Ruoff, Science 84324 (2009) 1312.

[99] X. Wang, J. Zhuang, M. Liu, C. Wang, Y. Zhong, H. Wang, X. Cheng, S. Liu, G. Cao, W. Li, J. Mater. Chem. 7 (2019) 19104.

[100] D. Lin, Y. Liu, Z. Liang, H.W. Lee, J. Sun, H. Wang, K. Yan, J. Xie, Y. Cui, Nat. Nanotechnol. 11 (2016) 626.

[101] H. Wang, D. Lin, J. Xie, Y. Liu, H. Chen, Y. Li, J. Xu, G. Zhou, Z. Zhang, A. Pei, Y. Zhu, K. Liu, K. Wang, Y. Cui, Adv. Energy Mater. 9 (2019) 1802720.

[102] Y. Zhang, W. Luo, C. Wang, Y. Li, C. Chen, J. Song, J. Dai, E.M. Hitz, S. Xu, C. Yang, Y. Wang, L. Hu, Proc. Natl. Acad. Sci. U.S.A. 114 (2017) 3584.

[103] Y. Liu, D. Lin, Z. Liang, J. Zhao, K. Yan, Y. Cui, Nat. Commun. 7 (2016) 1.

[104] C. Zhang, S. Liu, G. Li, C. Zhang, X. Liu, J. Luo, Adv. Mater. 30 (2018) 1801328

[105] S. Sen Chi, Y. Liu, W.L. Song, L.Z. Fan, Q. Zhang, Adv. Funct. Mater. 27 (2017),

[106] X. Guan, A. Wang, S. Liu, G. Li, F. Liang, Y.-W. Yang, X. Liu, J. Luo, Small 14 (2018) 1801423.

[107] Z. Huang, G. Zhou, W. Lv, Y. Deng, Y. Zhang, C. Zhang, F. Kang, Q.H. Yang, Nanomater. Energy 61 (2019) 47.

[108] K. Yan, Z. Lu, H.W. Lee, F. Xiong, P.C. Hsu, Y. Li, J. Zhao, S. Chu, Y. Cui, Nat. Energy 1 (2016).

[109] C. Yang, Y. Yao, S. He, H. Xie, E. Hitz, L. Hu, Adv. Mater. 29 (2017).

[110] H. Wang, Y. Liu, Y. Li, Y. Cui, Electrochem. Energy Rev. 2 (2019) 509.

[111] W. Li, J.R. Dahn, D.S. Wainwright, Science 84264 (1994) 1115.

[112] M. Tatsumisago, M. Nagao, A. Hayashi, J. Asian Ceram. Soc. 1 (2013) 17.

[113] S. Xia, X. Wu, Z. Zhang, Y. Cui, W. Liu, Inside Chem. 5 (2019) 753.

[114] A. Mauger, C.M. Julien, A. Paolella, M. Armand, K. Zaghib, Materials 12 (2019) 1.

[115] C. Yu, S. Ganapathy, E.R.H.V. Eck, H. Wang, S. Basak, Z. Li, M. Wagemaker, Nat. Commun. 8 (2017).

[116] J. Haruyama, K. Sodeyama, L. Han, K. Takada, Y. Tateyama, Chem. Mater. 26 (2014) 4248.

[117] J. Schnell, T. Günther, T. Knoche, C. Vieider, L. Köhler, A. Just, M. Keller, S. Passerini, G. Reinhart, J. Power Sources 382 (2018) 160.

[118] F. Hao, F. Han, Y. Liang, C. Wang, Y. Yao, MRS Bull. 43 (2018) 746.

[119] Y. Meesala, A. Jena, H. Chang, R.S. Liu, ACS Energy Lett 2 (2017) 2734.
[120] F. Lv, Z. Wang, L. Shi, J. Zhu, K. Edström, J. Mindemark, S. Yuan, J. Power Sources 441 (2019).

[121] X.Q. Zhang, X.B. Cheng, Q. Zhang, Adv. Mater. Interfaces 5 (2018) 1.

[122] K. Takada, J. Power Sources 394 (2018) 74.

[123] S. Ohno, T. Bernges, J. Buchheim, M. Duchardt, A.K. Hatz, M.A. Kraft, H. Kwak, A.L. Santhosha, Z. Liu, N. Minafra, F. Tsuji, A. Sakuda, R. Schlem, S. Xiong, Z. Zhang, P. Adelhelm, H. Chen, A. Hayashi, Y.S. Jung, B.V. Lotsch, B. Roling, N. M. Vargas-Barbosa, W.G. Zeier, ACS Energy Lett 5 (2020) 910.

[124] N. Kamaya, K. Homma, Y. Yamakawa, M. Hirayama, R. Kanno, M. Yonemura, T. Kamiyama, Y. Kato, S. Hama, K. Kawamoto, A. Mitsui, Nat. Mater. 10 (2011) 682.

[125] V. Thangadurai, S. Narayanan, D. Pinzaru, Chem. Soc. Rev. 43 (2014) 4714.

[126] Y. Li, H. Xu, P.H. Chien, N. Wu, S. Xin, L. Xue, K. Park, Y.Y. Hu, J.B. Goodenough, Angew. Chem. Int. Ed. 57 (2018) 8587.

[127] Y. Inaguma, L. Chen, M. Itoh, T. Nakamura, Solid State Ionics 70-71 (1994) 196.

[128] C. Cao, Z. Bin Li, X.L. Wang, X.B. Zhao, W.Q. Han, Front. Energy Res. 2 (2014) 1.

[129] D. Wang, G. Zhong, O. Dolotko, Y. Li, M.J. McDonald, J. Mi, R. Fu, Y. Yang, J. Mater. Chem. 2 (2014) 20271.

[130] Z. Hu, H. Liu, H. Ruan, R. Hu, Y. Su, L. Zhang, Ceram. Int. 42 (2016) 12156.

[131] R. Xu, Y. Xiao, R. Zhang, X. Cheng, C. Zhao, X. Zhang, C. Yan, Q. Zhang, J. Huang, Adv. Mater. 31 (2019) 1808392.

[132] H. Aono, E. Sugimoto, Y. Sadaoka, N. Imanaka, G.Y. Adachi, Electrochem. Sci. Technol. 140 (1993) 1827.

[133] A.D. Robertson, A.R. West, A.G. Ritchie, Solid State Ionics 104 (1997) 1.

[134] L.E. Camacho-Forero, P.B. Balbuena, J. Power Sources 396 (2018) 782.

[135] S. Wenzel, D.A. Weber, T. Leichtweiss, M.R. Busche, J. Sann, J. Janek, Solid State Ionics 286 (2016) 24.

[136] T. Ohtomo, A. Hayashi, M. Tatsumisago, K. Kawamoto, J. Mater. Sci. 48 (2013) 4137.

[137] N. Ohta, K. Takada, I. Sakaguchi, L. Zhang, R. Ma, K. Fukuda, M. Osada, T. Sasaki, Electrochem. Commun. 9 (2007) 1486.

[138] G. Oh, M. Hirayama, O. Kwon, K. Suzuki, R. Kanno, Chem. Mater. 28 (2016) 2634

[139] S. Ito, S. Fujiki, T. Yamada, Y. Aihara, Y. Park, T.Y. Kim, S.W. Baek, J.M. Lee, S. Doo, N. Machida, J. Power Sources 248 (2014) 943.

[140] J.W. Lee, Y.J. Park, J. Electrochem. Sci. Technol. 9 (2018) 176.

[141] A. Gurung, J. Pokharel, A. Baniya, R. Pathak, K. Chen, B.S. Lamsal, N. Ghimire, W. H. Zhang, Y. Zhou, Q. Qiao, Sustain. Energy Fuels 3 (2019) 3279.

[142] N. MacHida, J. Kashiwagi, M. Naito, T. Shigematsu, Solid State Ionics, Elsevier, 2012, pp. 354-358.

[143] K. Takada, N. Ohta, L. Zhang, K. Fukuda, I. Sakaguchi, R. Ma, M. Osada, T. Sasaki, Solid State Ionics 179 (2008) 1333.

[144] L. Xu, S. Tang, Y. Cheng, K. Wang, J. Liang, C. Liu, Y.C. Cao, F. Wei, L. Mai, Joule 2 (2018) 1991.

[145] Y. Zhang, Y. Tian, Y. Xiao, L.J. Miara, Y. Aihara, T. Tsujimura, T. Shi, M.C. Scott, G. Ceder, Adv. Energy Mater. (2020) 1903778.

[146] X. Xu, Z. Wen, X. Yang, J. Zhang, Z. Gu, Solid State Ionics 177 (2006) 2611.

[147] W.C. West, J.F. Whitacre, J.R. Lim, J. Power Sources 126 (2004) 134.

[148] W. Zhou, S. Wang, Y. Li, S. Xin, A. Manthiram, J.B. Goodenough, J. Am. Chem. Soc. 138 (2016) 9385

[149] A. Sharafi, E. Kazyak, A.L. Davis, S. Yu, T. Thompson, D.J. Siegel, N.P. Dasgupta, J. Sakamoto, Chem. Mater. 29 (2017) 7961.

[150] C. Ma, Y. Cheng, K. Yin, J. Luo, A. Sharafi, J. Sakamoto, J. Li, K.L. More, N, J. Dudney, M. Chi, Nano Lett. 16 (2016) 7030.

[151] K.K. Fu, Y. Gong, B. Liu, Y. Zhu, S. Xu, Y. Yao, W. Luo, C. Wang, S.D. Lacey, J. Dai, Y. Chen, Y. Mo, E. Wachsman, L. Hu, Sci. Adv. 3 (2017), e1601659.

[152] T. Krauskopf, B. Mogwitz, C. Rosenbach, W.G. Zeier, J. Janek (2019) 1902568.

[153] R. Inada, S. Yasuda, H. Hosokawa, M. Saito, T. Tojo, Y. Sakurai, Batteries 4 (2018) 26.

[154] S.H. Wang, J. Yue, W. Dong, T.T. Zuo, J.Y. Li, X. Liu, X.D. Zhang, L. Liu, J.L. Shi, Y.X. Yin, Y.G. Guo, Nat. Commun. 10 (2019) 1.

[155] C. Wang, Y. Gong, B. Liu, K. Fu, Y. Yao, E. Hitz, Y. Li, J. Dai, S. Xu, W. Luo, E D. Wachsman, L. Hu, Nano Lett. 17 (2017) 565.

[156] Y. Lu, X. Huang, Y. Ruan, Q. Wang, R. Kun, J. Yang, Z. Wen, J. Mater. Chem. 6 (2018) 18853.

[157] T. Kato, T. Hamanaka, K. Yamamoto, T. Hirayama, F. Sagane, M. Motoyama, Y. Iriyama, J. Power Sources 260 (2014) 292.

[158] S. Xin, Y. You, S. Wang, H.C. Gao, Y.X. Yin, Y.G. Guo, ACS Energy Lett 2 (2017) 1385.

[159] X. Han, Y. Gong, K. Kelvin, Fu, X. He, G.T. Hitz, J. Dai, A. Pearse, B. Liu, H. Wang, G. Rubloff, Y. Mo, V. Thangadurai, E.D. Wachsman, L. Hu, Nat. Mater. 16 (2016) 572 .

[160] G. Ferraresi, M. El Kazzi, L. Czornomaz, C.L. Tsai, S. Uhlenbruck, C. Villevieille, ACS Energy Lett 3 (2018) 1006.

[161] Z. Liang, D. Lin, J. Zhao, Z. Lu, Y. Liu, C. Liu, Y. Lu, H. Wang, K. Yan, X. Tao, Y. Cui, Proc. Natl. Acad. Sci. U.S.A. 113 (2016) 2862.

[162] S. Randau, D.A. Weber, O. Kötz, R. Koerver, P. Braun, A. Weber, E. Ivers-Tiffée, T. Adermann, J. Kulisch, W.G. Zeier, F.H. Richter, J. Janek, Nat. Energy 5 (2020) 259.

[163] J. Qian, B.D. Adams, J. Zheng, W. Xu, W.A. Henderson, J. Wang, M.E. Bowden, S. Xu, J. Hu, J.G. Zhang, Adv. Funct. Mater. 26 (2016) 7094.

[164] M. Genovese, A.J. Louli, R. Weber, S. Hames, J.R. Dahn, J. Electrochem. Soc. 165 (2018) A3321.

[165] T. Krauskopf, R. Dippel, H. Hartmann, K. Peppler, B. Mogwitz, F.H. Richter, W. G. Zeier, J. Janek, Joule 3 (2019) 2030. 
[166] T. Yamamoto, H. Iwasaki, Y. Suzuki, M. Sakakura, Y. Fujii, M. Motoyama, Y. Iriyama, Electrochem. Commun. 105 (2019) 106494.

[167] Y.G. Lee, S. Fujiki, C. Jung, N. Suzuki, N. Yashiro, R. Omoda, D.S. Ko, T. Shiratsuchi, T. Sugimoto, S. Ryu, J.H. Ku, T. Watanabe, Y. Park, Y. Aihara, D. Im, I.T. Han, Nat. Energy 5 (2020) 299.

[168] X. Yan, Z. Li, Z. Wen, W. Han, J. Phys. Chem. C 121 (2017) 1431.

[169] H.U. Choi, J.S. Jin, J.Y. Park, H.T. Lim, J. Alloys Compd. 723 (2017) 787.

[170] B.D. McCloskey, J. Phys. Chem. Lett. 6 (2015) 4581.

[171] B. Wu, S. Wang, W.J. Evans, D.Z. Deng, J. Yang, J. Xiao, J. Mater. Chem. 4 (2016) 15266.

[172] S. Kim, M. Hirayama, S. Taminato, R. Kanno, Dalton Trans. 42 (2013) 13112.

[173] A. Sakuda, A. Hayashi, T. Ohtomo, S. Hama, M. Tatsumisago, J. Power Sources 196 (2011) 6735.

[174] Y.-C. Perng, J. Cho, S.Y. Sun, D. Membreno, N. Cirigliano, B. Dunn, J.P. Chang, J. Mater. Chem. 2 (2014) 9566.

[175] M. Bitzer, T. Van Gestel, S. Uhlenbruck, Hans-Peter-Buchkremer, Thin Solid Films 615 (2016) 128.

[176] R.J. Chen, M. Huang, W.Z. Huang, Y. Shen, Y.H. Lin, C.W. Nan, J. Mater. Chem. 2 (2014) 13277.

[177] R. Inada, K. ichi Ishida, M. Tojo, T. Okada, T. Tojo, Y. Sakurai, Ceram. Int. 41 (2015) 11136.

[178] R. Inada, T. Okada, A. Bando, T. Tojo, Y. Sakurai, Prog. Nat. Sci. Mater. Int. 27 (2017) 350.

[179] F. Hippauf, B. Schumm, S. Doerfler, H. Althues, S. Fujiki, T. Shiratsushi, T. Tsujimura, Y. Aihara, S. Kaskel, Energy Storage Mater 21 (2019) 390.

[180] U. Ulissi, M. Agostini, S. Ito, Y. Aihara, J. Hassoun, Solid State Ionics 296 (2016) 13.

[181] Y. Kato, S. Hori, T. Saito, K. Suzuki, M. Hirayama, A. Mitsui, M. Yonemura, H. Iba, R. Kanno, Nat. Energy 1 (2016) 1.

[182] Y. Kato, S. Shiotani, K. Morita, K. Suzuki, M. Hirayama, R. Kanno, J. Phys. Chem. Lett. 9 (2018) 607.

[183] U. Ulissi, S. Ito, S.M. Hosseini, A. Varzi, Y. Aihara, S. Passerini, Adv. Energy Mater. 8 (2018) 1801462

[184] S.M. Hosseini, A. Varzi, S. Ito, Y. Aihara, S. Passerini, Energy Storage Mater 27 (2020) 61.

[185] S. Ohta, J. Seki, Y. Yagi, Y. Kihira, T. Tani, T. Asaoka, J. Power Sources 265 (2014) 40 .

[186] A. Manuel Stephan, K.S. Nahm, Polymer 47 (2006) 5952.

[187] H. Zhang, M. Armand, T. Rojo, J. Electrochem. Soc. 166 (2019) A679.

[188] Q. Zhang, K. Liu, F. Ding, X. Liu, Nano Res 10 (2017) 4139.

[189] Z. Gadjourova, Y.G. Andreev, D.P. Tunstall, P.G. Bruce, Nature 412 (2001) 520.

[190] Z. Stoeva, I. Martin-Litas, E. Staunton, Y.G. Andreev, P.G. Bruce, J. Am. Chem. Soc. 125 (2003) 4619.

[191] G.B. Appetecchi, F. Croce, J. Hassoun, B. Scrosati, M. Salomon, F. Cassel, J. Power Sources 114 (2003) 105.

[192] M. Watanabe, S. Nagano, K. Sanui, N. Ogata, Polym. J. 18 (1986) 809.

[193] P. Lightfoot, M.A. Mehta, P.G. Bruce, Science 262 (1993) 883.

[194] H.H. Sumathipala, J. Hassoun, S. Panero, B. Scrosati, Ionics 13 (2007) 281.

[195] S. Lascaud, M. Perrier, A. Vallée, S. Besner, J. Prud'homme, M. Armand, Macromolecules 27 (1994) 7469.

[196] Z. Xue, D. He, X. Xie, J. Mater. Chem. 3 (2015) 19218.

[197] F. Croce, L.L. Persi, B. Scrosati, F. Serraino-Fiory, E. Plichta, M.A. Hendrickson, Electrochim. Acta 46 (2001) 2457.

[198] A. Vallée, S. Besner, J. Prud'Homme, Electrochim. Acta 37 (1992) 1579.

[199] E. Quartarone, P. Mustarelli, A. Magistris, Solid State Ionics 110 (1998) 1.

[200] S. Panero, B. Scrosati, S.G. Greenbaum, Electrochim. Acta 37 (1992) 1533.

[201] I.E. Kelly, J.R. Owen, B.C.H. Steele, J. Power Sources 14 (1985) 13.

[202] J.E. Weston, B.C.H. Steele, Solid State Ionics 7 (1982) 75.

[203] F.S. Fiory, F. Croce, A. D’Epifanio, S. Licoccia, B. Scrosati, E. Traversa, J. Eur. Ceram. Soc. 24 (2004) 1385.

[204] S.H. Chung, Y. Wang, L. Persi, F. Croce, S.G. Greenbaum, B. Scrosati, E. Plichta, J. Power Sources, Elsevier, 2001, pp. 644-648.

[205] B. Scrosati, F. Croce, L. Persi, J. Electrochem. Soc. 147 (2000) 1718.

[206] B.W. Zewde, G.A. Elia, S. Admassie, J. Zimmermann, M. Hagemann, C.S. Isfort, B. Scrosati, J. Hassoun, Solid State Ionics 268 (2014) 174.

[207] F. Croce, G.B. Appetecchi, L. Persi, B. Scrosati, Nature 394 (1998) 456.

[208] Z. Wen, T. Itoh, T. Uno, M. Kubo, O. Yamamoto, Solid State Ionics 160 (2003) 141.

[209] R. Frech, S. Chintapalli, P.G. Bruce, C.A. Vincent, Macromolecules 32 (1999) 808.

[210] Y.T. Kim, E.S. Smotkin, Solid State Ionics 149 (2002) 29.

[211] J.-H. Shin, W.A. Henderson, C. Tizzani, S. Passerini, S.-S. Jeong, K.-W. Kim, J. Electrochem. Soc. 153 (2006) A1649.

[212] J.H. Shin, W.A. Henderson, G.B. Appetecchi, F. Alessandrini, S. Passerini, Electrochim. Acta, Pergamon, 2005, pp. 3859-3865.

[213] J.H. Shin, W.A. Henderson, S. Passerini, Electrochem. Commun. 5 (2003) 1016.

[214] R. Bouchet, S. Maria, R. Meziane, A. Aboulaich, L. Lienafa, J.-P. Bonnet, T.N. T Phan, D. Bertin, D. Gigmes, D. Devaux, R. Denoyel, M. Armand, (2013)..

[215] I. Aldalur, M. Martinez-Ibañez, A. Krztoń-Maziopa, M. Piszcz, M. Armand, H. Zhang, J. Power Sources 423 (2019) 218.

[216] V. Marangon, Y. Tominaga, J. Hassoun, J. Power Sources 449 (2020) 227508.

[217] Y.C. Jung, M.S. Park, D.H. Kim, M. Ue, A. Eftekhari, D.W. Kim, Sci. Rep. 7 (2017) 1.

[218] F.M. Gray, M.J. Smith, Altern. Energy Shale Gas Encycl, John Wiley \& Sons, Inc., Hoboken, NJ, USA, 2016, pp. 547-565.

[219] J. Hassoun, S. Panero, P. Reale, B. Scrosati, Adv. Mater. 21 (2009) 4807.
[220] D. Di Lecce, C. Fasciani, B. Scrosati, J. Hassoun, ACS Appl. Mater. Interfaces 7 (2015) 21198.

[221] I. Gracia, M. Armand, D. Shanmukaraj, R. Murugan, in: W. Weppner (Ed.), Solid Electrolytes Adv. Appl., Springer International Publishing, 2019, pp. 347-373.

[222] S. Liu, N. Imanishi, T. Zhang, A. Hirano, Y. Takeda, O. Yamamoto, J. Yang, J. Power Sources 195 (2010) 6847.

[223] L. Porcarelli, M.A. Aboudzadeh, L. Rubatat, J.R. Nair, A.S. Shaplov, C. Gerbaldi, D. Mecerreyes, J. Power Sources 364 (2017) 191.

[224] M. Wetjen, G.T. Kim, M. Joost, G.B. Appetecchi, M. Winter, S. Passerini, J. Power Sources 246 (2014) 846.

[225] L.X. Yuan, Z.H. Wang, W.X. Zhang, X.L. Hu, J.T. Chen, Y.H. Huang, J. B. Goodenough, Energy Environ. Sci. 4 (2011) 269.

[226] H. Zhang, F. Chen, O. Lakuntza, U. Oteo, L. Qiao, M. Martinez-Ibañez, H. Zhu, J. Carrasco, M. Forsyth, M. Armand, Angew. Chem. Int. Ed. 58 (2019) 12070.

[227] X. Judez, G.G. Eshetu, C. Li, L.M. Rodriguez-Martinez, H. Zhang, M. Armand, Joule 2 (2018) 2208.

[228] Https://faraday.ac.uk/wp-content/uploads/2020/01/High-Energy-batterytechnologies-FINAL.pdf, (n.d.).

[229] U. Ali, K.J.B.A. Karim, N.A. Buang, Polym. Rev. 55 (2015) 678.

[230] S. Choudhury, R. Mangal, A. Agrawal, L.A. Archer, Nat. Commun. 6 (2015) 1.

[231] Y. Tominaga, Polym. J. 49 (2017) 291.

[232] K. Kimura, M. Yajima, Y. Tominaga, Electrochem. Commun. 66 (2016) 46.

[233] A. Bhargav, J. He, A. Gupta, A. Manthiram, Joule 4 (2020) 285.

[234] Https://www.nasa.gov/sites/default/files/atoms/files/650_whkg_1400_whl_ recharg_batt_new_era_elect_mobility_ymikhaylik_0.pdf, (n.d.).

[235] Https://sionpower.com/2020/sion-power-demonstrates-key-electric-vehicle-evbattery-performance-requirements-in-its-lithium-metal-rechargeable-battery-celltechnology/, (n.d.).

[236] Https://ease-storage.eu/wp-content/uploads/2016/07/EASE_TD_ Electrochemical_LMP.pdf, (n.d.).

[237] H. Zhang, C. Li, G.G. Eshetu, S. Laruelle, S. Grugeon, K. Zaghib, C. Julien, A. Mauger, D. Guyomard, T. Rojo, N. Gisbert-Trejo, S. Passerini, X. Huang, Z. Zhou, P. Johansson, M. Forsyth, Angew. Chem. Int. Ed. 59 (2020) 534.

[238] Https://www.bluecar.fr/sites/bluecar/files/medias/PDF/2_bluecar_20_p.pdf, (n. d.).

[239] (n.d.), https://www.bluebus.fr/sites/bluebus/files/medias/images/PDF/techni cal_specifications_bluebus_6_meters.pdf.

[240] Https://blue-storage.com/bollore-assets/uploads/2019/05/fiche-techniquepack-lmp-63.pdf, (n.d.).

[241] Https://blue-storage.com/bollore-assets/uploads/2019/05/fiche-technique-bluelmp-250-blue-lmp-400-1.pdf., (n.d.).

[242] Y. Ye, F. Wu, Y. Liu, T. Zhao, J. Qian, Y. Xing, W. Li, J. Huang, L. Li, Q. Huang, X. Bai, R. Chen, Adv. Mater. 29 (2017) 1700598

[243] M. Wild, G. Offer, Lithium Sulfur Batteries, n.d.

[244] X. Chen, T.Z. Hou, B. Li, C. Yan, L. Zhu, C. Guan, X.B. Cheng, H.J. Peng, J. Q. Huang, Q. Zhang, Energy Storage Mater 8 (2017) 194.

[245] M. Wild, L. O’Neill, T. Zhang, R. Purkayastha, G. Minton, M. Marinescu, G. J. Offer, Energy Environ. Sci. 8 (2015) 3477.

[246] R. Cao, W. Xu, D. Lv, J. Xiao, J.G. Zhang, Adv. Energy Mater. 5 (2015).

[247] Y.V. Mikhaylik, J.R. Akridge, J. Electrochem. Soc. 151 (2004) A1969.

[248] D. Aurbach, E. Pollak, R. Elazari, G. Salitra, C.S. Kelley, J. Affinito, J. Electrochem. Soc. 156 (2009) A694.

[249] X.B. Cheng, C. Yan, J.Q. Huang, P. Li, L. Zhu, L. Zhao, Y. Zhang, W. Zhu, S. T. Yang, Q. Zhang, Energy Storage Mater 6 (2017) 18.

[250] L. Li, C. Chen, A. Yu, Sci. China Chem. 60 (2017) 1402.

[251] T. Tao, S. Lu, Y. Fan, W. Lei, S. Huang, Y. Chen, Adv. Mater. 29 (2017).

[252] H. Zhao, N. Deng, J. Yan, W. Kang, J. Ju, Y. Ruan, X. Wang, X. Zhuang, Q. Li, B. Cheng, Chem. Eng. J. 347 (2018) 343.

[253] Y. Zhao, Y. Ye, F. Wu, Y. Li, L. Li, R. Chen, Adv. Mater. 31 (2019) 1806532.

[254] G. Wang, F. Li, D. Liu, D. Zheng, C.J. Abeggien, Y. Luo, X.Q. Yang, T. Ding, D. Qu, Energy Storage Mater 24 (2020) 147.

[255] Y. Luo, L. Guo, M. Xiao, S. Wang, S. Ren, D. Han, Y. Meng, J. Mater. Chem. 8 (2020) 4629.

[256] Y. Wang, E. Sahadeo, G. Rubloff, C.F. Lin, S.B. Lee, J. Mater. Sci. 54 (2019) 3671.

[257] S. Liu, G.R. Li, X.P. Gao, ACS Appl. Mater. Interfaces 8 (2016) 7783.

[258] C. Yan, X.Q. Zhang, J.Q. Huang, Q. Liu, Q. Zhang, Trends Chem 1 (2019) 693.

[259] T. Cleaver, P. Kovacik, M. Marinescu, T. Zhang, G. Offer, J. Electrochem. Soc. 165 (2018) A6029.

[260] S. Dörfler, H. Althues, P. Härtel, T. Abendroth, B. Schumm, S. Kaskel, Joule 4 (2020) 539.

[261] J. Betz, G. Bieker, P. Meister, T. Placke, M. Winter, R. Schmuch, Adv. Energy Mater. 9 (2019).

[262] D. Zheng, X.-Q. Yang, D. Qu, ChemSusChem 9 (2016) 2348.

[263] S. Xiong, K. Xie, Y. Diao, X. Hong, Electrochim. Acta 83 (2012) 78.

[264] S. Xiong, K. Xie, Y. Diao, X. Hong, J. Power Sources 236 (2013) 181.

[265] S. Xiong, K. Xie, Y. Diao, X. Hong, J. Power Sources 246 (2014) 840.

[266] W. Li, H. Yao, K. Yan, G. Zheng, Z. Liang, Y.M. Chiang, Y. Cui, Nat. Commun. 6 (2015) 1.

[267] C. Yan, X.B. Cheng, C.Z. Zhao, J.Q. Huang, S.T. Yang, Q. Zhang, J. Power Sources 327 (2016) 212.

[268] Y. Han, X. Duan, Y. Li, L. Huang, D. Zhu, Y. Chen, Mater. Res. Bull. 68 (2015) 160.

[269] L. Cheng, L.A. Curtiss, K.R. Zavadil, A.A. Gewirth, Y. Shao, K.G. Gallagher, ACS Energy Lett 1 (2016) 503.

[270] C.W. Lee, Q. Pang, S. Ha, L. Cheng, S.D. Han, K.R. Zavadil, K.G. Gallagher, L. F. Nazar, M. Balasubramanian, ACS Cent. Sci. 3 (2017) 605. 
[271] K.A. See, H.L. Wu, K.C. Lau, M. Shin, L. Cheng, M. Balasubramanian, K. G. Gallagher, L.A. Curtiss, A.A. Gewirth, ACS Appl. Mater. Interfaces 8 (2016) 34360.

[272] H. Moon, T. Mandai, R. Tatara, K. Ueno, A. Yamazaki, K. Yoshida, S. Seki, K. Dokko, M. Watanabe, J. Phys. Chem. C 119 (2015) 3957.

[273] K. Ueno, R. Tatara, S. Tsuzuki, S. Saito, H. Doi, K. Yoshida, T. Mandai, M. Matsugami, Y. Umebayashi, K. Dokko, M. Watanabe, Phys. Chem. Chem. Phys. 17 (2015) 8248.

[274] Q.J. Meisner, T. Rojas, N.L. Dietz Rago, J. Cao, J. Bareño, T. Glossmann, A. Hintennach, P.C. Redfern, D. Pahls, L. Zhang, I.D. Bloom, A.T. Ngo, L. A. Curtiss, Z. Zhang, J. Power Sources 438 (2019) 226939.

[275] C. Zu, N. Azimi, Z. Zhang, A. Manthiram, J. Mater. Chem. 3 (2015) 14864.

[276] C. Weller, S. Thieme, P. Härtel, H. Althues, S. Kaskel, J. Electrochem. Soc. 164 (2017) A3766.

[277] H. Yang, A. Naveed, Q. Li, C. Guo, J. Chen, J. Lei, J. Yang, Y. Nuli, J. Wang, Energy Storage Mater 15 (2018) 299.

[278] Z. Chen, J. Zhou, Y. Guo, C. Liang, J. Yang, J. Wang, Y. Nuli, Electrochim. Acta 282 (2018) 555.

[279] E. Markevich, G. Salitra, Y. Talyosef, F. Chesneau, D. Aurbach, J. Electrochem. Soc. 164 (2017) A6244.

[280] X. Li, M. Banis, A. Lushington, X. Yang, Q. Sun, Y. Zhao, C. Liu, Q. Li, B. Wang, W. Xiao, C. Wang, M. Li, J. Liang, R. Li, Y. Hu, L. Goncharova, H. Zhang, T. K. Sham, X. Sun, Nat. Commun. 9 (2018) 1.

[281] H. Schneider, T. Weiß, C. Scordilis-Kelley, J. Maeyer, K. Leitner, H.J. Peng, R. Schmidt, J. Tomforde, Electrochim. Acta 243 (2017) 26.

[282] I.A. Hunt, Y. Patel, M. Szczygielski, L. Kabacik, G.J. Offer, J. Energy Storage 2 (2015) 25.

[283] Https://www.youtube.com/watch?v=iUpwtKGAKOY, (n.d.).

[284] Https://batterie-2020.de/projekte/forschungsfelder/zukuenftigebatteriesysteme/sepalis-neue-separatorbeschichtungen/, (n.d.).

[285] C. Qu, Y. Chen, X. Yang, H. Zhang, X. Li, H. Zhang, Nanomater. Energy 39 (2017) 262.

[286] C. Weller, J. Pampel, S. Dörfler, H. Althues, S. Kaskel, Energy Technol. 7 (2019) 1900625.

[287] T. Yamada, S. Ito, R. Omoda, T. Watanabe, Y. Aihara, M. Agostini, U. Ulissi, J. Hassoun, B. Scrosati, J. Electrochem. Soc. 162 (2015) A646.

[288] H. Nagata, Y. Chikusa, J. Power Sources 264 (2014) 206.

[289] J. Chen, K.S. Han, W.A. Henderson, K.C. Lau, M. Vijayakumar, T. Dzwiniel, H. Pan, L.A. Curtiss, J. Xiao, K.T. Mueller, Y. Shao, J. Liu, Adv. Energy Mater. 6 (2016) 1600160

[290] S. Wei, Z. Li, K. Kimura, S. Inoue, L. Pandini, D. Di Lecce, Y. Tominaga, J. Hassoun, Electrochim. Acta 306 (2019) 85.

[291] R. Younesi, G.M. Veith, P. Johansson, K. Edström, T. Vegge, Energy Environ. Sci. 8 (2015) 1905.

[292] H. Zhang, U. Oteo, X. Judez, G.G. Eshetu, M. Martinez-Ibañez, J. Carrasco, C. Li, M. Armand, Joule 3 (2019) 1689.

[293] G.G. Eshetu, X. Judez, C. Li, M. Martinez-Ibañez, I. Gracia, O. Bondarchuk, J. Carrasco, L.M. Rodriguez-Martinez, H. Zhang, M. Armand, J. Am. Chem. Soc. 140 (2018) 9921.

[294] Y. Xiao, B. Han, Y. Zeng, S. Chi, X. Zeng, Z. Zheng, K. Xu, Y. Deng, Adv. Energy Mater. 10 (2020) 1903937.

[295] H. Zhang, X. Judez, A. Santiago, M. Martinez-Ibañez, M.Á. Muñoz-Márquez, J. Carrasco, C. Li, G.G. Eshetu, M. Armand, Adv. Energy Mater. 9 (2019) 1900763.

[296] G.G. Eshetu, X. Judez, C. Li, O. Bondarchuk, L.M. Rodriguez-Martinez, H. Zhang, M. Armand, Angew. Chem. Int. Ed. 56 (2017) 15368.

[297] G. Ma, Z. Wen, M. Wu, C. Shen, Q. Wang, J. Jin, X. Wu, Chem. Commun. 50 (2014) 14209.

[298] M. Li, X. Liu, Q. Li, Z. Jin, W. Wang, A. Wang, Y. Huang, Y. Yang, J. Energy Chem. 41 (2020) 27.

[299] Q. Pang, X. Liang, A. Shyamsunder, L.F. Nazar, Joule 1 (2017) 871.

[300] C. Sun, X. Huang, J. Jin, Y. Lu, Q. Wang, J. Yang, Z. Wen, J. Power Sources 377 (2018) 36.

[301] W. Wang, X. Yue, J. Meng, J. Wang, X. Wang, H. Chen, D. Shi, J. Fu, Y. Zhou, J. Chen, Z. Fu, Energy Storage Mater 18 (2019) 414.

[302] X.B. Cheng, C. Yan, X. Chen, C. Guan, J.Q. Huang, H.J. Peng, R. Zhang, S.T. Yang, Q. Zhang, Inside Chem. 2 (2017) 258.

[303] I. Bauer, S. Thieme, J. Brückner, H. Althues, S. Kaskel, J. Power Sources 251 (2014) 417.

[304] J. Luo, R.C. Lee, J.T. Jin, Y.T. Weng, C.C. Fang, N.L. Wu, Chem. Commun. 53 (2017) 963.

[305] X. Qian, L. Jin, D. Zhao, X. Yang, S. Wang, X. Shen, D. Rao, S. Yao, Y. Zhou, X. Xi, Electrochim. Acta 192 (2016) 346.

[306] U. Stoeck, J. Balach, M. Klose, D. Wadewitz, E. Ahrens, J. Eckert, L. Giebeler, J. Power Sources 309 (2016) 76.

[307] Z. Du, C. Guo, L. Wang, A. Hu, S. Jin, T. Zhang, H. Jin, Z. Qi, S. Xin, X. Kong, Y. G. Guo, H. Ji, L.J. Wan, ACS Appl. Mater. Interfaces 9 (2017) 43696.

[308] X. Judez, M. Martinez-Ibañez, A. Santiago, M. Armand, H. Zhang, C. Li, J. Power Sources 438 (2019) 226985

[309] H.K. Jing, L.L. Kong, S. Liu, G.R. Li, X.P. Gao, J. Mater. Chem. 3 (2015) 12213.

[310] Y. Guan, A. Wang, S. Liu, Q. Li, W. Wang, Y. Huang, J. Alloys Compd. 765 (2018) 544

[311] H. Xu, L. Qie, A. Manthiram, Nanomater. Energy 26 (2016) 224.

[312] X. Judez, G.G. Eshetu, I. Gracia, P. López-Aranguren, J.A. González-Marcos, M. Armand, L.M. Rodriguez-Martinez, H. Zhang, C. Li, ChemElectroChem 6 (2019) 326.
[313] X. Judez, L. Qiao, M. Armand, H. Zhang, ACS Appl. Energy Mater. 2 (2019) 4008.

[314] D.D. Han, S. Liu, Y.T. Liu, Z. Zhang, G.R. Li, X.P. Gao, J. Mater. Chem. 6 (2018) 18627.

[315] A. Freitag, U. Langklotz, A. Rost, M. Stamm, L. Ionov, Energy Storage Mater 9 (2017) 105.

[316] Q. Li, F.L. Zeng, Y.P. Guan, Z.Q. Jin, Y.Q. Huang, M. Yao, W.K. Wang, A.B. Wang, Energy Storage Mater 13 (2018) 151.

[317] Y.B. Yang, Y.X. Liu, Z. Song, Y.H. Zhou, H. Zhan, ACS Appl. Mater. Interfaces 9 (2017) 38950

[318] G. Li, Y. Gao, X. He, Q. Huang, S. Chen, S.H. Kim, D. Wang, Nat. Commun. 8 (2017) 1.

[319] A.N. Dey, J. Electrochem. Soc. 118 (1971) 1547.

[320] C.M. Park, J.H. Kim, H. Kim, H.J. Sohn, Chem. Soc. Rev. 39 (2010) 3115.

[321] M. Piwko, T. Kuntze, S. Winkler, S. Straach, P. Härtel, H. Althues, S. Kaskel, J. Power Sources 351 (2017) 183.

[322] L. Kong, L. Wang, Z. Ni, S. Liu, G. Li, X. Gao, Adv. Funct. Mater. 29 (2019) 1808756.

[323] X.-B. Cheng, H.-J. Peng, J.-Q. Huang, F. Wei, Q. Zhang, Small 10 (2014) n/a.

[324] X. Zhang, W. Wang, A. Wang, Y. Huang, K. Yuan, Z. Yu, J. Qiu, Y. Yang, J. Mater. Chem. 2 (2014) 11660.

[325] Z. Wang, X. Wang, W. Sun, K. Sun, Electrochim. Acta 252 (2017) 127.

[326] L.L. Kong, Z. Zhang, Y.Z. Zhang, S. Liu, G.R. Li, X.P. Gao, ACS Appl. Mater. Interfaces 8 (2016) 31684

[327] X.B. Cheng, H.J. Peng, J.Q. Huang, R. Zhang, C.Z. Zhao, Q. Zhang, ACS Nano 9 (2015) 6373.

[328] Y.J. Zhang, X.H. Xia, X.L. Wang, C.D. Gu, J.P. Tu, RSC Adv. 6 (2016) 66161.

[329] R. Zhang, X. Chen, X. Shen, X.Q. Zhang, X.R. Chen, X.B. Cheng, C. Yan, C.Z. Zhao, Q. Zhang, Joule 2 (2018) 764.

[330] Y. An, Z. Zhang, H. Fei, X. Xu, S. Xiong, J. Feng, L. Ci, J. Power Sources 363 (2017) 193.

[331] K. Fan, Y. Tian, X. Zhang, J. Tan, J. Electroanal. Chem. 760 (2016) 80.

[332] H. Zhang, X. Liao, Y. Guan, Y. Xiang, M. Li, W. Zhang, X. Zhu, H. Ming, L. Lu, J. Qiu, Y. Huang, G. Cao, Y. Yang, L. Mai, Y. Zhao, H. Zhang, Nat. Commun. 9 (2018) 1.

[333] S. Nanda, A. Gupta, A. Manthiram, Adv. Energy Mater. 8 (2018) 1801556.

[334] D. Aurbach, B.D. McCloskey, L.F. Nazar, P.G. Bruce, Nat. Energy 1 (2016) 16128.

[335] H.-D. Lim, B. Lee, Y. Bae, H. Park, Y. Ko, H. Kim, J. Kim, K. Kang, Chem. Soc. Rev. 46 (2017) 2873.

[336] Y. Wang, Y.-C. Lu, Energy Storage Mater 28 (2020) 235.

[337] N. Mahne, O. Fontaine, M.O. Thotiyl, M. Wilkening, S.A. Freunberger, Chem. Sci. 8 (2017) 6716.

[338] N. Mahne, B. Schafzahl, C. Leypold, M. Leypold, S. Grumm, A. Leitgeb, G. A. Strohmeier, M. Wilkening, O. Fontaine, D. Kramer, C. Slugovc, S.M. Borisov, S. A. Freunberger, Nat. Energy 2 (2017) 17036.

[339] S.A. Freunberger, Nat. Energy 2 (2017) 17091.

[340] C. Prehal, S.A. Freunberger, Joule 3 (2019) 321.

[341] A.C. Luntz, B.D. McCloskey, Nat. Energy 2 (2017) 17056.

[342] D.G. Kwabi, V.S. Bryantsev, T.P. Batcho, D.M. Itkis, C. V Thompson, Y. ShaoHorn, Angew. Chem. Int. Ed. 55 (2016) 3129.

[343] E. Mourad, Y.K. Petit, R. Spezia, A. Samojlov, F.F. Summa, C. Prehal, C. Leypold, N. Mahne, C. Slugovc, O. Fontaine, S. Brutti, Energy Environ. Sci. 12 (2019) 2559.

[344] L. Johnson, C. Li, Z. Liu, Y. Chen, S.A. Freunberger, P.C. Ashok, B.B. Praveen, K. Dholakia, J.M. Tarascon, P.G. Bruce, Nat. Chem. 6 (2014) 1091.

[345] N.B. Aetukuri, B.D. McCloskey, J.M. García, L.E. Krupp, V. Viswanathan, A. C. Luntz, Nat. Chem. 7 (2014) 50.

[346] V. Viswanathan, K.S. Thygesen, J.S. Hummelshj, J.K. Nrskov, G. Girishkumar, B. D. McCloskey, A.C. Luntz, J. Chem. Phys. 135 (2011) 214704.

[347] Z. Li, S. Ganapathy, Y. Xu, J.R. Heringa, Q. Zhu, W. Chen, M. Wagemaker, Chem. Mater. 29 (2017) 1577.

[348] R.R. Mitchell, B.M. Gallant, Y. Shao-Horn, C. V Thompson, J. Phys, Chem. Lett. 4 (2013) 1060 .

[349] B.M. Gallant, D.G. Kwabi, R.R. Mitchell, J. Zhou, C. V Thompson, Y. Shao-Horn, Energy Environ. Sci. 6 (2013) 2518.

[350] J. Yang, D. Zhai, H.H. Wang, K.C. Lau, J.A. Schlueter, P. Du, D.J. Myers, Y.K. Sun, L.A. Curtiss, K. Amine, Phys. Chem. Chem. Phys. 15 (2013) 3764.

[351] U. Das, K.C. Lau, P.C. Redfern, L.A. Curtiss, J. Phys. Chem. Lett. 5 (2014) 813.

[352] T.K. Zakharchenko, A.Y. Kozmenkova, D.M. Itkis, E.A. Goodilin, Beilstein J. Nanotechnol. 4 (2013) 758.

[353] A.C. Luntz, V. Viswanathan, J. Voss, J.B. Varley, J.K. Norskov, R. Scheffler, A. Speidel, J. Phys. Chem. Lett. 4 (2013) 3494.

[354] C.M. Burke, V. Pande, A. Khetan, V. Viswanathan, B.D. McCloskey, Proc. Natl. Acad. Sci. U.S.A. 112 (2015) 9293.

[355] B.D. Adams, C. Radtke, R. Black, M.L. Trudeau, K. Zaghib, L.F. Nazar, Energy Environ. Sci. 6 (2013) 1772.

[356] L.D. Griffith, A.E.S. Sleightholme, J.F. Mansfield, D.J. Siegel, C.W. Monroe, ACS Appl. Mater. Interfaces 7 (2015) 7670.

[357] M.D. Radin, D.J. Siegel, Energy Environ. Sci. 6 (2013) 2370.

[358] F. Tian, M.D. Radin, D.J. Siegel, Chem. Mater. 26 (2014) 2952.

[359] W.T. Geng, B.L. He, T. Ohno, J. Phys. Chem. C 117 (2013) 25222.

[360] M.D. Radin, C.W. Monroe, D.J. Siegel, J. Phys. Chem. Lett. 6 (2015) 3017.

[361] J.G. Simmons, J. Appl. Phys. 34 (1963) 1793.

[362] Y. Yin, A. Torayev, C. Gaya, Y. Mammeri, A.A. Franco, J. Phys. Chem. C 121 (2017) 19577.

[363] S. Lau, L.A. Archer, Nano Lett. 15 (2015) 5995.

[364] F.S. Gittleson, R.E. Jones, D.K. Ward, M.E. Foster, Energy Environ. Sci. 10 (2017) 1167. 
[365] D.G. Kwabi, T.P. Batcho, S. Feng, L. Giordano, C. V Thompson, Y. Shao-Horn, Phys. Chem. Chem. Phys. 18 (2016) 24944.

[366] K.M. Abraham, J. Electrochem. Soc. 162 (2015) A3021.

[367] T.K. Zakharchenko, M. V Avdeev, A. V Sergeev, A. V Chertovich, O.I. Ivankov, V. I. Petrenko, Y. Shao-Horn, L. V Yashina, D.M. Itkis, Nanoscale 11 (2019) 6838.

[368] K.U. Schwenke, M. Metzger, T. Restle, M. Piana, H.A. Gasteiger, J. Electrochem. Soc. 162 (2015) A573.

[369] S. Kang, Y. Mo, S.P. Ong, G. Ceder, Chem. Mater. 25 (2013) 3328.

[370] S. Ganapathy, B.D. Adams, G. Stenou, M.S. Anastasaki, K. Goubitz, X.-F. Miao, L. F. Nazar, M. Wagemaker, J. Am. Chem. Soc. 136 (2014) 16335.

[371] Y.-C. Lu, Y. Shao-Horn, J. Phys. Chem. Lett. 4 (2012) 93.

[372] Y. Wang, N.-C. Lai, Y.-R. Lu, Y. Zhou, C.-L. Dong, Y.-C. Lu, Joule 2 (2018) 2364.

[373] Y. Wang, Y.-R. Lu, C.-L. Dong, Y.-C. Lu, ACS Energy Lett (2020) 1355.

[374] B.D. McCloskey, A. Valery, A.C. Luntz, S.R. Gowda, G.M. Wallraff, J.M. Garcia, T. Mori, L.E. Krupp, J. Phys. Chem. Lett. 4 (2013) 2989.

[375] B.D. Adams, R. Black, Z. Williams, R. Fernandes, M. Cuisinier, E.J. Berg, P. Novak, G.K. Murphy, L.F. Nazar, Adv. Energy Mater. 5 (2015) 1400867.

[376] M.M. Ottakam Thotiyl, S.A. Freunberger, Z. Peng, Y. Chen, Z. Liu, P.G. Bruce, Nat. Mater. 12 (2013) 1050.

[377] M.M. Ottakam Thotiyl, S.A. Freunberger, Z. Peng, P.G. Bruce, J. Am. Chem. Soc. 135 (2013) 494.

[378] D. Sharon, P. Sharon, D. Hirshberg, M. Salama, M. Afri, L.J.W. Shimon, W.J. Kwak, Y.-K. Sun, A.A. Frimer, D. Aurbach, J. Am. Chem. Soc. 139 (2017) 11690.

[379] J. Hassoun, F. Croce, M. Armand, B. Scrosati, Angew. Chem. Int. Ed. 50 (2011) 2999.

[380] J. Wandt, P. Jakes, J. Granwehr, H.A. Gasteiger, R.-A. Eichel, Angew. Chem. Int. Ed. 55 (2016) 6892.

[381] B.D. McCloskey, A. Speidel, R. Scheffler, D.C. Miller, V. Viswanathan, J. S. Hummelshøj, J.K. Nørskov, A.C. Luntz, J. Phys. Chem. Lett. 3 (2012) 997.

[382] M. Carboni, A.G. Marrani, R. Spezia, S. Brutti, J. Electrochem. Soc. 165 (2018) A118.

[383] K. Chaisiwamongkhol, C. Batchelor-McAuley, R.G. Palgrave, R.G. Compton, Angew. Chem. Int. Ed. 57 (2018) 6270.

[384] W.-J. Kwak, H. Kim, Y.K. Petit, C. Leypold, T.T. Nguyen, N. Mahne, P. Redfern, L. A. Curtiss, H.-G. Jung, S.M. Borisov, S.A. Freunberger, Y.-K. Sun, Nat. Commun. 10 (2019) 1380.

[385] Y.K. Petit, C. Leypold, N. Mahne, E. Mourad, L. Schafzahl, C. Slugovc, S. M. Borisov, S.A. Freunberger, Angew. Chem. Int. Ed. 58 (2019) 6535.

[386] N. Mahne, S.E. Renfrew, B.D. McCloskey, S.A. Freunberger, Angew. Chem. Int. Ed. 57 (2018) 5529.

[387] P. Hartmann, C.L. Bender, M. Vračar, A.K. Dürr, A. Garsuch, J. Janek, P. Adelhelm, Nat. Mater. 12 (2012) 228.

[388] Y. Zhang, X. Zhang, J. Wang, W.C. McKee, Y. Xu, Z. Peng, J. Phys. Chem. C 120 (2016) 3690.

[389] V. Giordani, Abstr. 16th IMLB S6-3 (2012). Jeju, Korea.

[390] Y. Chen, S.A. Freunberger, Z. Peng, O. Fontaine, P.G. Bruce, Nat. Chem. 5 (2013) 489.
[391] J.-B. Park, S.H. Lee, H.-G. Jung, D. Aurbach, Y.-K. Sun, Adv. Mater. 30 (2018) 1704162.

[392] X. Gao, Y. Chen, L. Johnson, P.G. Bruce, Nat. Mater. 15 (2016) 882.

[393] T. Liu, J.T. Frith, G. Kim, R.N. Kerber, N. Dubouis, Y. Shao, Z. Liu, P.C.M. M. Magusin, M.T.L. Casford, N. Garcia-Araez, C.P. Grey, J. Am. Chem. Soc. 140 (2018) 1428.

[394] Z. Liang, Y.-C. Lu, J. Am. Chem. Soc. 138 (2016) 7574.

[395] I. Landa-Medrano, I. Lozano, N. Ortiz-Vitoriano, I. Ruiz de Larramendi, T. Rojo, J. Mater. Chem. 7 (2019) 8746.

[396] W.-J. Kwak, H.-G. Jung, D. Aurbach, Y.-K. Sun, Adv. Energy Mater. 7 (2017) 1701232.

[397] G. Cong, W. Wang, N.-C. Lai, Z. Liang, Y.-C. Lu, Nat. Mater. 18 (2019) 390.

[398] W.-J. Kwak, J. Park, T.T. Nguyen, H. Kim, H.R. Byon, M. Jang, Y.-K. Sun, J. Mater. Chem. 7 (2019) 3857.

[399] B.G. Kim, J.-S. Kim, J. Min, Y.-H. Lee, J.H. Choi, M.C. Jang, S.A. Freunberger, J. W. Choi, Adv. Funct. Mater. 26 (2016) 1747.

[400] V. Giordani, W. Walker, V.S. Bryantsev, J. Uddin, G. V Chase, D. Addison, J. Electrochem. Soc. 160 (2013) A1544.

[401] W. Walker, V. Giordani, J. Uddin, V.S. Bryantsev, G. V Chase, D. Addison, J. Am. Chem. Soc. 135 (2013) 2076.

[402] E. Wang, S. Dey, T. Liu, S. Menkin, C.P. Grey, ACS Energy Lett 5 (2020) 1088.

[403] S. Akabayov Rosy, M. Leskes, M. Noked, ACS Appl. Mater. Interfaces 10 (2018) 29622.

[404] T. Zhang, K. Liao, P. He, H. Zhou, Energy Environ. Sci. 9 (2016) 1024.

[405] W.-J. Kwak, Y.-K. Sun, ECS Meet. Abstr. MA2018-01, 2018.

[406] B. Liu, W. Xu, P. Yan, X. Sun, M.E. Bowden, J. Read, J. Qian, D. Mei, C.-M. Wang, J.-G. Zhang, Adv. Funct. Mater. 26 (2016) 605.

[407] N. Togasaki, T. Momma, T. Osaka, J. Power Sources 307 (2016) 98.

[408] W.-J. Kwak, H.-S. Lim, P. Gao, R. Feng, S. Chae, L. Zhong, J. Read, M.H. Engelhard, W. Xu, J.-G. Zhang, Adv. Funct. Mater. n/a (n.d.) 2002927. doi: 10.1002/adfm.202002927.

[409] Q.-C. Liu, J.-J. Xu, S. Yuan, Z.-W. Chang, D. Xu, Y.-B. Yin, L. Li, H.-X. Zhong, Y.S. Jiang, J.-M. Yan, X.-B. Zhang, Adv. Mater. 27 (2015) 5241.

[410] Z. Peng, S.A. Freunberger, Y. Chen, P.G. Bruce, Science 84337 (2012) 563.

[411] J. Ma, F. Meng, Y. Yu, D. Liu, J. Yan, Y. Zhang, X. Zhang, Q. Jiang, Nat. Chem. 11 (2018) 64.

[412] L. Ye, M. Liao, H. Sun, Y. Yang, C. Tang, Y. Zhao, L. Wang, Y. Xu, L. Zhang, B. Wang, F. Xu, X. Sun, Y. Zhang, H. Dai, P.G. Bruce, H. Peng, Angew. Chem. Int. Ed. 58 (2019) 2437.

[413] Https://bits-chips.nl/artikel/imec-sets-energy-density-record-for-solid-state-liion-batteries/, (n.d.).

[414] Https://sionpower.com/2014/sion-powers-lithium-sulfur-batteries-power-highaltitude-pseudo-satellite-flight/, (n.d.).

[415] Christian Prehal, Aleksej Samojlov, Manfred Nachtnebel, Manfred Kriechbaum, Heinz Amenitsch, Stefan A. Freunberger, A revised $\mathrm{O}_{2}$ reduction model in $\mathrm{Li}-\mathrm{O}_{2}$ batteries as revealed by in situ small angle X-ray scattering, ChemRxiv (2019), https://doi.org/10.26434/chemrxiv.11447775.v1. Submitted for publication, htt ps://chemrxiv.org/articles/preprint/A_Revised_O2_Reduction_Model_in_ Li-O2_Batteries_as_Revealed_by_in_Situ_Small_Angle_X-Ray_Scattering/11447775. 